\title{
Review Article \\ TSH and Thyrotropic Agonists: Key Actors in Thyroid Homeostasis
}

\author{
Johannes W. Dietrich, ${ }^{1}$ Gabi Landgrafe, ${ }^{1,2}$ and Elisavet H. Fotiadou ${ }^{1}$ \\ ${ }^{1}$ Lab XU44, Medical Hospital I, Bergmannsheil University Hospitals, Ruhr University of Bochum (UK RUB), \\ Bürkle-de-la-Camp-Platz 1, 44789 Bochum, NRW, Germany \\ ${ }^{2}$ Klinik für Allgemein- und Visceralchirurgie, Agaplesion Bethesda Krankenhaus Wuppertal gGmbH, Hainstraße 35, \\ 42109 Wuppertal, NRW, Germany
}

Correspondence should be addressed to Johannes W. Dietrich, johannes.dietrich@ruhr-uni-bochum.de

Received 8 October 2012; Accepted 21 November 2012

Academic Editor: Rudolf Hoermann

Copyright ( $) 2012$ Johannes W. Dietrich et al. This is an open access article distributed under the Creative Commons Attribution License, which permits unrestricted use, distribution, and reproduction in any medium, provided the original work is properly cited.

This paper provides the reader with an overview of our current knowledge of hypothalamic-pituitary-thyroid feedback from a cybernetic standpoint. Over the past decades we have gained a plethora of information from biochemical, clinical, and epidemiological investigation, especially on the role of TSH and other thyrotropic agonists as critical components of this complex relationship. Integrating these data into a systems perspective delivers new insights into static and dynamic behaviour of thyroid homeostasis. Explicit usage of this information with mathematical methods promises to deliver a better understanding of thyrotropic feedback control and new options for personalised diagnosis of thyroid dysfunction and targeted therapy, also by permitting a new perspective on the conundrum of the TSH reference range.

\section{Introduction}

As thyroid hormones play a critical role for metabolism, growth, and tissue differentiation, exact and robust regulation of hormone levels is required. Although a thyrotropic hormone from anterior pituitary has first been described at the beginning of the 20th century $[1,2]$, it was not before 1940 that Salter postulated the existence of a control loop linking the pituitary and thyroid gland [3]. This idea was inspired by the then recent description of the two gonadotropic feedback control loops [4-7]. Only a few years later, Astwood and Hoskins independently could demonstrate both existence and pathophysiological relevance of this thyrotropic feedback control system [8-10].

Apart from a deeper insight into fundamental physiological principles, both diagnostic evaluation and dosage of substitutive therapy benefit from this knowledge. However, growing complexities of the respective relations increasingly question the validity of predictions that try to map reactions of the feedback loop to certain parameter changes. Additionally, there is an increasing gap between molecular and systems-level insights and a similar hiatus between findings of basic research and clinical applications.

Systems theoretic models try to incorporate both data from a molecular level and those from a systemic perspective on the level of the whole organism in an integrative way. Depending on their design principles the resulting cybernetic models may facilitate medical decision making and deliver hypotheses that may again serve as a basis for ongoing research.

\section{Physiology of Thyrotropic Feedback Control}

From a systems biologic perspective, thyroid homeostasis is a processing structure whose signalling is implemented by two different mechanisms, conversion and relaying [11]. Examples of relaying are the control of $\mathrm{T} 4$ secretion by TSH or of TSH secretion by TRH. Central and peripheral deiodinases convert $\mathrm{T} 4$ to the active hormone $\mathrm{T} 3$ and further to inactive iodothyronines. Another example of conversion processes is transport of thyroid hormones by plasma and transmembrane transporters. 
2.1. Classical Pituitary-Thyroid Axis (Astwood-Hoskins Loop). Apart from pituitary and thyroid, key components of the classical feedback control loop are the hypothalamus, and other organs like liver, brown adipose tissue, skeletal muscle and kidney that are capable of deiodination, as well as peripheral and central compartments, where iodothyronines distribute, act and are catabolised [12, 13]. Plasma transporters like TBG and membrane transporters like MCT8 facilitate convey of thyroid hormones in body fluids and through membranes and the blood-brain barrier [1418].

Due to the long half-life of iodothyronines the reaction of the thyroid to stimulating TSH pulses from the pituitary is slow. A large portion of thyroxine binds reversibly to plasma proteins. Only a small free fraction $(0.02 \%$ to $0.03 \%)$ is available for conversion to T3 and transport to cytoplasm. T3 is formed from T4 by $5^{\prime}$ deiodination at the outer ring by type 1 deiodinase predominantly in liver, kidney, and thyroid. Type 2 deiodinase mediates intracellular deiodination in glial cells, pituitary, brown adipose tissue, skeletal muscle, and placenta [19]. Obviously, intracellular deiodination facilitates feedback at the pituitary level by providing a mainly T4-dependent mechanism, which is faster than one that would depend on T3 from systemic circulation [20]. In addition, T3 is regulated by nonthyroidal factors, first of all peripheral deiodination $[19,21-25]$ that is subject of multiple metabolic control inputs [19, 26-30], which would also render a primarily T3-dependent feedback mechanism ineffective. High pituitary DIO2 expression rate ensures operative feedback despite T4-induced ubiquitination of type 2 deiodinase [31].

TSH is secreted in a pulsatile manner [32] with a mean pulse amplitude of $0.6 \mathrm{mU} / \mathrm{L}$ and a frequency of 5 to 20 per 24 hours [33]. Experiments suggested that there is no correlation among pulsatile secretion of TRH and TSH [34].

TSH pulses are superimposed by a 24 hour rhythm that leads to maximum TSH secretion shortly after midnight [35]. Interestingly, the interaction seems to be more than pure addition as the amplitude of short TSH pulses also rises in the second half of night. Therefore, unlike the frequency of fast pulses, their amplitude and that of diurnal rhythm of TSH seem to be controlled by TRH, as demonstrated in rat hypothalamic slices [36].

\subsection{Ultrashort-Loop Control of Thyrotropin Incretion} (Brokken-Wiersinga-Prummel Loop). Patients suffering from Graves' disease may continue to show decreased TSH levels despite normal or even low FT4 and FT3 levels and despite being clinically euthyroid over long time periods $[37,38]$. A similar constellation was described in patients with both familiar [39] and sporadic [40] activating TSH receptor mutations and in an infant born to a mother with Graves' disease [41]. This and the fact that ultrashort loop feedback control of thyrotropin secretion had been observed in rabbits $[42,43]$ led to the discovery of TSH receptors on folliculostellate cells of anterior pituitary lobe [44-46] and consecutive confirmation of a similar autocrine or paracrine effect in humans $[47,48]$. This feedback loop might prevent excessively high TSH levels and also be a source of TSH pulsatility, as suggested by investigations based on fractal geometry [49].

The existence of this loop may be a challenge for interpretation of laboratory results, especially in patients with Graves' disease, where TRAbs may suppress TSH secretion independently from current FT4 levels [50] resulting in TSH levels being lower than expected in relation to current FT4 levels (see Section 4.3).

2.3. Long Feedback Control (Fekete-Lechan Loop). As early as 1969 DiStefano postulated the existence of two-loop feedback of thyroid hormones targeting both hypothalamus and pituitary [51]. Based on control theoretical considerations, he had concluded that a model including proportional feedback at the hypothalamic level and rate (differential) feedback at the level of the pituitary provides best performance. At this time, unidirectional signalling from hypothalamus to pituitary resulting in stimulation of thyroid output had been described [52-54], but the existence of a long feedback loop was yet to be confirmed by experimental methods.

The presence of this additional long feedback loop that links iodothyronine levels in CNS with TRH release could be later confirmed in animal experiments [55-60].

Due to limitations in research methods this relationship cannot be directly investigated in humans. However, observations in animal models with induced nonthyroidal illness syndrome and phenomenologically similar observations in critically ill humans suggest this feedback loop is also effective in human physiology [61]. With current methodology the relative contribution of direct inhibition of TSH release by iodothyronine feedback and of indirect TSH reduction by suppressed TRH signalling cannot be isolated. More and more hints, however, indicate a central role of the TRH neuron in energy homeostasis, where thyroid signalling is a critical component $[62,63]$.

2.4. Alternative Mechanisms of Thyroid Control. The mentioned classical feedback mechanism controls the level of thyroid hormones via T4 formation and release. Additional mechanisms of homeostasis include autoregulation, where clearance of iodothyronines increases with their plasma levels [64-66], increased degradation of TSH in hyperthyroidism [67], possible ultrashort feedback control of TRH secretion, [68] and numerous mechanisms involving control of thyroid hormone transporters and receptor density $[15,17,69-$ 73]. Moreover, iodothyronines are subject to enterohepatic circulation that is a target of additional control signals $[16,74]$ and due to the prokinetic effects of iodothyronines possibly including thyroid hormones themselves [75, 76].

Ultrashort-loop feedback control mechanism at the site of the thyroid may exist in form of direct inhibition of TSH signalling by high levels of thyroid hormones [77-80], but from current scientific knowledge it is unclear if such a mechanism exists in humans. 
Posttranslational modifications of TSH may be a possible important, but still understudied mechanism of auxiliary thyrotropic control. Like other glycoprotein hormones TSH contains asparagine-linked biantennary and triantennary oligosaccharide structures with a terminal $\mathrm{N}$-acetylgalactosamine (GalNAc) sulfate signal and varying sialic acid content [81-83]. Plasma half-life of sialylated TSH is markedly prolonged, whereas asialo-TSH with terminal mannose, galactose, GalNAc sulfate, N-acetylglucosamine or fucose moieties is rapidly captured by hepatocyte asialoglycoprotein receptors and, in consequence, subject to degradation [82]. However, bioactivity of sialylated TSH seems to be reduced $[84,85]$. This could be related to prolonged half-life and resulting desensitization of TSH receptors [86] by virtue of reduced TSH pulsatility. Different TSH glycoforms may contribute to overall control of thyroid homeostasis, as suggested by increased sialo-TSH content in hypothyroidism [87, 88] and decreased sialylation in nonthyroidal illness syndrome [89]. Glycosylation patterns of TSH may also be one of the reasons for concentration-independent modulation of TSH bioaction, as represented by a lack of correlation between TSH levels and FT4 concentration in central hypothyroidism [90].

In addition to TSH, sialylation of other components of thyrotropic feedback control like thyroglobulin [91] and TSH receptor [92] was observed. The effect of the above mechanisms however on overall homeostasis is still less well understood.

2.5. Mathematical and Simulative Models of Thyroid Homeostasis. Cybernetic models of thyrotropic feedback control help to understand the relation between structure and behaviour of the system and to predict dynamical responses to input signals and loads. Occasionally, these models may also be used as generators of hypotheses and even diagnostic procedures.

As early as 1968 Panda and Turner delivered a first quantitative description of the relation of thyroxine and TSH levels that was derived from empirical observations [115]. The first theoretically based mathematical models of thyroid homeostasis, however, had already been developed in the preceding decade $[93,94]$. While these early and also some more recent models relied on a pure phenomenological approach usually on the ground of linear or polynomial relations $[95,106]$, improved models gradually shifted to a more and more parametrically isomorphic description, trying to map results of physiological and molecular research to a cybernetic description of the information processing structure $[11,49,96,97,99,101-103,105,108,110,111,113]$ (Table 1).

As a result of increased confidence in modelling results, attempts have been made to apply some of the newer approaches $[11,23,49,113,116]$ to clinical research $[23$, 117-119] and medical decision making $[11,116,120]$.

The standard model of thyroid homeostasis (Figure 1) postulates a logarithmic relationship between FT4 levels and pituitary TSH release $[105,121]$. This theory complies with empirical distributions of thyroid hormones in different

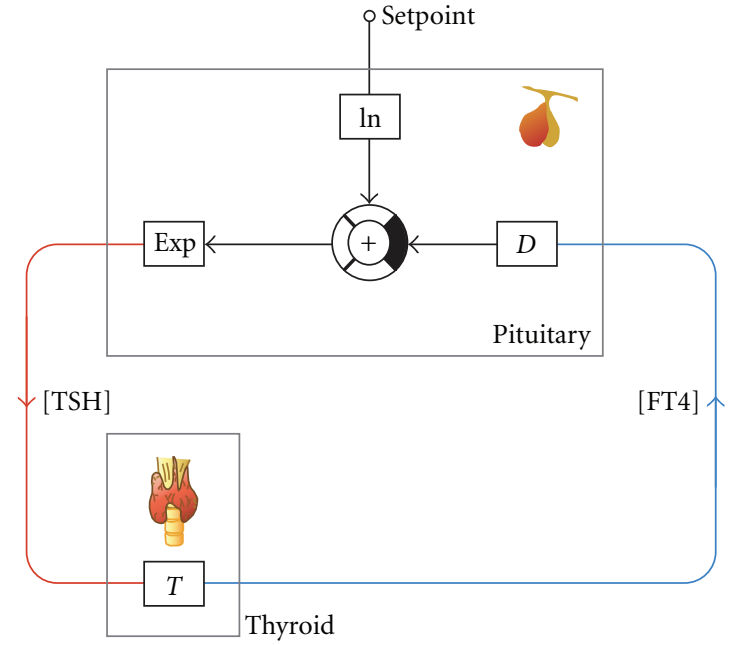

Figure 1: Information processing structure of the logarithmic standard model of thyroid homeostasis $[105,121]$.

populations $[122,123]$ and also with changes in FT3 levels in patients on substitution therapy [124]. Clinical applications try to exploit this postulated relation for diagnosis of pituitary disorders $[120,125,126]$. Recently, however, several population-based studies revealed discrepancies of bihormonal distributions from the standard logarithmic model in both euthyroidism and thyroid dysfunctions [127-129].

Alternative parametrically isomorphic models (e.g., the nonlinear model depicted in Figure 2) result from "bottomup" modelling based on molecular, cellular, and pharmacokinetic data. Not surprisingly, their mathematical theory is a great deal more complex. Therefore, computer simulations, for example, the open-source software SimThyr (Figure 3 [130]) have been developed to allow for a more intuitive understanding of the system's reactions and its temporal dynamics. The advantage of this kind of modelling approach is that parameters are well founded in thyroid biology and that resulting models therefore help to deliver hypotheses even in pathological conditions $[49,112]$.

"Small" models of thyroid homeostasis confine themselves to well-defined parts of the information processing structure. Examples are compartment-analytical models of iodine metabolism [131-134], kinetics of thyroid hormones [135] including their plasma protein binding [136], uptake of radioiodine [137-150], and intracellular dynamics of iodothyronine synthesis [110] and effect [151, 152].

Most models rely on parameters that have been obtained from humans. Only a minority deals with control of iodothyronine metabolism in animals, for example, cattle [133], sheep [132, 133], and rats [112].

Today, modelling of pituitary-thyroid axis is faced with the challenge of newly discovered complexities in the information processing structure, like ultrashort and long feedback loops and temporal dynamics of iodothyronine transporters. Although our knowledge benefits from excellent molecular and clinical studies, the growing intricacy of 
TABLE 1: Overview of published models of thyrotropic feedback control. Applications for research refer to any scientific exploitation outside of the modelling context itself, for example, for reasoning in clinical trials or generation of hypotheses.

\begin{tabular}{|c|c|c|c|c|c|c|}
\hline Authors & Year & Transfer characteristics & $\begin{array}{c}\text { Type of modelling } \\
\text { approach }\end{array}$ & $\begin{array}{l}\text { Applications } \\
\text { for research }\end{array}$ & $\begin{array}{c}\text { Clinical } \\
\text { applications }\end{array}$ & Reference \\
\hline $\begin{array}{l}\text { Danziger and } \\
\text { Elmergreen }\end{array}$ & 1956 & Linear & Phenomenological & - & - & {$[93]$} \\
\hline Roston & 1959 & Linear with basal secretion & Phenomenological & - & - & {$[94]$} \\
\hline Norwich and Reiter & 1965 & Linear & Phenomenological & - & - & {$[95]$} \\
\hline DiStefano and Stear & 1968 & Linear with basal secretion & $\begin{array}{l}\text { Phenomenological, } \\
\text { partly parametrically } \\
\text { isomorphic }\end{array}$ & - & - & {$[96]$} \\
\hline DiStefano and Chang & 1969,1971 & Linear with basal secretion & $\begin{array}{l}\text { Phenomenological, } \\
\text { partly parametrically } \\
\text { isomorphic }\end{array}$ & - & - & {$[97,98]$} \\
\hline DiStefano et al. & 1975 & N/A & $\begin{array}{l}\text { Parametrically } \\
\text { isomorphic }\end{array}$ & - & - & [99] \\
\hline Sudova and Langer & 1975 & $\begin{array}{l}\text { Exponential with } \\
\text { compartment-analytical } \\
\text { components }\end{array}$ & $\begin{array}{l}\text { Phenomenological, } \\
\text { partly parametrically } \\
\text { isomorphic }\end{array}$ & - & - & {$[100]$} \\
\hline Saratchandran et al. & 1976 & Logarithmic and linear & $\begin{array}{l}\text { Phenomenological, } \\
\text { partly parametrically } \\
\text { isomorphic }\end{array}$ & - & - & {$[101]$} \\
\hline Seif & 1977 & Logarithmic and linear & $\begin{array}{l}\text { Phenomenological, } \\
\text { partly parametrically } \\
\text { isomorphic }\end{array}$ & - & - & {$[102]$} \\
\hline Wilkin et al. & 1977 & Limit elements & $\begin{array}{l}\text { Phenomenological, } \\
\text { partly parametrically } \\
\text { isomorphic }\end{array}$ & - & - & {$[103]$} \\
\hline Hatakeyama and Yagi & 1985 & $\begin{array}{l}\text { Linear with first order time } \\
\text { constants }\end{array}$ & Phenomenological & - & - & {$[104]$} \\
\hline Cohen & 1990 & Logarithmic & Phenomenological & + & + & {$[105]$} \\
\hline Li et al. & 1995,1994 & Complex polynoms & $\begin{array}{l}\text { Phenomenological, } \\
\text { partly parametrically } \\
\text { isomorphic }\end{array}$ & - & - & {$[106,107]$} \\
\hline Dietrich et al. & 1997 & $\begin{array}{l}\text { Linear and } \\
\text { Michaelis-Menten kinetics }\end{array}$ & $\begin{array}{l}\text { Phenomenological, } \\
\text { partly parametrically } \\
\text { isomorphic }\end{array}$ & - & - & {$[108]$} \\
\hline Dietrich et al. & 2002,2004 & $\begin{array}{l}\text { Michaelis-Menten kinetics, } \\
\text { noncompetitive divisive } \\
\text { inhibition, first order time } \\
\text { constants }\end{array}$ & $\begin{array}{c}\text { Parametrically } \\
\text { isomorphic } \\
\text { (parameters for adult } \\
\text { humans) }\end{array}$ & + & + & {$[11,49]$} \\
\hline Falaschi et al. & 2004 & Linear & Phenomenological & - & - & {$[109]$} \\
\hline Degon et al. & 2008 & $\begin{array}{l}\text { Based on compartment and } \\
\text { flux analysis }\end{array}$ & $\begin{array}{l}\text { Phenomenological, } \\
\text { partly parametrically } \\
\text { isomorphic }\end{array}$ & - & - & {$[110]$} \\
\hline Leow & 2007 & $\begin{array}{c}\text { 2nd order Bernoulli } \\
\text { differential equations, } \\
\text { hysteresis, } \\
\text { inverse exponential power } \\
\text { law of TSH response }\end{array}$ & $\begin{array}{l}\text { Phenomenological, } \\
\text { partly parametrically } \\
\text { isomorphic }\end{array}$ & - & - & {$[111]$} \\
\hline Mclanahan et al. & 2008 & $\begin{array}{l}\text { Michaelis-Menten kinetics, } \\
\text { noncompetitive divisive } \\
\text { inhibition, first order time } \\
\text { constants }\end{array}$ & $\begin{array}{c}\text { Parametrically } \\
\text { isomorphic } \\
\text { (parameters for adult } \\
\text { rats) }\end{array}$ & - & - & {$[112]$} \\
\hline Eisenberg et al. & 2008,2010 & $\begin{array}{c}\text { Based on earlier models by } \\
\text { DiSefano et al. }\end{array}$ & $\begin{array}{l}\text { Phenomenological, } \\
\text { partly parametrically } \\
\text { isomorphic }\end{array}$ & + & - & {$[113,114]$} \\
\hline
\end{tabular}




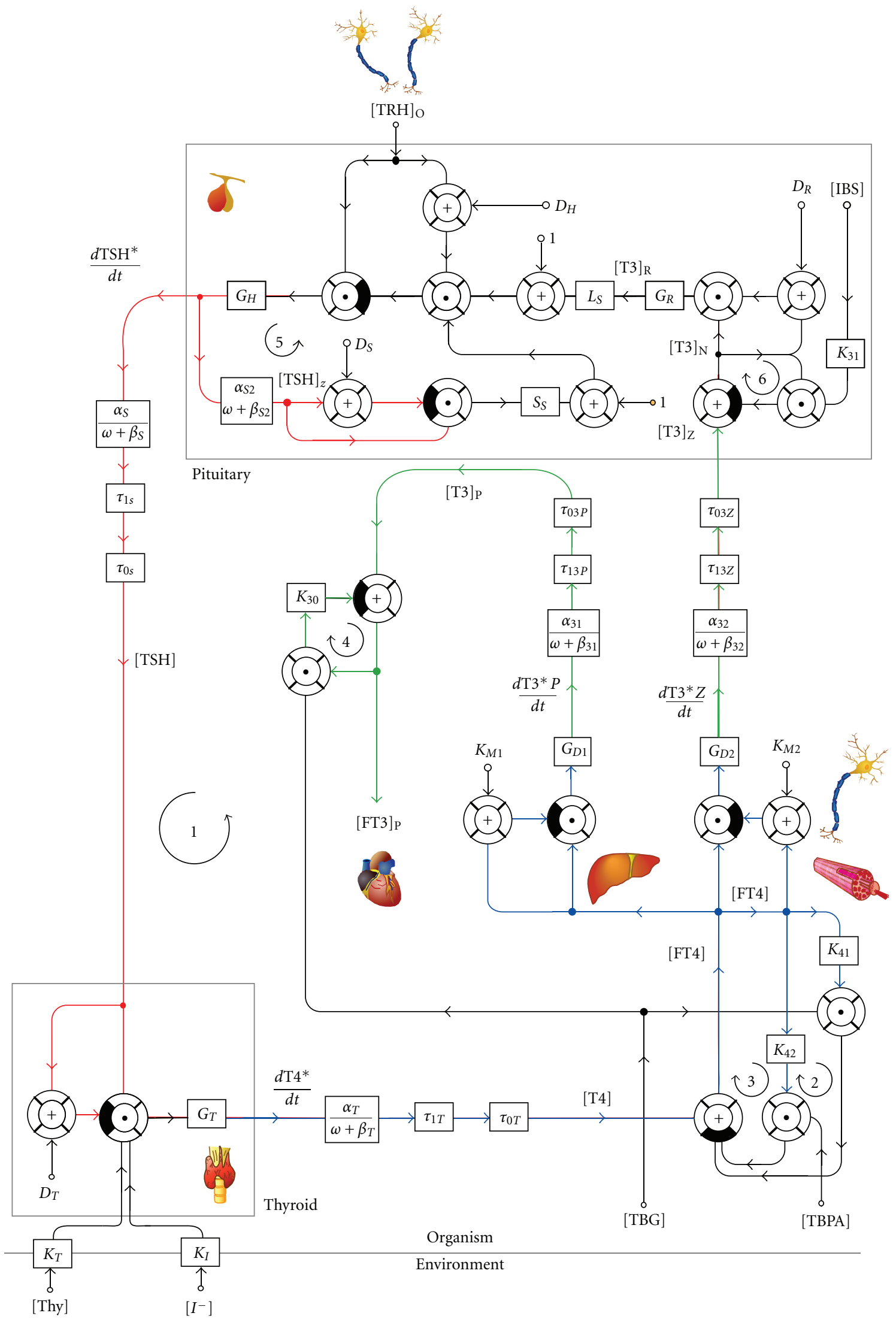

FIgURE 2: Information processing structure of a nonlinear parametrically isomorphic model based on Michaelis-Menten kinetics, noncompetitive divisive inhibition, and pharmacokinetic data [11]. Modified with permission from [49]. 


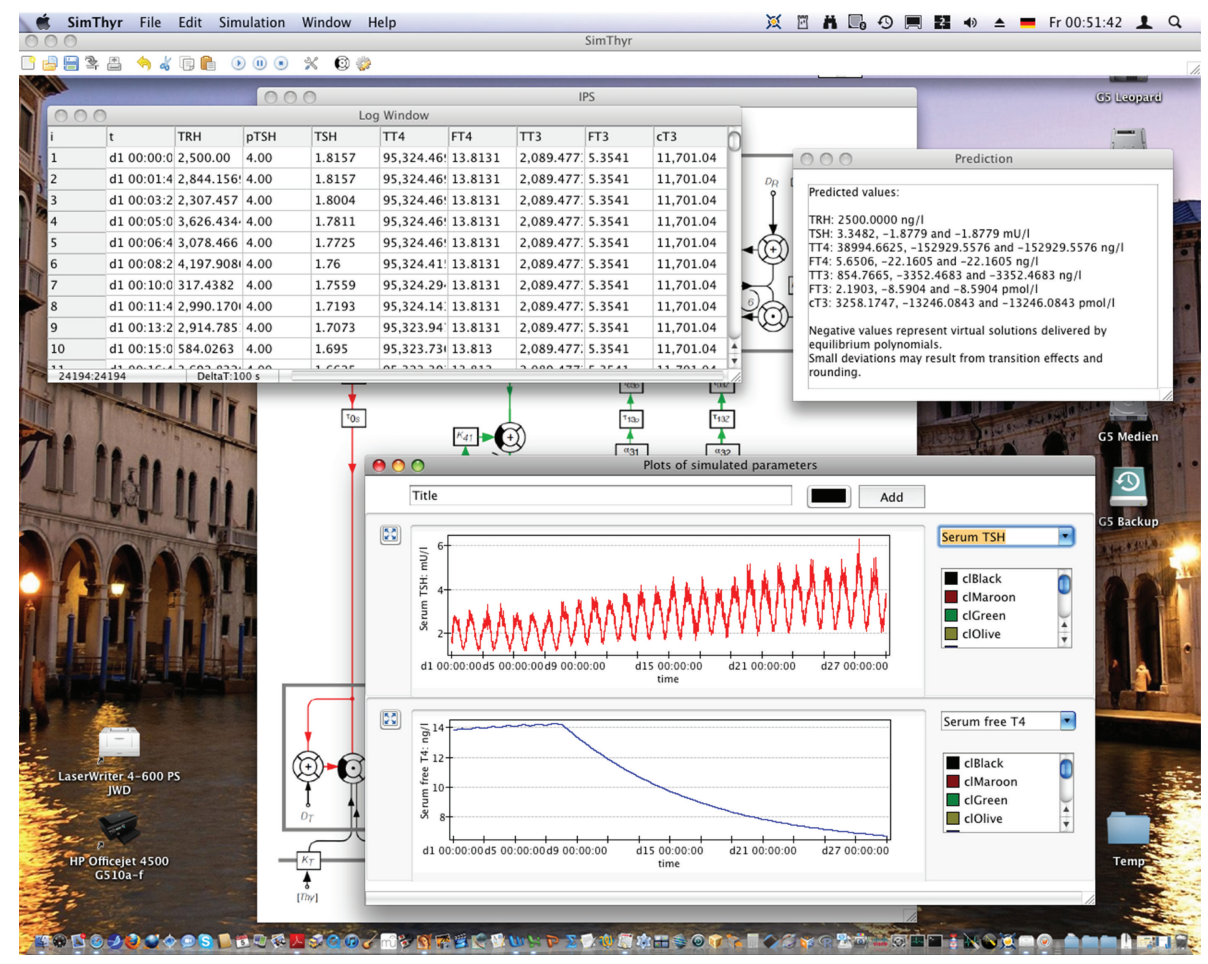

Figure 3: SimThyr, a continuous simulation program for thyrotropic feedback control [11].

resulting models turns out to be an obstacle for continued modelling attempts.

\section{Allostatic and Pathological Conditions}

In general, pathological dysregulations may result from a disconnected feedback loop or from feed-in of autonomously generated signalling substances. The processing structure may be interrupted at virtually any site, with resulting characteristic patterns that usually allow for an estimate of where the disturbance is located.

Unlike dysregulations, allostatic responses may provide life-saving adaptation mechanisms in extreme situations, for example, in critical illness, starvation, or hibernation.

In euthyroid subjects and in most cases of thyroid dysfunction the equilibrium point that is defined by steady-state levels of TSH and FT4, often in an oversimplifying manner referred to as setpoint, emanates from the intersection of characteristic curves of pituitary and thyroid (Figure 4).

Not surprisingly, the location of the equilibrium point may be modulated by changes in virtually any component of the feedback loop resulting in distortions of pituitary or thyroid characteristic curves. For instance, alterations of the setpoint have also been described in patients suffering from mutations of thyroid hormone transporters, first of all MCT8 [154-161], and in several polymorphisms of deiodinases [154, 162-167]. Additionally polymorphisms of thyroid hormone receptors [168, 169] and transcriptional cofactor heterogeneity $[170,171]$ may determine the location of the setpoint, but this association is still understudied.
3.1. Primary Thyroid Dysfunction. Primary functional disorders, marked by partial or complete disconnection of the feedback loop at the site of the thyroid, result from substantially reduced or increased thyroid's secretory capacity $\left(G_{T}\right)$, that is, the maximum stimulated amount the thyroid can produce in a given time unit. Common reasons for reduced $G_{T}$ are autoimmune or silent thyroiditis and iatrogenic causes including thyroid surgery or radioiodine ablation. Increased $G_{T}$ frequently ensues from heterostimulation of TSH receptors in Graves' disease or activating mutations of TSH receptors in toxic adenoma and toxic multinodular goitre $[11,116]$.

As shown in Figure 5 the FT4 component of the equilibrium point sinks while the TSH dimension rises with decreasing $G_{T}$. It is the nonlinear form of the response curves that gives rise to the evolution of subclinical and overt patterns of hypothyroidism.

It may astonish that the range of $G_{T}$ resulting in subclinical hypothyroidism is rather small in the plot, although in clinical practice subclinical thyroid disorders are very common. In vivo, these effects may be synergistically augmented by proliferative effects of slightly reduced FT4 levels on thyrotrophs, thus effectively broadening the zone of subclinical disorders [172-174]. Other synergistic effects widening the window of subclinical hypothyroidism include long feedback and the above-mentioned alternative modes of thyroid control.

Apart from alterations in $G_{T}$, which reflect mainly variations in the mass of functional thyroid tissue, primary heterostasis may also ensue from modified transduction properties of the TSH receptor by virtue of alterations in 


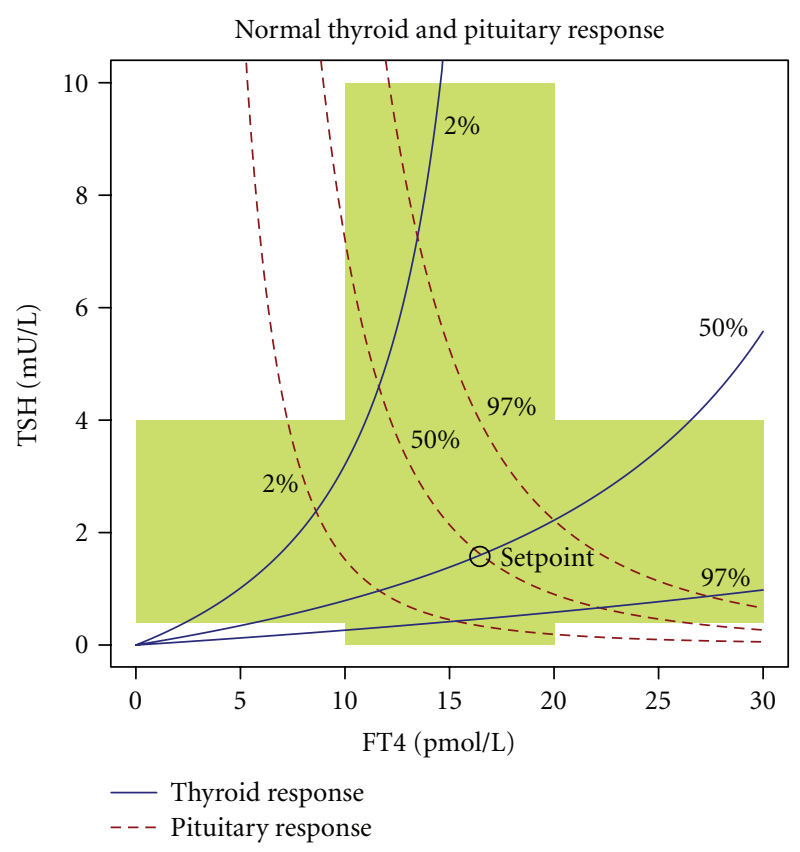

FIgURE 4: Characteristic curves of pituitary and thyroid. The area shaded in green denotes univariate reference ranges for TSH and FT4. The dashed red line denotes the pituitary's response in form of TSH incretion to varying FT4 levels; the continuous blue line represents the thyroid's response to TSH. Note that for the response curve of the thyroid - contrary to convention - the ordinate (TSH) is the independent axis, while the dependent axis is the abscissa (FT4). This uncommon notation facilitates superposition of both characteristic curves. Marked is a normal equilibrium point (also referred to as setpoint) defined by the intersection of both $50 \%$ percentiles. Response curves were calculated from percentiles for secretory capacities of pituitary $\left(G_{H}\right)$ and thyroid $\left(G_{T}\right)$ using the mathematical model displayed in Figure 2. Structure parameters were derived from a subgroup of subjects included in the NOMOTHETICOS trial [153].

its dissociation constant $\left(D_{T}\right)$, for example, by nonpolymorphic mutations [175-182]. However this mechanism that underlies nonautoimmune isolated hyperthyrotropinemia is assumed to be a comparably rare condition, [183, 184]. Things are even more complex since it is expected that chronic understimulation of the thyroid by mutations in the TSH receptor eventually leads to reduced thyroid mass and thus lower $G_{T}$ [185-187].

3.2. Secondary and Tertiary Thyroid Dysfunction. Central hypothyroidism or thyrotropic insufficiency, defined as reduced thyroid hormone secretion resulting from deficient stimulation of an intrinsically normal thyroid gland by TSH [188], may be of pituitary (secondary) or hypothalamic (tertiary) origin. On the basis of hormone levels and even of TRH stimulation tests, secondary and tertiary forms are nearly indistinguishable without utilization of additional information, for example, from imaging studies. To add further confusion, TSH secretion may be impaired not only quantitatively but also qualitatively resulting from secretion of biologically inactive TSH $[189,190]$, as discussed above.

On a phenomenological level, however, two forms may be distinguished. In partial thyrotropic insufficiency FT4 is decreased while TSH is normal (but inadequately low in relation to reduced FT4 levels), and in complete thyrotropic insufficiency levels of both hormones are decreased. These phenotypes may be explained by nonlinear response curves of pituitary and thyroid (Figure 6).

Central hyperthyroidism, for example, resulting from TSH secreting pituitary adenomas [191] or central thyroid hormone resistance $[189,192,193]$ (see Section 3.4), is a very rare condition. Interestingly, in both cases TSH levels may be excessively high, while peripheral thyroid hormone concentrations are only mildly elevated [191]. This is a consequence of nonlinear action of thyrotropin at TSHr that is well explained by the Michaelis-Menten-like inputoutput relation at the thyroid in some of the recent models of feedback control [11, 49].

3.3. Thyroid Allostasis in Critical Illness, Tumours, Uraemia, and Starvation (TACITUS). In 1973, two independent study groups described alterations of thyroid metabolism in the starving organism $[194,195]$. Later it was demonstrated that similar alterations are also common in critically ill patients and that they are associated with increased morbidity and mortality [22, 196-200].

This complex constellation, referred to as euthyroid sick syndrome or nonthyroidal illness syndrome (NTIS), is characterised by three components that may occur singly or in combination: low TSH and normal or low FT4 levels phenomenologically similar to central hypothyroidism (transient thyrotropic adaptation, occasionally leading to low-T4 syndrome) [201], impaired protein binding of thyroid hormones $[202,203]$, and reduced formation of T3 with simultaneously increased conversion to rT3 (lowT3 syndrome) [22-24]. Few observations report that the iodothyroacetic acids TRIAC and TETRAC are increased in NTIS and starvation [204-206]. Currently, little is known about the role of thyronamines [207] in NTIS. The fact that thyronamines are able to induce hypothermic torpor [208] and that they are a possible source of iodothyroacetate formation [209] suggests them to be increased in critical illness.

Different explanations have been proposed for the evolution NTIS. Up to now, in essence five hypotheses are discussed in the literature $[22,23]$.

(i) All observed abnormalities are the result of test artefacts by flawed assays in the presence of plasmatic interference factors. In reality, the patients are euthyroid.

(ii) The changes in the levels of peripheral thyroid hormones mirror the effect of certain binding inhibitors that influence either laboratory determinations only or also the transfer of thyroid hormones into tissue of diseased persons and thus diminish binding of iodothyronines to $\mathrm{T} 3$ receptors. 


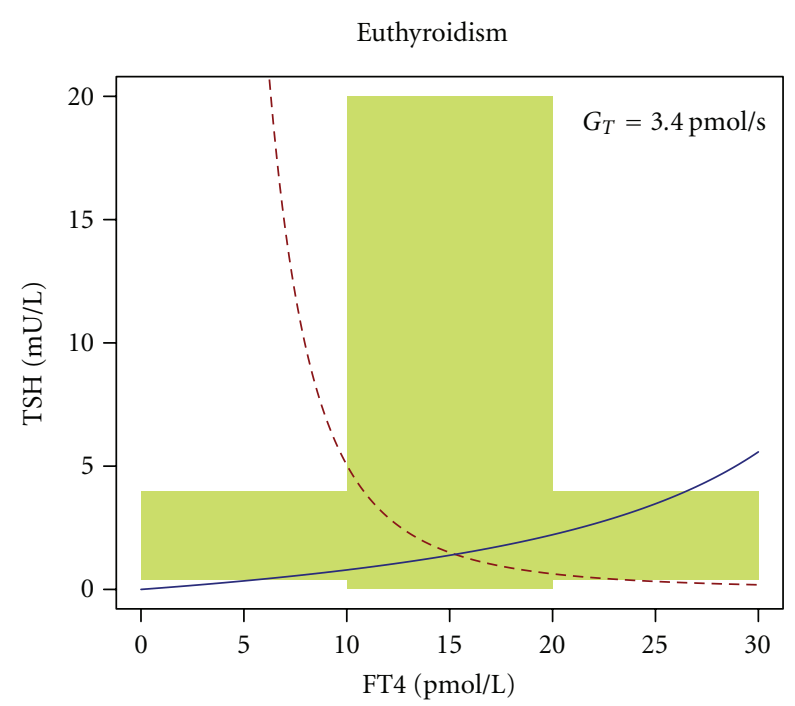

(a)

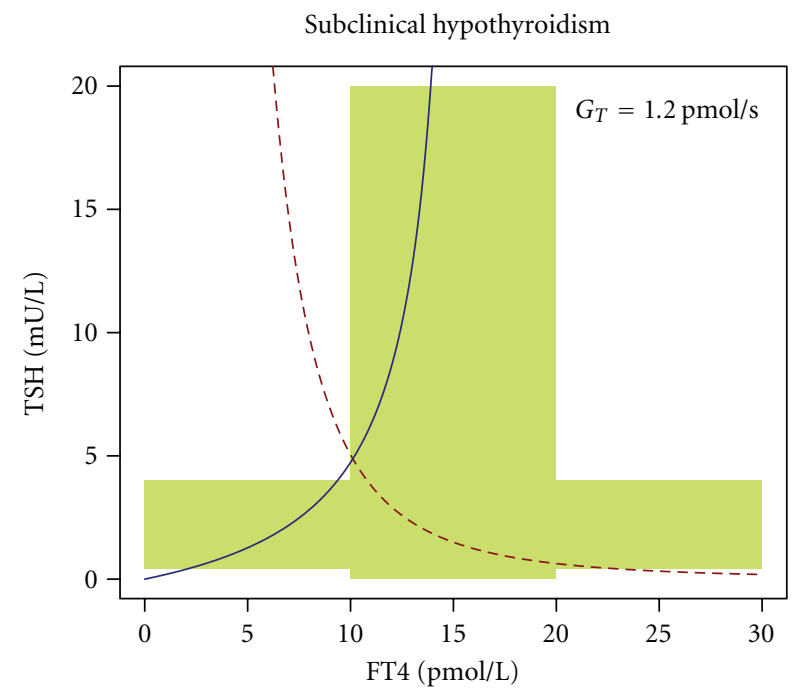

(c)

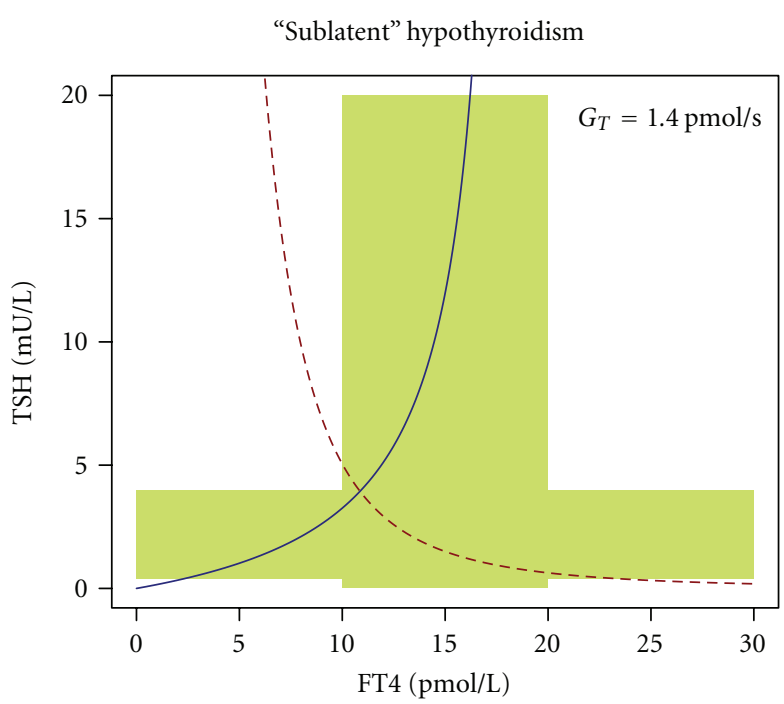

(b)

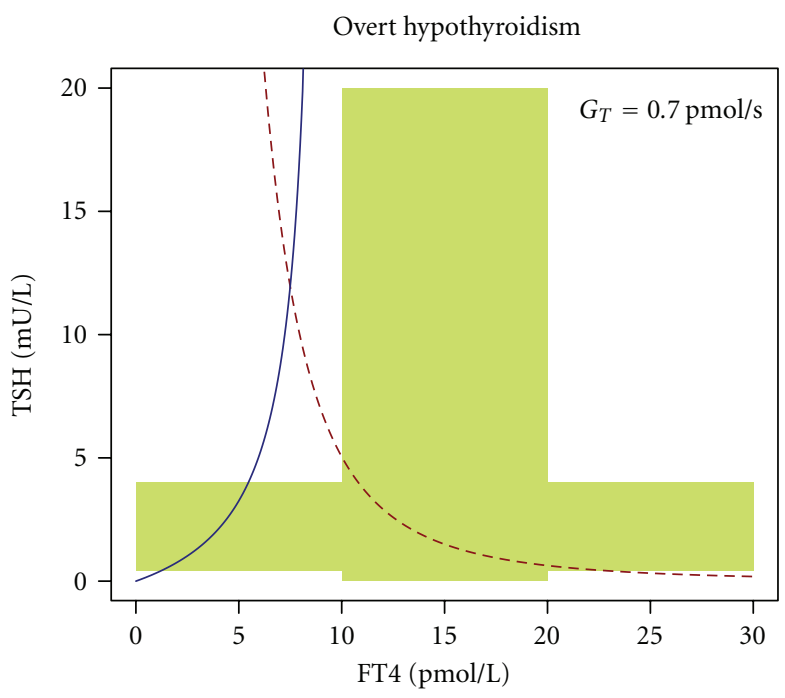

(d)

FIGURE 5: Successive development of hypothyroidism as a consequence of decreasing $G_{T}$. Beginning with a hypothetical "sublatent" form defined by reduced $G_{T}$ and still normal levels of TSH and FT4 (panel b), further steps are subclinical hypothyroidism with increased TSH levels and FT4 still in the lowest fraction of the reference region (panel c) and overt hypothyroidism where both parameters have left their reference region (panel d). See text for additional information.

(iii) Due to increased local deiodination, $\mathrm{T} 3$ levels are normal in the pituitary gland while they are low in the rest of the organism.

(iv) Levels of peripheral thyroid hormones are actually low so that affected patients are biochemically hypothyroid. However, this useful physiological function should not be interfered with.

(v) NTIS is a form of central hypothyroidism. The resulting tissue hypothyroidism should be treated with appropriate substitution therapy.

Today, NTIS is still poorly understood from an integrative view. As similar alterations are observed with very different assay techniques and a comparable phenotype is also observed in starving or hibernating organisms [210-214] it seems to be more than only the result of flawed assays. Obviously, it is an extreme form of a more general allostatic response ensuring survival in certain stress situations. We therefore propose the more neutral term thyroid allostasis in critical illness, tumours, uraemia, and starvation (TACITUS) for this form of adaptation taking place in a broader context of physiological extremes.

Provided that patients with NTIS are faced with poor prognosis, several trials have been conducted to evaluate the question of a possible treatment [22, 197]. However, their results were ambiguous. Some studies could show a benefit of substitution therapy with thyroid hormones, for example, regarding the incidence of atrial fibrillation 


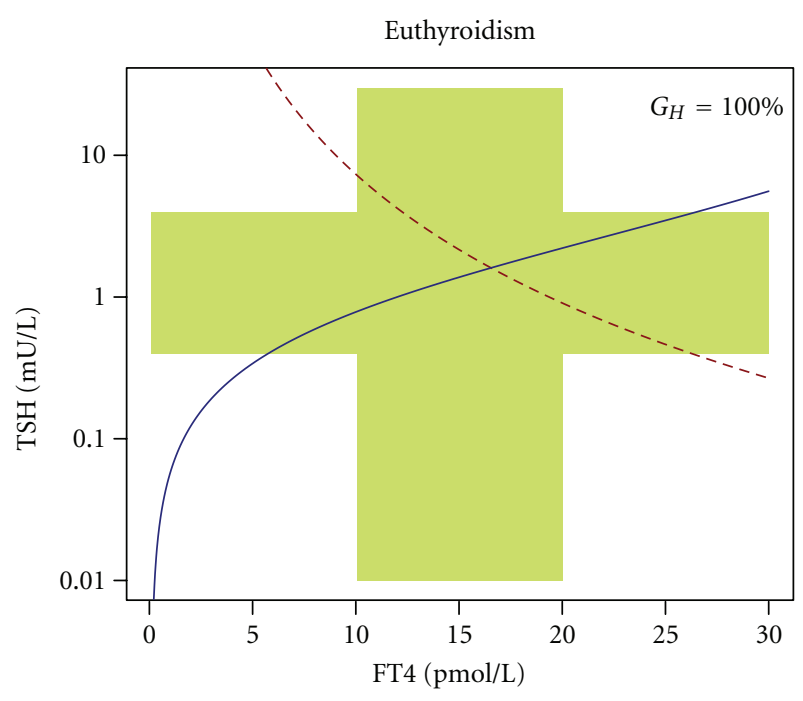

(a)

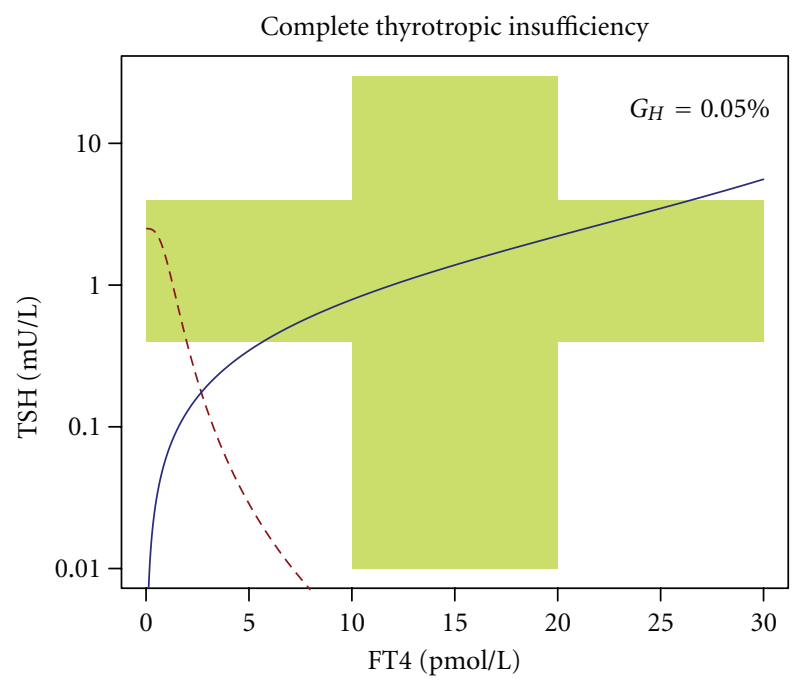

(c)

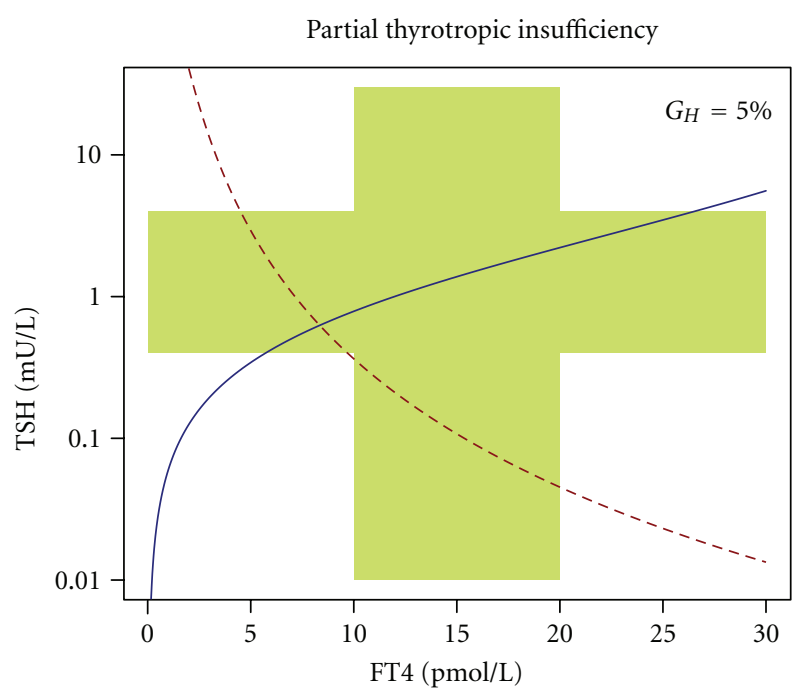

(b)

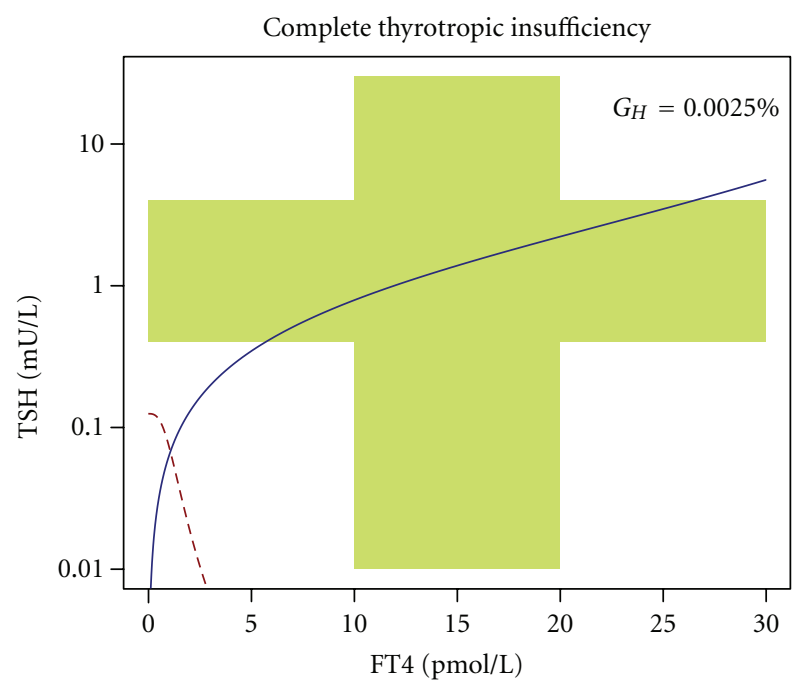

(d)

Figure 6: Partial and complete thyrotropic insufficiency as results of nonlinear interaction of pituitary and thyroid. TSH axis is logarithmically scaled in order to zoom small values. $G_{H}$ values are given in percent from normal values. See text for additional information.

$[22,197,215,216]$ and hemodynamic parameters $[217,218]$ while others could not observe relevant differences in outcome between treated and untreated patients [219-221] or even described detrimental effects of substitution therapy [222-225].

Today, more and more investigations reveal a fundamental, albeit not exclusive, role of central components in the evolution of TACITUS [22-24, 61, 226]. This may even apply to hypodeiodination leading to low-T3 syndrome, as TSH is able to stimulate D2 expression via cAMP [26, 227-230]. Conversely, central hyperdeiodination may lead to suppressed TSH levels, as both evidenced by animal experiments [61,231] and computer simulations (Figure 7).

Thyrotropic adaptation is a challenge affecting clinical practice, as it is nearly indistinguishable from latent (subclinical) hyperthyroidism - although pathophysiology and therapeutic implications are opposed [196, 232].
3.4. Rare Conditions of Thyroid Function. In most cases high-T3 syndrome and T3 thyrotoxicosis result from T4 hyperthyroidism with consecutive surplus substrate supply for deiodinases. Isolated high-T3 syndrome with normal or even low FT4 levels is a rare form of NTIS that is caused by hyperdeiodination. Cases of high-T3 syndrome have been described in toxic adenoma [233], Graves' disease [234], nodular goitre [233], follicular thyroid carcinoma [235, 236], and systemic sclerosis [237]. Increased TSH signalling in the first two conditions gives further evidence for the relevant role of thyrotropin in control of deiodinase activity [238].

Thyroid hormone resistance is usually caused by mutation of the nuclear thyroid hormone receptor beta gene (TRbeta), with a resulting hormone pattern similar to central hyperthyroidism and a split phenotype of clinical thyrotoxicosis with regard to peripheral organs and heterogeneous 

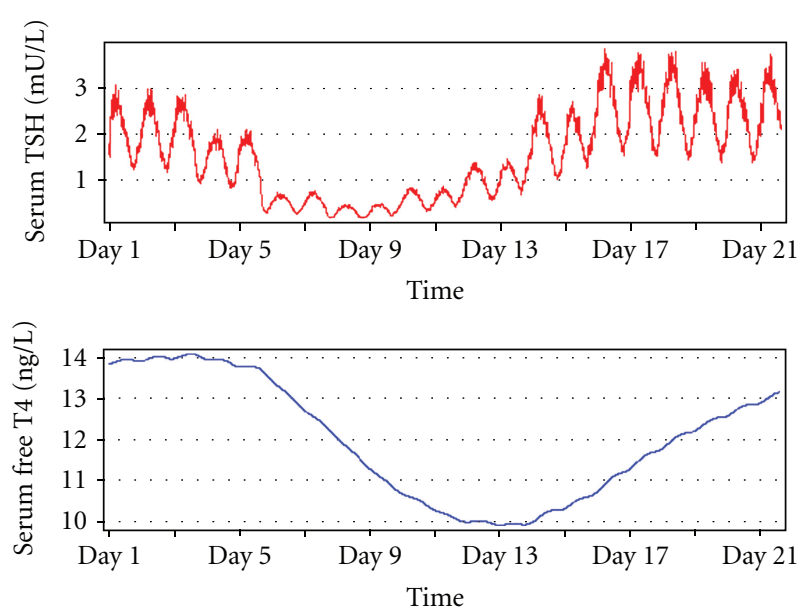

FIGURE 7: Computer simulation of thyrotropic adaptation in critical illness. A gradual increase of central type 2 deiodinase activity over several days with subsequent restoration to normal values has been simulated with SimThyr using the mathematical model shown in Figure 2. Note the temporarily increased TSH values after day 17 that are occasionally observed also in vivo in patients recovering from nonthyroidal illness syndrome.

manifestations at the site of the central nervous system [192, 239].

Recently, the first case of thyroid hormone receptor alpha mutation was reported. The phenotypical pattern consisted in skeletal abnormalities, microsomia, constipation, and hyperdeiodination [240].

The existence of acquired partial thyroid hormone resistance has been postulated [241, 242], but this condition may be rare or underrecognised. In NTIS, however, disruption of thyroid hormone signalling by cytokines, metabolites, toxins or drugs may contribute substantially to the clinical phenotype of affected patients [242]. Possible mechanisms of acquired thyroid hormone resistance include impairments of transmembrane transport [15, 16, 243], deiodination $[19,227,228,244]$, entry into nucleus [245, 246], receptor binding [243, 247-253], and nongenomic effects of iodothyronines [28, 254-264]. Similar effects may ensue from exposure to endocrine disruptors [265] like phthalates [266-268], brominated flame retardants [266, 267, 269], perfluorinated compound [266, 267, 270], polychlorinated biphenyls [271-276], bisphenol A [254, 266-269, 274], or bisphenol F [277].

Some environmental toxins may also act as thyroid hormone agonists, as demonstrated for certain polychlorinated biphenyls [278, 279].

\subsection{Calculated Structure Parameters as Diagnostic Methods} Beyond Univariate Hormone Determinations. Decision making based on TSH levels alone may lead to misinterpretations of serious impact, especially in cases of possible overt thyroid heterostasis [127-129] and even more in potential central dysregulations [280]. However, introducing FT3 or FT4 levels while leaving the process of diagnostic reasoning in a univariate manner does not prove to be helpful due to the lack of combination rules and low diagnostic sensitivity of peripheral thyroid hormone levels [11].

Combining hormone levels with model-based calculations delivers structure parameters of thyroid homeostasis that may in certain conditions add valuable information for clinical research and differential diagnosis of thyroid disorders, even beyond of classical primary and secondary heterostasis.

The simplest and probably earliest method to exploit existing knowledge about thyroid homeostasis for diagnostic purposes is calculating T3/T4 ratio. It can be calculated from either total or free thyroid hormones. T3/T4 ratio has been applied in numerous publications, and it was shown that this parameter is elevated in certain thyroid disorders [234, 236, 281, 282] and iodine deficiency [283], while it is reduced in nonthyroidal illness $[284,285]$. Furthermore, T3/T4 ratio mirrors nutritional [286] and drug effects on deiodination [287], and it may be useful to distinguish thyroiditis from other causes of thyrotoxicosis [288]. Reduced T3/T4 ratio in central hypothyroidism is another hint for the stimulating role of TSH for deiodination [289].

The T3/T4 ratio ignores fundamental biochemical principles by implying a linear relationship between T3 and T4. This is corrected by an alternative approach, calculating sum activity of peripheral deiodinases $\left(G_{D}\right.$, also referred to as SPINA- $G_{D}$ ) with

$$
\hat{G}_{D}=\frac{\beta_{31}\left(K_{M 1}+[\mathrm{FT} 4]\right)\left(1+K_{30}[\mathrm{TBG}]\right)[\mathrm{FT} 3]}{\alpha_{31}[\mathrm{FT} 4]}
$$

from free $\mathrm{T} 4$, free $\mathrm{T} 3$, and parameters for protein binding, dissociation, and hormone kinetics (Table 2) [11, 23]. The equation had been derived from a nonlinear model of thyrotropic feedback control by solving the transfer equation for $G_{D}$ under the condition of equilibrium [49]. It could be demonstrated that $G_{D}$ correlates with body mass index [11]. Additionally, the parameter was observed to be reduced in certain forms of NTIS including renal failure [290] and inflammatory bowel diseases [291].

The T3/rT3 ratio is a measure of relative contributions of type 2 and type 3 deiodinases on deiodination of T4. It was observed to be decreased in critical illness [296, 297] and hyperthyroidism [298], and to be increased in insulin resistance [299].

Theoretical thyroid's secretory capacity $\left(G_{T}\right.$ or SPINA$G_{T}$ ) denotes the maximum amount of thyroxine the thyroid can produce in a given time unit under stimulated conditions. Formally similar to $G_{D}$, it can be calculated in vivo with

$$
\widehat{G}_{T}=\frac{\beta_{T}\left(D_{T}+[\mathrm{TSH}]\right)\left(1+K_{41}[\mathrm{TBG}]+K_{42}[\mathrm{TBPA}]\right)[\mathrm{FT} 4]}{\alpha_{T}[\mathrm{TSH}]}
$$

from TSH levels, FT4 levels, and constant parameters for kinetics and protein binding (Table 2) [23]. $G_{T}$ has been observed to correlate with thyroid volume as determined by ultrasonography and to be elevated in hyperthyroidism and reduced in hypothyroidism [11, 116]. Furthermore, 
TABLE 2: Constant parameters for diagnostic calculations.

\begin{tabular}{llcc}
\hline Symbol & Explanation & Value & Reference \\
\hline$\beta$ & Correction coefficient for log-linear model & -0.1345 & {$[120]$} \\
$\alpha_{T}$ & Dilution factor for T4 (reciprocal of apparent volume of distribution) & $0,1 \mathrm{~L}^{-1}$ & {$[11,23]$} \\
$\beta_{T}$ & Clearance exponent for T4 & $1,1 * 10^{-6} \mathrm{sec}^{-1}$ & {$[11,23,292]$} \\
$D_{T}$ & EC $_{50}$ for TSH & $2,75 \mathrm{mU} / \mathrm{L}$ & {$[11,23,293]$} \\
$K_{41}$ & Dissociation constant T4-TBG & $2 * 10^{10} \mathrm{~L} / \mathrm{mol}$ & {$[11,23,106]$} \\
$K_{42}$ & Dissociation constant T4-TBPA & $2 * 10^{8} \mathrm{~L} / \mathrm{mol}$ & {$[11,23,106]$} \\
$\alpha_{31}$ & Dilution factor for T3 & $0,026 \mathrm{~L}-1$ & {$[11,23]$} \\
$\beta_{31}$ & Clearance exponent for T3 & $8 * 10^{-6} \mathrm{sec}^{-1}$ & {$[11,23]$} \\
$K_{M 1}$ & Dissociation constant of type 1 deiodinase & $5 * 10^{-7} \mathrm{~mol}_{/} \mathrm{L}$ & {$[11,23,294]$} \\
$K_{30}$ & Dissociation constant T3-TBG & $2 * 10^{9} \mathrm{~L} / \mathrm{mol}$ & {$[11,23,295]$} \\
\hline
\end{tabular}

TABLE 3: Test-retest reliability measures of TSH, FT4, FT3, SPINA-GT, and SPINA-GD from repeated measurements with at least one month interval in 20 healthy volunteers from the SPINA network $[11,116] . e$ : repeatability $=($ interindividual variance)/(intraindividual variance + interindividual variance) [300]. Larger figures denote higher reliability.

\begin{tabular}{lcc}
\hline Parameter & $e$ & $R^{2}$ \\
\hline TSH & 0.63 & 0.16 \\
FT4 & 0.71 & $0.35^{* *}$ \\
FT3 & 0.68 & $0.36^{* *}$ \\
SPINA-GT & 0.73 & $0.42^{* *}$ \\
SPINA-GD & 0.64 & $0.36^{* *}$ \\
\hline
\end{tabular}

$* * P<0.01$.

$G_{T}$ correlates with creatinine clearance suggesting a negative influence of uremic toxins on thyroid biology [290]. In healthy volunteers $G_{T}$ showed a higher reliability compared with TSH, FT4, or FT3 (Table 3) [11]. These results imply that, unlike $G_{D}$ or univariate hormone levels that mirror acute regulation, $G_{T}$ might represent a constant parameter of thyroid homeostasis.

Recently, a small study that has been published as abstract revealed calculating $G_{T}$ to be beneficial in differential diagnosis of NTIS with thyrotropic adaptation and latent (subclinical) hyperthyroidism [301].

Additionally, specific thyroid's secretory capacity $\left(G_{T S}\right)$ had been defined by calculating a ratio of $G_{T}$ and thyroid volume, as determined, for example, by ultrasonography [11]. This structure parameter denotes the maximum amount of thyroxine that can be produced by $1 \mathrm{~mL}$ of thyroid tissue under stimulated conditions. In one study a significant positive correlation between body mass or BMI, respectively, and thyroid volume was observed, while in the same population the correlation between body mass and $G_{T S}$ was negative, suggesting reduced functional quality of thyroid tissue in obesity [11].

Thyrotroph T4 Sensitivity Index (TTSI)

$$
\mathrm{TTSI}=\frac{100[\mathrm{TSH}][\mathrm{FT} 4]}{l_{u}}
$$

with $l_{u}$ being the upper limit of the reference interval for FT4 has been suggested as a screening parameter for thyroid hormone resistance [302]. However up to now, this parameter has not been widely adopted. TSH-FT4 product, a similar measure, was demonstrated to have a significant heritable component in a large cohort of twin pairs [303].

An alternative method to assess thyrotropic function of anterior pituitary is Jostel's TSH index [120]. This calculated parameter is based on the logarithmic standard model of thyroid homeostasis. Calculating

$$
\mathrm{TSHI}=\ln [\mathrm{TSH}]-\beta[\mathrm{FT} 4]
$$

delivers a raw value. A second standardised form of TSHI is based on mean values (2.7) and standard deviations (0.676) of TSHI

$$
\text { sTSHI }=\frac{\text { TSHI }-2.7}{0.676}
$$

TSHI predicts the risk of failure in dynamic pituitary testing and correlates with functional measures of other anterior pituitary axes [120].

Although calculated structure parameters may add value to the determination of classical univariate hormone values, their informative value depends in a critical manner on the quality of the assays used for underlying hormone measurements. Although assays for TSH, free, and total peripheral thyroid hormones have been continually improved over the previous decades [304-312], some indeterminacy persists [307, 313-315]. Additionally, if certain input parameters, for example, TBG and binding constants for calculation of $G_{T}$ and $G_{D}$, are not biochemically determined but, as usual, replaced by standard values, some bias may ensue. Therefore, $G_{T}$ and $G_{D}$ will be overestimated in NTIS, where plasma protein levels are reduced $[202,203]$. Although this will usually not pose problems in differential diagnosis, as the impairment of protein binding affects all investigated groups, the person calculating structure parameters and interpreting their results should at least be aware of these difficulties. Of course, the same considerations also apply to empirical parameters like TTSI and TSHI, the more, as here the origin of bias is less obvious, since protein levels and binding constants are not explicitly stated in the equations. 


\section{Alternative Thyrotropic Agonists}

TSH is one of five related glycoprotein hormones consisting of two noncovalently bound chains. TSH, LH, FSH, and HCG share a common alpha subunit that is encoded on human chromosome 6 and contains a protein core of 92 amino acid residues in humans $[316,317]$. The specific information is encoded by the beta subunit that has a different amino acid sequence for each hormone, and especially a certain "seat belt" region, where the beta chain wraps around the alpha chain $[318,319]$. Free alpha or beta subunits are devoid of bioactivity. A fifth glycoprotein hormone, thyrostimulin (TSH 2) with a similar molecular structure, has been described. It contains both a different alpha and beta subunit [320].

Gene expression of both alpha and beta subunits are controlled positively by a PKA/PKC-CBP-CREB pathway that is stimulated by TRH and AVP and inhibited by Dopamine. Additionally, expression of both subunits is inhibited by a negative thyroid hormone response element (nTRE) that is dependent on TR-beta receptor [316] signalling.

TSH and thyrotropic agonists bind to the TSH receptor (TSHr), a heptahelical G-protein-coupled receptor that has homologies to FSHr and LH/CGr [321] (Figure 8). Like in TSH (see Section 2.4), variable sialylation of glycosylated side-chains modifies bioactivity of glycoprotein hormones $[81,85,91,322]$, for example, by affecting cooperative effects of individual TSH domains in receptor activation [317].

Due to the above-mentioned considerations it is not surprising that considerable crosstalk exists between thyrotropic and gonadotropic feedback controls. In addition, TSHr antibodies [323] as well as small molecule "drug-like" ligands $[324,325]$ may stimulate or block signal transduction.

4.1. HCG. Although in human embryos the thyroid is able to produce T3 and T4 in the 10th or 11th week, and pituitary thyrotrophs are detectable in the 13th week, maturation of functional thyrotropic feedback control is not effective before the 18th to 20th week [326, 327].

Therefore, the embryo is dependent from maternal supply with thyroid hormones in the first half of pregnancy. This and the fact that the binding of iodothyronines to TBG is increased in pregnancy require some upregulation of $\mathrm{T} 4$ biosynthesis.

Sequence similarities between TSH and HCG, and between their receptors, allow for some promiscuous activation of TSHr by HCG in the first trimester of pregnancy [321].

Stimulation of the thyroid gland by HCG in pregnancy accounts for an inverse relationship between serum concentrations of TSH and HCG [328]. In cases of extremely elevated HCG levels, for example, in hydatidiform mole or chorionic carcinoma, overt hyperthyroidism and even thyroid storm may ensue [329-331]. The same pathomechanism may lead to hyperthyroidism in embryonal testicular carcinoma [332, 333].

Interestingly, heterostimulation of TSHr by HCG is a matter of both quantity and quality. In Chinese hamster ovary cells transfected with human TSHr enhanced thyrotropic activity was observed in sera from women with trophoblastic disease. If $\mathrm{CHO}$ cells were transfected with LH/CGr, however, cAMP production was higher in sera from women with normal pregnancy. These diverging results may ensue from microheterogeneity of hCG, for example, in form of different carbohydrate modifications [334, 335].

Mutations of TSH receptor leading to increased sensitivity to HCG may lead to overt hyperthyroidism even in normal pregnancy [336].

Theoretically, HCG should also be able to activate pituitary TSH receptors and lead to suppression of TSH secretion via the Brokken-Wiersinga-Prummel loop. Although this possibility could be useful for targeted therapy of hypothyroidism in pregnancy, up to now no data are available from clinical trials.

4.2. Thyrostimulin. Based on GenBank searches Nakabayashi et al. identified two additional human glycoprotein hormone subunit-like genes with structural similarity to the genes of the common alpha subunit and the beta chain for TSH, respectively. Using a yeast two-hybrid assay they found the two units to be able to heterodimerize and finally they confirmed their colocalization in the anterior pituitary and the ability of the resulting heterodimeric protein to bind and activate human TSH receptors, but not $\mathrm{LH}$ and FSH receptors [320]. Consequently, they named the A2/B5 heterodimeric glycoprotein thyrostimulin; other designations are TSH 2 or corticotroph-derived glycoprotein hormone (CGH), as both chains are expressed in corticotrophs of anterior pituitary [337].

Today, the physiological role of thyrostimulin is still not well understood. It has been proposed to play a role for Brokken-Wiersinga-Prummel loop [338] or in paracrine effects within the pituitary [320]. It has also been hypothesised that thyrostimulin may be responsible for thyroid heterostimulation in cases of diffuse thyroid autonomy [339], but this assumption has not been proved up to now. Expression of thyrostimulin subunits was observed in pituitary, central nervous system, adrenal gland, gastrointestinal organs, retina, skin, and testes [340]. LPS and inflammatory cytokines are able to upregulate thyrostimulin expression $[338,341]$, which may be another factor in the pathogenesis of thyrotropic adaptation in NTIS.

4.3. Thyrotropin Receptor Antibodies. Classical Graves' disease (autoimmune thyroiditis type $3 \mathrm{~A}$ ) is caused by formation of stimulating TSH receptor antibodies (sTRAbs, also referred to as thyroid stimulating antibodies, TSAbs) by intrathyroidal $\mathrm{B}$ cells with resulting hyperthyroidism. Retroorbital TRAb formation leads to endocrine ophthalmopathy, and it is assumed that other manifestations of Graves' disease derive from extrathyroidal TRAb effects, too.

As mentioned above sTRAbs may suppress TSH secretion independently from FT4 levels by activation of the BrokkenWiersinga-Prummel loop [47]. Therefore, in Graves' disease low TSH levels may persist despite even low FT4 levels [50]. 


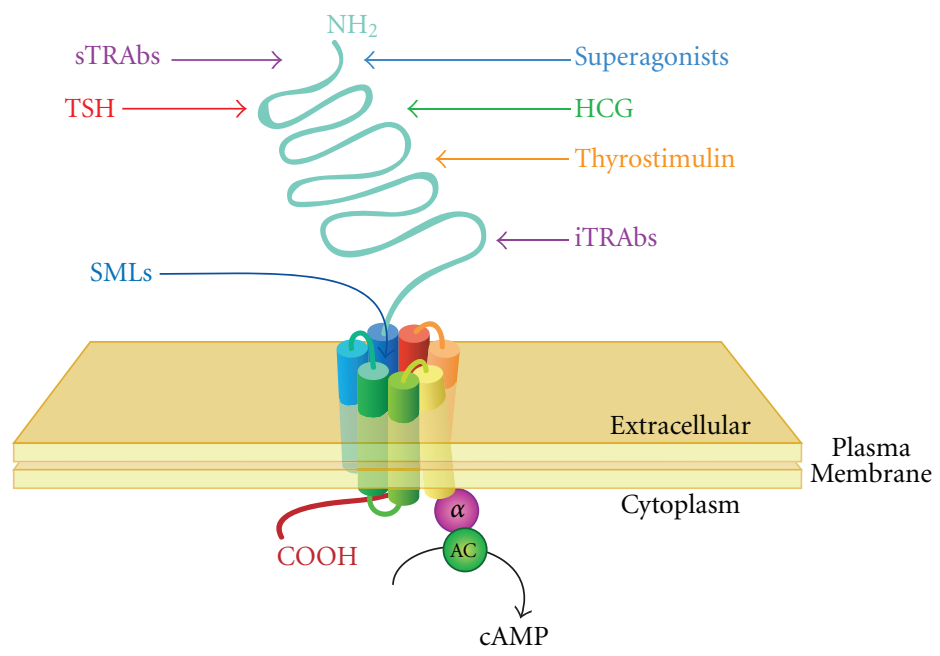

FIGURE 8: Interaction of TSH, thyrotropic agonists, and thyrotropic antagonists with TSH receptor. SMLs bind to a pocket within the heptahelical transmembrane domain, while TSH, HCG, and TRAbs bind primarily to the TSHr amino-terminal ectodomain.

Obviously, this also applies to children born to mothers with Graves's disease and high antibody load [41]. Immunogenic TSH suppression may complicate diagnosis of thyroid status and dosage of thyroid hormones or thyrostatic agents in Graves' disease.

Inhibiting TSH receptor autoantibodies (iTRAbs, or TSH-stimulation blocking antibodies, TSBAbs) block signal transduction at the TSH receptor. Up to now, their effect on global thyroid homeostasis or ultrashort loop control of TSH secretion has not been investigated, which may also be a consequence of still limited availability of reliable sTRAb and iTRAb assays for routine use. Over the time, the proportion of stimulating or inhibiting TRAbs may change in individual patients [342].

Synthetic TSH receptor antibodies are described below.

4.4. Orosomucoid. Orosomucoid, also referred to as alpha1 -acid glycoprotein (AGP), is an acute-phase glycoprotein that is synthesised primarily in hepatocytes. It is known to act as a carrier of neutrally charged and basic lipophilic molecules [343, 344]. AGP in low concentrations was observed to stimulate the TSH receptor and intracellular cAMP accumulation. On the other hand, high concentrations of AGP inhibited TSH signalling [345]. Orosomucoid might therefore play a role in the pathogenesis of NTIS, but additional studies are needed to get a more thorough understanding of its role in thyroid physiology.

4.5. Synthetic TSH Receptor Agonists and Antagonists. Recently, a wide range of substances stimulating or blocking signal transduction at the TSH receptor has been developed. These agents may be divided in agonists (that activate receptors), neutral antagonists (that inhibit receptor activation by agonists, but do not display any activity on their own), and inverse agonists (that both block receptor activation by agonists and inhibit basal, constitutive signalling in an agonist-independent manner). TSHr ligands have been isolated in form of monoclonal antibodies, engineered glycoprotein hormones, and small molecules.

The first attempts to obtain monoclonal TSH receptor antibodies resulted in low-affinity and partly low-specific MAbs [346-354]. In the past decade, however, different highaffinity monoclonal TRAbs with agonist activity (TSMAbs 13 [355], MS-1 [356], M22 [357], and K1-18 [358]), neutral antagonist activity (Mab-B2 [359] and k1-70 [358]), and inverse agonist activity (5C9 $[360,361])$ have been isolated $[323,362,363]$. These macromolecules helped to understand important pathophysiological aspects of Graves' disease and to develop and validate TRAb test kits [364].

A series of superactive analogues of mammalian glycoprotein hormones has been designed by a combination of evolutionary mechanisms, sequence comparisons, and homology modelling. The resulting superagonists demonstrated substantial increases in receptor binding affinity and intrinsic activity $[365,366]$. Similarly, increased bioactivity was observed in a construct of TSH alpha and beta chains fusioned to a single polypeptide [367].

Small molecule "drug-like" ligands (SMLs) exhibit different binding properties. Similar to MAbs, SMLs have been developed with agonistic (NCGC00161870), neutral antagonistic (NCGC00242595), and inverse agonistic activity (NCGC00161856, NCGC00229600, and Org 274179-0) $[324,325]$, but unlike antibodies they bind to a pocket within the transmembrane domain (Figure 8), thus also being able to activate TSH receptors bearing mutations in their ectodomain.

Agonistic TSHr ligands may be useful thyroid stimulators in patients with thyroid cancer in place of rhTSH for radioiodine therapy, thyroid scan, or thyroglobulin determination. Neutral antagonists could be beneficial for patients suffering from Graves' disease or endocrine ophthalmopathy, and inverse agonists may be a perspective in the treatment of toxic adenoma or thyroid cancer, in the latter case as an adjunct or substitute to TSH suppression [323, 324]. 


\section{The TSH Reference Range-An Ongoing Controversy}

Measuring serum levels of TSH and total or free peripheral thyroid hormones delivers univariate reference ranges that are usually defined by a tolerance region covering 95\% of healthy individuals.

Recently, a new debate on the boundaries of TSH reference range has emerged $[368,369]$, since it was observed that patients with TSH levels of more than $2.5 \mathrm{mU} / \mathrm{L}$ are exposed to increased risk of developing overt hypothyroidism [370374]. Additionally, in this group of what we would suggest to term "sublatent hypothyroidism," elevated levels of thyroid autoantibodies $[375,376]$ and increased frequency of hypoechogenicity in thyroid ultrasound [377] were observed. Moreover, there is evidence that the intraindividual variation of TSH levels is narrower than the width of the population based reference range $[378,379]$.

These findings may result from the effect of thyrotropic feedback control in general and from nonlinear distortions of the FT4-TSH relationships in euthyroid individuals and patients with thyroid dysfunction [127-129].

Therefore, it has been postulated to lower the upper limit of the TSH reference range from $4 \mathrm{mU} / \mathrm{L}$ to $2.5 \mathrm{mU} / \mathrm{L}$ [380382]. However, this suggestion is subject to disputation, as lowering the reference range border would lead to a high number of false positive results and an increase in health-care expenses [383].

Alternative biomarkers to assess the supply of the organism with thyroid hormones include resting heart rate and other determinants of cardiac output [384, 385], oxygen consumption $[386,387]$, respiratory quotient [388, 389], thermogenesis [26, 390-392], methylhistidine excretion [393-397] and plasma levels of lipids [398, 399], SHBG [400-405], sclerostin [406], ceruloplasmin [407], lead [408], copper [407-410], arsenic [408], or MBL [411, 412]. These parameters have not been well evaluated, however, and due to the fact that they are subject to multiple extrathyroidal influencing factors they are not expected to deliver superior results as diagnostic tools.

A possible solution could be interpretation of laboratory results based on a system's level understanding of thyrotropic feedback control. As shown in Figure 9 a complex reference region based on percentiles of pituitary and thyroid response has considerable overlap with conventional univariate reference values, but also significant deviations in the corners of the respective regions. As a result, a TSH level of $6 \mathrm{mU} / \mathrm{L}$ may be normal if FT4 level is $13 \mathrm{pmol} / \mathrm{L}$, but a sign of primary hypothyroidism if FT4 level is $10 \mathrm{pmol} / \mathrm{L}$. Conversely, a TSH level of $0.5 \mathrm{mU} / \mathrm{L}$ would suggest central hypothyroidism if FT4 is $11 \mathrm{pmol} / \mathrm{L}$, but be normal if FT4 is $16 \mathrm{pmol} / \mathrm{L}$.

Today, this is not more than a perspective for a more differentiated method to-be for interpreting results of thyroid hormone determinations. Future studies evaluating this approach in clinical settings are warranted.

Another challenge, especially for dosage of substitution therapy with levothyroxine, is the fact that the twodimensional location of the individual equilibrium point

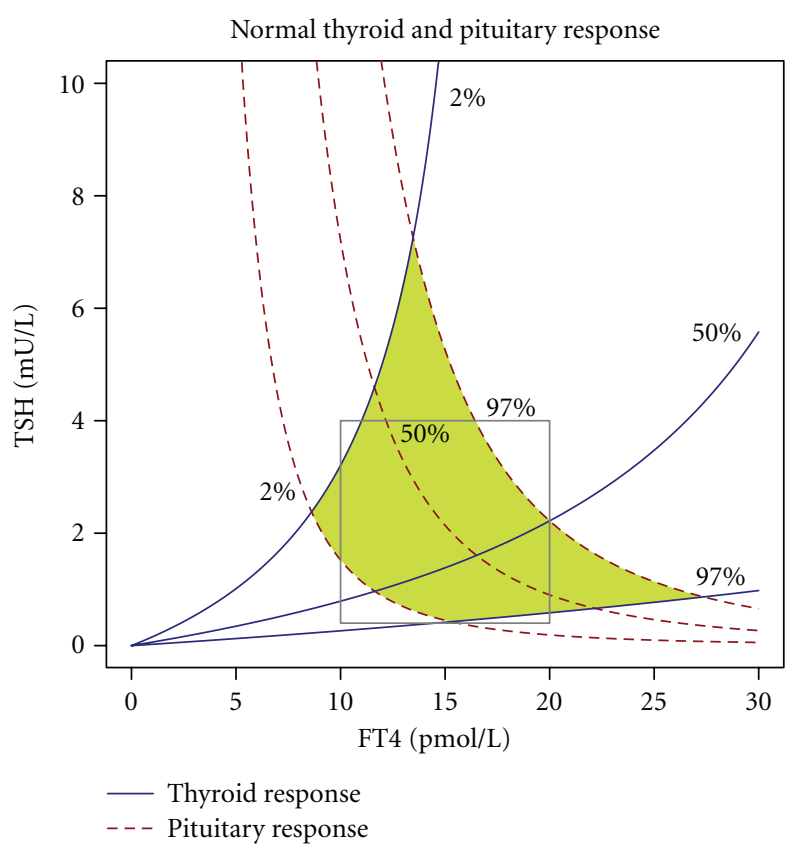

Figure 9: Comparison of conventional univariate reference ranges for TSH and FT4 (grey box) and a bihormonal reference region (green kite-like area) from nonlinear modelling of thyroid homeostasis. For more information see text and legend of Figure 4.

(setpoint) is unknown in the targetpopulation. Obviously, the individual setpoint would be the ideal target for dosing algorithms, but unfortunately, in clinical practice it is impossible to infer its location from characteristic curves of pituitary and thyroid gland, as the thyroid response curve is either distorted or vanished in thyroid disorders. It is another task for future clinical research to find a methodology to reconstruct the setpoint from pituitary behaviour or metabolic markers of thyroid signalling.

Lastly, substitution therapy may be complicated by interindividual variations of deiodination. The question, if monotherapy with T4 or a combination of T4 and T3 should be preferred, is for years subject of debate. Numerous trials [413-422] did not lead to a standard recommendation. Persons with abnormal sum activity of deiodinases, however, might benefit from additional treatment with liothyronine $[414,423]$, although this does not hold true for all polymorphisms of deiodinases [424]. Calculating $G_{D}$ or T3/T4 ratio might help to stratify patients for an individualised therapy, but the required trials are still to be designed.

\section{Conclusions}

Methodological advances in mathematical and simulative modelling of thyroid homeostasis have led to a better understanding of static and dynamic behaviour of thyroid hormones in health and disease. Together with results from molecular and clinical research on the central role of TSH in thyroid homeostasis such progress has permitted the development of advanced methods for interpretation 
of laboratory results that provide previously inaccessible information on pituitary and thyroid function. A future perspective overcoming the limits of univariate reference ranges for TSH, FT4, and FT3 promises the development of approaches for personalised diagnosis of thyroid homeostasis that may also be a foundation for targeted dosing of thyroid hormone substitution.

\section{Abbreviations}

AGP: Alpha-1-acid glycoprotein (orosomucoid)

AVP:

Arginine-vasopressin

CAMP:

CBP:

Cyclic adenosine monophosphate

CREB:

CREB-binding protein

FSH:

cAMP response element

FSHr:

Follicle-stimulating hormone

FT3:

FT4:

$G_{D}$ :

$G_{T}:$

HCG:

iTRAb:

LH:

LH/CGr

MAb:

MBL:

NTIS:

PKA:

PKC:

rhTSH:

rT3:

SHBG:

FSH receptor

Free triiodothyronine

Free thyroxine

"Gain of deiodinase," sum activity of activating deiodinases

"Gain of thyroid," secretory capacity of the thyroid gland

Human chorionic gonadotropin

SMLs:

Inhibiting TSH receptor autoantibody

Luteinizing hormone

sTRAb: Stimulating TSH receptor autoantibody

sTSHI: $\quad$ Standardised TSH index

T3: $\quad$ Triiodothyronine

T4: $\quad$ Thyroxine

TACITUS: Thyroid allostasis in critical illness, tumours, uraemia and starvation

TBPA: Transthyretin

TRAb: TSH receptor autoantibody

TRH: $\quad$ TSH releasing hormone, thyroliberin

TSAb: Thyroid stimulating antibody

TSBAb: TSH-stimulation blocking antibody

TSH: Thyroid stimulating hormone, thyrotropin

TSH 2: $\quad$ thyrostimulin

TSHI: Jostel's TSH index

TSHr: $\quad$ TSH receptor.

\section{Conflict of Interests}

The authors declare that there is no conflict of interests that could be perceived as prejudicing impartiality of the information reported.

\section{References}

[1] M. Aron, "Action de la préhypophyse sur la thyroïde chez le cobaye," Comptes Rendus des Séances de la Société de Biologie, vol. 102, pp. 682-684, 1929.

[2] F. A. Crew and B. P. Wiesner, "On the existence of a fourth hormone, thyreotropic in nature, of the anterior pituitary," British Medical Journal, vol. 1, pp. 777-778, 1930.

[3] W. Salter, The Endocrine Function of Iodine, Harvard University Press, Cambridge, Mass, USA, 1940.

[4] W. Hohlweg and K. Junkmann, "Die hormonal-nervöse Regulierung des Hypophysenvorderlappens [The hormonal and neurogenic regulation of the function of the anterior pituitary]," Klinische Wochenschrift, vol. 11, pp. 321-323, 1932.

[5] D. R. McCullagh, "Dual endocrine activity of the testes," Science, vol. 76, no. 1957, pp. 19-20, 1932.

[6] C. R. Moore and D. Price, "The question of sex hormone antagonism," Proceedings of the Society For Experimental Biology and Medicine, vol. 28, pp. 38-40, 1930.

[7] C. R. Moore and D. Price, "Gonadal hormone functions, and the reciprocal influence between gonads and hypophysis with its bearing on the problem of sex hormone antagonism," American Journal of Anatomy, vol. 50, pp. 13-67, 1932.

[8] E. B. Astwood, "Mechanism of action of antithyroid compounds," Brookhaven Symposia in Biology, vol. 7, pp. 61-73, 1955.

[9] R. Hoskins, "The thyroid-pituitary apparatus as a servo (feed-back) mechanism," The Journal of Clinical Endocrinology \& Metabolism, vol. 9, pp. 1429-1431, 1949.

[10] M. M. Stanley and E. B. Astwood, "The response of the thyroid gland in normal human subjects to the administration of thyrotropin, as shown by studies with I131," Endocrinology, vol. 44, pp. 49-60, 1949.

[11] J. W. Dietrich, "Der Hypophysen-Schilddrüsen-Regelkreis. Entwicklung und klinische Anwendung eines nichtlinearen Modells," in Entwicklung Und Klinische Anwendung Eines Nichtlinearen Modells, Logos, Berlin, Germany, 2002.

[12] S. Sam and L. A. Frohman, "Normal physiology of hypothalamic pituitary regulation," Endocrinology and Metabolism Clinics of North America, vol. 37, no. 1, pp. 1-22, 2008.

[13] R. T. Zoeller, S. W. Tan, and R. W. Tyl, "General background on the hypothalamic-pituitary-thyroid (HPT) axis," Critical Reviews in Toxicology, vol. 37, no. 1-2, pp. 11-53, 2007.

[14] E. C. H. Friesema, S. Ganguly, A. Abdalla, J. E. Manning Fox, A. P. Halestrap, and T. J. Visser, "Identification of monocarboxylate transporter 8 as a specific thyroid hormone transporter," The Journal of Biological Chemistry, vol. 278, no. 41, pp. 40128-40135, 2003.

[15] E. C. H. Friesema, J. Jansen, and T. J. Visser, "Thyroid hormone transporters," Biochemical Society Transactions, vol. 33, no. 1, pp. 228-232, 2005.

[16] J. W. Dietrich, K. Brisseau, and B. O. Boehm, "Resorption, Transport und Bioverfügbarkeit von Schilddrüsenhormonen [Absorption, transport and bio-availability of iodothyronines]," Deutsche Medizinische Wochenschrift, vol. 133, pp. 1644-1648, 2008.

[17] U. Feldt-Rasmussen and Å. K. Rasmussen, "Thyroid hormone transport and actions," in Diseases of the Thyroid in Childhood and Adolescence, E. KG, S. A. Rivkees, and W. K. Basel, Eds., vol. 11, pp. 80-103, Karger, 2007.

[18] S. Refetoff, Y. Murata, Y. Mori, O. E. Janssen, K. Takeda, and Y. Hayashi, "Thyroxine-binding globulin: organization of 
the gene and variants," Hormone Research, vol. 45, no. 3-5, pp. 128-138, 1996.

[19] B. Gereben, A. M. Zavacki, S. Ribich et al., "Cellular and molecular basis of deiodinase-regulated thyroid hormone signaling," Endocrine Reviews, vol. 29, no. 7, pp. 898-938, 2008.

[20] J. E. Silv and P. R. Larsen, "Contribution of plasma triiodothyronine and local thyroxine monodeiodination to triiodothyronine to nuclear triiodothyronine receptor saturation in pituitary, liver, and kidney of hypothyroid rats," The Journal of Clinical Investigation, vol. 61, no. 5, pp. 1247-1259, 1978.

[21] A. Boelen, J. Kwakkel, D. C. Thijssen-Timmer, A. Alkemade, E. Fliers, and W. M. Wiersinga, "Simultaneous changes in central and peripheral components of the hypothalamuspituitary-thyroid axis in lipopolysaccharide-induced acute illness in mice," Journal of Endocrinology, vol. 182, no. 2, pp. 315-323, 2004.

[22] L. J. De Groot, "Non-thyroidal illness syndrome is a manifestation of hypothalamic-pituitary dysfunction, and in view of current evidence, should be treated with appropriate replacement therapies," Critical Care Clinics, vol. 22, no. 1, pp. 57-86, 2006.

[23] J. W. Dietrich, A. Stachon, B. Antic, H. H. Klein, and S. Hering, "The AQUA-FONTIS study: protocol of a multidisciplinary, cross-sectional and prospective longitudinal study for developing standardized diagnostics and classification of non-thyroidal illness syndrome," BMC Endocrine Disorders, vol. 8, article 13, 2008.

[24] G. Van den Berghe, "Dynamic neuroendocrine responses to critical illness," Frontiers in Neuroendocrinology, vol. 23, no. 4, pp. 370-391, 2002.

[25] E. D. R. Arrojo and A. C. Bianco, "Type 2 deiodinase at the crossroads of thyroid hormone action," International Journal of Biochemistry and Cell Biology, vol. 43, no. 10, pp. 14321441, 2011.

[26] A. C. Bianco, A. L. Maia, W. S. da Silva, and M. A. Christoffolete, "Adaptive activation of thyroid hormone and energy expenditure," Bioscience Reports, vol. 25, no. 3-4, pp. 191-208, 2005.

[27] R. Martinez-deMena and M. J. Obregón, "Insulin increases the adrenergic stimulation of $5^{\prime}$ deiodinase activity and mRNA expression in rat brown adipocytes; role of MAPK and PI3K," Journal of Molecular Endocrinology, vol. 34, no. 1, pp. 139-151, 2005.

[28] G. C. Garcia, L. Lopez-Bojorquez, J. Nunez, R. C. Valverde, and A. Orozco, "3,5-Diiodothyronine in vivo maintains euthyroidal expression of type 2 iodothyronine deiodinase, growth hormone, and thyroid hormone receptor $\beta 1$ in the killifish," American Journal of Physiology, vol. 293, no. 2, pp. R877-R883, 2007.

[29] C. Thomas, J. Auwerx, and K. Schoonjans, "Bile acids and the membrane bile acid receptor TGR5-connecting nutrition and metabolism," Thyroid, vol. 18, no. 2, pp. 167-174, 2008.

[30] M. Watanabe, S. M. Houten, C. Mataki et al., "Bile acids induce energy expenditure by promoting intracellular thyroid hormone activation," Nature, vol. 439, no. 7075, pp. 484-489, 2006.

[31] M. A. Christoffolete, R. Ribeiro, P. Singru et al., "Atypical expression of type 2 iodothyronine deiodinase in thyrotrophs explains the thyroxine-mediated pituitary thyrotropin feedback mechanism," Endocrinology, vol. 147, no. 4, pp. 1735$1743,2006$.
[32] G. Brabant, U. Ranft, K. Ocran, R. D. Hesch, and A. von zur Mühlen, "Thyrotropin—an episodically secreted hormone," Acta Endocrinologica, vol. 112, no. 3, pp. 315-322, 1986.

[33] S. L. Greenspan, A. Klibanski, D. Schoenfeld, and E. C. Ridgway, "Pulsatile secretion of thyrotropin in man," The Journal of Clinical Endocrinology \& Metabolism, vol. 63, no. 3, pp. 661-668, 1986.

[34] M. H. Samuels, P. Henry, M. Luther, and E. C. Ridgway, "Pulsatile TSH secretion during 48-hour continuous TRH infusions," Thyroid, vol. 3, no. 3, pp. 201-206, 1993.

[35] G. Brabant, K. Prank, U. Ranft et al., "Physiological regulation of circadian and pulsatile thyrotropin secretion in normal man and woman," The Journal of Clinical Endocrinology \& Metabolism, vol. 70, no. 2, pp. 403-409, 1990.

[36] L. Covarrubias, J. L. Redondo, M. A. Vargas et al., "In vitro TRH release from hypothalamus slices varies during the diurnal cycle," Neurochemical Research, vol. 19, no. 7, pp. 845-850, 1994.

[37] J. A. Franklyn, "Drug therapy: the management of hyperthyroidism," The New England Journal of Medicine, vol. 330, no. 24, pp. 1731-1738, 1994.

[38] B. E. W. Brownlie and H. M. Legge, "Thyrotropin results in euthyroid patients with a past history of hyperthyroidism," Acta Endocrinologica, vol. 122, no. 5, pp. 623-627, 1990.

[39] H. Jaeschke, M. Eszlinger, J. Lueblinghoff, R. Coslovsky, and R. Paschke, "Prolonged inappropriate TSH suppression during hypothyroidism after thyroid ablation in a patient with nonautoimmune familial hyperthyroidism," Hormone and Metabolic Research, vol. 43, no. 7, pp. 500-504, 2011.

[40] G. Gelwane, N. de Roux, D. Chevenne, J. C. Carel, and J. Léger, "Pituitary-thyroid feedback in a patient with a sporadic activating thyrotropin (TSH) receptor mutation: implication that thyroid-secreted factors other than thyroid hormones contribute to serum TSH levels," The Journal of Clinical Endocrinology \& Metabolism, vol. 94, no. 8, pp. 27872791, 2009.

[41] N. Zwaveling-Soonawala, P. van Trotsenburg, and T. Vulsma, "Central hypothyroidism in an infant born to an adequately treated mother with Graves' disease: an effect of maternally derived thyrotrophin receptor antibodies?" Thyroid, vol. 19, no. 6, pp. 661-662, 2009.

[42] T. Kakita, N. P. Laborde, and W. D. Odell, "Autoregulatory control of thyrotropin in rabbits," Endocrinology, vol. 114, no. 6, pp. 2301-2305, 1984.

[43] T. Kakita and W. D. Odell, "Pituitary gland: one site of ultrashort-feedback regulation for control of thyrotropin," American Journal of Physiology, vol. 250, no. 2, pp. E121E124, 1986.

[44] M. F. Prummel, G. Méduri, and H. Loosfeldt, "Human anterior pituitary contains a TSH-receptor," Journal of Endocrinological Investigation, vol. 20, article 27, 1997.

[45] M. F. Prummel, L. J. S. Brokken, G. Meduri, M. Misrahi, O. Bakker, and W. M. Wiersinga, "Expression of the thyroidstimulating hormone receptor in the folliculo-stellate cells of the human anterior pituitary," The Journal of Clinical Endocrinology \& Metabolism, vol. 85, no. 11, pp. 4347-4353, 2000.

[46] L. J. S. Brokken, O. Bakker, W. M. Wiersinga, and M. F. Prummel, "Functional thyrotropin receptor expression in the pituitary folliculo-stellate cell line TtT/GF," Experimental and Clinical Endocrinology and Diabetes, vol. 113, no. 1, pp. 1320, 2005. 
[47] L. J. S. Brokken, J. W. C. Scheenhart, W. M. Wiersinga, and M. F. Prummel, "Suppression of serum TSH by Graves' Ig: evidence for a functional pituitary TSH receptor," The Journal of Clinical Endocrinology \& Metabolism, vol. 86, no. 10, pp. 4814-4817, 2001.

[48] M. F. Prummel, L. J. S. Brokken, and W. M. Wiersinga, "Ultra short-loop feedback control of thyrotropin secretion," Thyroid, vol. 14, no. 10, pp. 825-829, 2004.

[49] J. W. Dietrich, A. Tesche, C. R. Pickardt, and U. Mitzdorf, "Thyrotropic feedback control: evidence for an additional ultrashort feedback loop from fractal analysis," Cybernetics and Systems, vol. 35, no. 4, pp. 315-331, 2004.

[50] L. J. S. Brokken, W. M. Wiersinga, and M. F. Prummel, "Thyrotropin receptor autoantibodies are associated with continued thyrotropin suppression in treated euthyroid Graves' disease patients," The Journal of Clinical Endocrinology \& Metabolism, vol. 88, no. 9, pp. 4135-4138, 2003.

[51] J. J. DiStefano III, "Hypothalamic and rate feedback in the thyroid hormone regulation system: an hypothesis," The Bulletin of Mathematical Biophysics, vol. 31, no. 2, pp. 233246, 1969.

[52] H. J. Campbell, R. George, and G. W. Harris, "The acute effects of injection of thyrotrophic hormone or of electrical stimulation of the hypothalamus on thyroid activity," The Journal of Physiology, vol. 152, pp. 527-544, 1960.

[53] G. W. Harris and J. W. Woods, "The effect of electrical stimulation of the hypothalamus or pituitary gland on thyroid activity," The Journal of Physiology, vol. 143, no. 2, pp. 246-274, 1958.

[54] K. Shizume, K. Matsuda, M. Irie et al., "Effect of electrical stimulation of the hypothalamus on thyroid function," Endocrinology, vol. 70, pp. 298-302, 1962.

[55] R. M. Lechan and C. Fekete, "Feedback regulation of thyrotropin-releasing hormone (TRH): mechanisms for the non-thyroidal illness syndrome," Journal of Endocrinological Investigation, vol. 27, no. 6, pp. 105-119, 2004.

[56] G. E. Dahl, N. P. Evans, L. A. Thrun, and F. J. Karsch, "A central negative feedback action of thyroid hormones on thyrotropin- releasing hormone secretion," Endocrinology, vol. 135, no. 6, pp. 2392-2397, 1994.

[57] J. M. M. Rondeel, W. J. de Greef, P. van der Schoot, B. Karels, W. Klootwijk, and T. J. Visser, "Effect of thyroid status and paraventricular area lesions on the release of thyrotropinreleasing hormone and catecholamines into hypophysial portal blood," Endocrinology, vol. 123, no. 1, pp. 523-527, 1988.

[58] C. Von Euler and B. Holmgren, "The role of hypothalamohypophysial connexions in thyroid secretion," The Journal of Physiology, vol. 131, no. 1, pp. 137-146, 1956.

[59] C. Von Euler and B. Holmgren, "The thyroxine receptor of the thyroid-pituitary system," The Journal of Physiology, vol. 131, no. 1, pp. 125-136, 1956.

[60] E. M. Bogdanove and E. V. Crabill, "Thyroid-pituitary feedback: direct or indirect? A comparison of the effects of intrahypothalamic and intrapituitary thyroid autotransplants on piuitary thyroidectomy reactions in the rat," Endocrinology, vol. 69, pp. 581-595, 1961.

[61] C. Fekete, B. Gereben, M. Doleschall et al., "Lipopolysaccharide induces type 2 iodothyronine deiodinase in the mediobasal hypothalamus: implications for the nonthyroidal illness syndrome," Endocrinology, vol. 145, no. 4, pp. 1649$1655,2004$.
[62] R. M. Lechan and C. Fekete, "The TRH neuron: a hypothalamic integrator of energy metabolism," Progress in Brain Research, vol. 153, pp. 209-235, 2006.

[63] M. I. Chiamolera and F. E. Wondisford, "Minireview: thyrotropin-releasing hormone and the thyroid hormone feedback mechanism," Endocrinology, vol. 150, no. 3, pp. 1091-1096, 2009.

[64] T. R. Bauman, R. R. Anderson, and C. W. Turner, "Effects of induced mild hyperthyroidism on serum protein-bound iodine, thyroxine distribution volume, and biological halflife of thyroxine-131-I in dairy cattle," Journal of Dairy Science, vol. 52, no. 2, pp. 245-249, 1969.

[65] M. J. Cullen, G. F. Doherty, and S. H. Ingbar, "The effect of hypothyroidism and thyrotoxicosis on thyroxine metabolism in the rat," Endocrinology, vol. 92, no. 4, pp. 1028-1033, 1973.

[66] J. T. Nicoloff, J. C. Low, J. H. Dussault, and D. A. Fisher, "Simultaneous measurement of thyroxine and triiodothyronine peripheral turnover kinetics in man," The Journal of Clinical Investigation, vol. 51, no. 3, pp. 473-483, 1972.

[67] W. D. Odell, R. D. Utiger, J. F. Wilber, and P. G. Condliffe, "Estimation of the secretion rate of thyrotropin in man," The Journal of Clinical Investigation, vol. 46, no. 6, pp. 953-959, 1967.

[68] T. O. Bruhn, J. M. M. Rondeel, and I. M. D. Jackson, "Thyrotropin-releasing hormone gene expression in the anterior pituitary. IV. Evidence for paracrine and autocrine regulation," Endocrinology, vol. 139, no. 8, pp. 3416-3422, 1998.

[69] G. Hennemann, "Notes on the history of cellular uptake and deiodination of thyroid hormone," Thyroid, vol. 15, no. 8, pp. 753-756, 2005.

[70] G. Hennemann, R. Docter, E. C. H. Friesema, M. de Jong, E. P. Krenning, and T. J. Visser, "Plasma membrane transport of thyroid hormones and its role in thyroid hormone metabolism and bioavailability," Endocrine Reviews, vol. 22, no. 4, pp. 451-476, 2001.

[71] R. P. Peeters, S. D. van Geyten, P. J. Wouters et al., "Tissue thyroid hormone levels in critical illness," The Journal of Clinical Endocrinology \& Metabolism, vol. 90, no. 12, pp. 6498-6507, 2005.

[72] D. C. Thijssen-Timmer, R. P. Peelers, P. Wouters et al., "Thyroid hormone receptor isoforni expression in livers of critically ill patients," Thyroid, vol. 17, no. 2, pp. 105-112, 2007.

[73] M. H. Warner and G. J. Beckett, "Mechanisms behind the non-thyroidal illness syndrome: an update," Journal of Endocrinology, vol. 205, no. 1, pp. 1-13, 2010.

[74] M. T. Hays, "Thyroid hormone and the gut," Endocrine Research, vol. 14, no. 2-3, pp. 203-224, 1988.

[75] L. Ciobanu and D. L. Dumitrascu, "Gastrointestinal motility disorders in endocrine diseases," Polskie Archiwum Medycyny Wewnetrznej, vol. 121, no. 4, pp. 129-136, 2011.

[76] O. Yaylali, S. Kirac, M. Yilmaz et al., "Does hypothyroidism affect gastrointestinal motility?" Gastroenterology Research and Practice, vol. 2009, Article ID 529802, 7 pages, 2009.

[77] Y. Friedman, M. Lang, and G. Burke, "Inhibition of thyroid adenylate cyclase by thyroid hormone: a possible locus for the 'short-loop' negative feedback phenomenon," Endocrinology, vol. 101, no. 3, pp. 858-868, 1977.

[78] P. D. Goldenheim, S. M. Amir, H. Uchimura, and S. H. Ingbar, "Studies of the binding of thyroid hormones and their short loop feedback effects in bovine thyroid tissue," Endocrinology, vol. 105, no. 6, pp. 1308-1313, 1979. 
[79] C. M. Rotella, A. Tanini, R. Zonefrati, and R. Toccafondi, "Interaction between iodothyronines and thyrotropin receptor in human cultured thyroid cells," Journal of Receptor Research, vol. 2, no. 4, pp. 367-382, 1981.

[80] S. Yu, Y. Friedman, R. Richman, and G. Burke, "Altered thyroidal responsivity to thyrotropin induced by circulating thyroid hormones. A "short loop" regulatory mechanism?" The Journal of Clinical Investigation, vol. 57, no. 3, pp. 745755, 1976.

[81] J. U. Baenziger and E. D. Green, "Pituitary glucoprotein hormone oligosaccharides: structure, synthesis and function of the asparagine-linked oligosaccharides on lutropin, follitropin and thyrotropin," Biochimica et Biophysica Acta, vol. 947, no. 2, pp. 287-306, 1988.

[82] S. Donadio, A. Pascual, J. H. H. Thijssen, and C. Ronin, "Feasibility study of new calibrators for thyroid-stimulating hormone (TSH) immunoprocedures based on remodeling of recombinant TSH to mimic glycoforms circulating in patients with thyroid disorders," Clinical Chemistry, vol. 52, no. 2, pp. 286-297, 2006.

[83] N. Gesundheit, J. A. Magner, T. Chen, and B. D. Weintraub, "Differential sulfation and sialylation of secreted mouse thyrotropin (TSH) subunits: regulation by TSH-releasing hormone," Endocrinology, vol. 119, no. 2, pp. 455-463, 1986.

[84] L. Persani, "Hypothalamic thyrotropin-releasing hormone and thyrotropin biological activity," Thyroid, vol. 8, no. 10, pp. 941-946, 1998.

[85] L. Persani, S. Borgato, R. Romoli, C. Asteria, A. Pizzocaro, and P. Beck-Peccoz, "Changes in the degree of sialylation of carbohydrate chains modify the biological properties of circulating thyrotropin isoforms in various physiological and pathological states," The Journal of Clinical Endocrinology \& Metabolism, vol. 83, no. 7, pp. 2486-2492, 1998.

[86] M. Saji, S. Ikuyama, T. Akamizu, and L. D. Kohn, "Increases in cytosolic $\mathrm{Ca}++$ down regulate thyrotropin receptor gene expression by a mechanism different from the cAMP signal," Biochemical and Biophysical Research Communications, vol. 176, no. 1, pp. 94-101, 1991.

[87] P. W. Gyves, N. Gesundheit, N. R. Thotakura, B. S. Stannard, G. S. DeCherney, and B. D. Weintraub, "Changes in the sialylation and sulfation of secreted thyrotropin in congenital hypothyroidism," Proceedings of the National Academy of Sciences of the United States of America, vol. 87, no. 10, pp. 3792-3796, 1990.

[88] J. Trojan, M. Theodoropoulou, K. H. Usadel, G. K. Stalla, and L. Schaaf, "Modulation of human thyrotropin oligosaccharide structures-enhanced proportion of sialylated and terminally galactosylated serum thyrotropin isoforms in subclinical and overt primary hypothyroidism," Journal of Endocrinology, vol. 158, no. 3, pp. 359-365, 1998.

[89] J. Magner, P. Roy, L. Fainter, V. Barnard, and P. Fletcher Jr., "Transiently decreased sialylation of thyrotropin (TSH) in a patient with the euthyroid sick syndrome," Thyroid, vol. 7, no. 1, pp. 55-61, 1997.

[90] L. Persani, E. Ferretti, S. Borgato, G. Faglia, and P. BeckPeccoz, "Circulating thyrotropin bioactivity in sporadic central hypothyroidism," The Journal of Clinical Endocrinology \& Metabolism, vol. 85, no. 10, pp. 3631-3635, 2000.

[91] A. G. Morell, G. Gregoriadis, I. H. Scheinberg, J. Hickman, and G. Ashwell, "The role of sialic acid in determining the survival of glycoproteins in the circulation," The Journal of Biological Chemistry, vol. 246, no. 5, pp. 1461-1467, 1971.

[92] R. Frenzel, K. Krohn, M. Eszlinger, A. Tönjes, and R. Paschke, "Sialylation of human thyrotropin receptor improves and prolongs its cell-surface expression," Molecular Pharmacology, vol. 68, no. 4, pp. 1106-1113, 2005.

[93] L. Danziger and G. L. Elmergreen, "The thyroid-pituitary homeostatic mechanism," The Bulletin of Mathematical Biophysics, vol. 18, no. 1, pp. 1-13, 1956.

[94] S. Roston, "Mathematical representation of some endocrinological systems," The Bulletin of Mathematical Biophysics, vol. 21, no. 3, pp. 271-282, 1959.

[95] K. H. Norwich and R. Reiter, "Homeostatic control of thyroxin concentration expressed by a set of linear differential equations," The Bulletin of Mathematical Biophysics, vol. 27, no. 2, pp. 133-144, 1965.

[96] J. J. DiStefano and E. B. Stear, "Neuroendocrine control of thyroid secretion in living systems: a feedback control system model," The Bulletin of Mathematical Biophysics, vol. 30, no. 1, pp. 3-26, 1968.

[97] J. J. DiStefano, "A model of the normal thyroid hormone glandular secretion mechanism," Journal of Theoretical Biology, vol. 22, no. 3, pp. 412-417, 1969.

[98] J. J. DiStefano III and R. F. Chang, "Computer simulation of thyroid hormone binding, distribution, and disposal dynamics in man," The American Journal of Physiology, vol. 221, no. 5, pp. 1529-1544, 1971.

[99] J. J. DiStefano and E. B. Stear, "Neuroendocrine control of thyroid secretion in living systems: a feedback control system model," The Bulletin of Mathematical Biophysics, vol. 30, no. 1, pp. 3-26, 1968.

[100] K. Sudova and P. Langer, "Iodine kinetics and hypothalamo pituitary regulation of thyroid function following its short term inhibition: simulation with the aid of compartmental system modelling (COSMO)," Computers and Biomedical Research, vol. 8, no. 1, pp. 88-96, 1975.

[101] P. Saratchandran, E. R. Carson, and J. Reeve, "An improved mathematical model of human thyroid hormone regulation," Clinical Endocrinology, vol. 5, no. 5, pp. 473-483, 1976.

[102] F. J. Seif, "Mathematical model of pituitary thyrotropic function," Experientia, vol. 33, no. 9, pp. 1243-1245, 1977.

[103] T. J. Wilkin, B. E. Storey, T. E. Isles, J. Crooks, and J. Swanson Beck, "High TSH concentrations in "euthyroidism": explanation based on control loop theory," British Medical Journal, vol. 1, no. 6067, pp. 993-996, 1977.

[104] T. Hatakeyama and H. Yagi, "Computer simulation for hormones related to primary thyropathy," Biological Cybernetics, vol. 52, no. 4, pp. 259-266, 1985.

[105] J. L. Cohen, "Thyroid-stimulation hormone and its disorders," in Principles and Practice of Endocrinology and Metabolism, K. L. Becker, Ed., pp. 144-152, J. B. Lippincott Company, Philadelphia, Pa, USA, 1990.

[106] G. Li, B. Liu, and Y. Liu, "A dynamical model of the pulsatile secretion of the hypothalamo-pituitary-thyroid axis," BioSystems, vol. 35, no. 1, pp. 83-92, 1995.

[107] Y. Liu, B. Liu, J. Xie, and Y. X. Liu, "A new mathematical model of hypothalamo-pituitary-thyroid axis," Mathematical and Computer Modelling, vol. 19, no. 9, pp. 81-90, 1994.

[108] J. W. Dietrich, U. Mitzdorf, R. Weitkunat, and C. R. Pickardt, "The pituitary-thyroid feedback control: stability and oscillations in a new nonlinear model," Journal of Endocrinological Investigation, vol. 20, no. 5, 1997.

[109] P. Falaschi, A. Martocchia, A. Proietti et al., "The hypothalamic-pituitary-thyroid axis in subjects with subclinical thyroid diseases: the impact of the negative feedback mechanism," Neuroendocrinology Letters, vol. 25, no. 4, pp. 292-296, 2004. 
[110] M. Degon, S. R. Chipkin, C. V. Hollot, R. T. Zoeller, and Y. Chait, "A computational model of the human thyroid," Mathematical Biosciences, vol. 212, no. 1, pp. 22-53, 2008.

[111] M. K. S. Leow, "A mathematical model of pituitary-thyroid interaction to provide an insight into the nature of the thyrotropin-thyroid hormone relationship," Journal of Theoretical Biology, vol. 248, no. 2, pp. 275-287, 2007.

[112] E. D. Mclanahan, M. E. Andersen, and J. W. Fisher, "A biologically based dose-response model for dietary iodide and the hypothalamic-pituitary-thyroid axis in the adult rat: evaluation of iodide deficiency," Toxicological Sciences, vol. 102, no. 2, pp. 241-253, 2008.

[113] M. Eisenberg, M. Samuels, and J. J. DiStefano III, "Extensions, validation, and clinical applications of a feedback control system simulator of the hypothalamo-pituitarythyroid axis," Thyroid, vol. 18, no. 10, pp. 1071-1085, 2008.

[114] M. C. Eisenberg, F. Santini, A. Marsili, A. Pinchera, and J. J. DiStefano III, "TSH regulation dynamics in central and extreme primary hypothyroidism," Thyroid, vol. 20, no. 11, pp. 1215-1228, 2010.

[115] J. N. Panda and C. W. Turner, "Thyroxine feed-back on the regulation of thyrotropin [TSH] secretion," The Journal of Physiology, vol. 195, no. 1, pp. 29-37, 1968.

[116] J. W. Dietrich, M. R. Fischer, J. Jauch, E. Pantke, R. Gärtner, and C. R. Pickardt, "SPINA-THYR: a novel systems theoretic approach to determine the secretion capacity of the thyroid gland," European Journal of Internal Medicine, vol. 10, supplement 1, p. S34, 1999.

[117] M. Eisenberg and J. J. DiStefano, "TSH-based protocol, tablet instability, and absorption effects on L-T 4 bioequivalence," Thyroid, vol. 19, no. 2, pp. 103-110, 2009.

[118] M. Eisenberg, M. Samuels, and J. J. DiStefano III, "LT4 bioequivalence and hormone replacement studies via feedback control simulations," Thyroid, vol. 16, no. 12, pp. 1279-1292, 2006.

[119] R. Ben-Shachar, M. Eisenberg, S. A. Huang, and J. J. DiStefano III, "Simulation of post-thyroidectomy treatment alternatives for triiodothyronine or thyroxine replacement in pediatric cancer patients," Thyroid, vol. 22, pp. 595-603, 2012.

[120] A. Jostel, W. D. J. Ryder, and S. M. Shalet, "The use of thyroid function tests in the diagnosis of hypopituitarism: definition and evaluation of the TSH Index," Clinical Endocrinology, vol. 71, no. 4, pp. 529-534, 2009.

[121] S. Reichlin and R. D. Utiger, "Regulation of the pituitarythyroid axis in man: relationship of TSH concentration to concentration of free and total thyroxine in plasma," The Journal of Clinical Endocrinology \& Metabolism, vol. 27, no. 2, pp. 251-255, 1967.

[122] Z. Baloch, P. Carayon, B. Conte-Devolx et al., "Laboratory medicine practice guidelines. Laboratory support for the diagnosis and monitoring of thyroid disease," Thyroid, vol. 13, no. 1, pp. 3-126, 2003.

[123] J. Jonklaas and S. J. Soldin, "Tandem mass spectrometry as a novel tool for elucidating pituitary-thyroid relationships," Thyroid, vol. 18, no. 12, pp. 1303-1311, 2008.

[124] M. Ito, A. Miyauchi, S. Morita et al., "TSH-suppressive doses of levothyroxine are required to achieve preoperative native serum triiodothyronine levels in patients who have undergone total thyroidectomy," European Journal of Endocrinology, vol. 167, pp. 373-378, 2012.

[125] N. Benhadi, E. Fliers, T. J. Visser, J. B. Reitsma, and W. M. Wiersinga, "Pilot study on the assessment of the setpoint of the hypothalamus- pituitary-thyroid axis in healthy volunteers," European Journal of Endocrinology, vol. 162, no. 2, pp. 323-329, 2010.

[126] S. Ercan-Fang, H. L. Schwartz, C. N. Mariash, and J. H. Oppenheimer, "Quantitative assessment of pituitary resistance to thyroid hormone from plots of the logarithm of thyrotropin versus serum free thyroxine index," The Journal of Clinical Endocrinology \& Metabolism, vol. 85, no. 6, pp. 2299-2303, 2000.

[127] R. Hoermann, W. Eckl, C. Hoermann, and R. Larisch, "Complex relationship between free thyroxine and TSH in the regulation of thyroid function," European Journal of Endocrinology, vol. 162, no. 6, pp. 1123-1129, 2010.

[128] P. M. Clark, R. L. Holder, S. M. Haque, F. D. Hobbs, L. M. Roberts, and J. A. Franklyn, "The relationship between serum TSH and free T4 in older people," Journal of Clinical Pathology, vol. 65, pp. 463-465, 2012.

[129] K. Rothacker, N. C. Hadlow, R. Wardrop, and J. P. Walsh, "The relationship between TSH and free T4 is not log-linear and differs between genders and age groups," in Proceedings of the ASN Events: The Annual Scientific Meeting of the Endocrine Society of Australia and the Society for Reproductive Biology, Gold Coast, Queensland, Australia, August 2012.

[130] J. W. Dietrich, "SimThyr. 3.2 edition, Fairfax, VA: sourceforge," 2012, http://simthyr.sourceforge.net/.

[131] L. J. Degroot, P. Decostre, and R. Phair, "A mathematical model of human iodine metabolism," The Journal of Clinical Endocrinology \& Metabolism, vol. 32, no. 6, pp. 757-765, 1971.

[132] C. Blincoe, "Computer simulation of iodine metabolism by mammals," Journal of Animal Science, vol. 40, no. 2, pp. 342350, 1975.

[133] C. Blincoe, "Thyroid homeostasis as studied by computer simulation," International Journal of Bio-Medical Computing, vol. 12, no. 2, pp. 101-108, 1981.

[134] V. Berkovski, "New iodine models family for simulation of short-term biokinetics processes, pregnancy and lactation," Food and Nutrition Bulletin, vol. 23, no. 3, pp. 87-94, 2002.

[135] P. H. Mak and J. J. DiStefano, "Optimal control policies for the prescription of thyroid hormones," Mathematical Biosciences, vol. 42, no. 3-4, pp. 159-186, 1978.

[136] K. Brown-Grant, R. D. Brennan, and F. E. Yates, "Simulation of the thyroid hormone-binding protein interactions in human plasma," The Journal of Clinical Endocrinology \& Metabolism, vol. 30, no. 6, pp. 733-751, 1970.

[137] S. Endo, Y. Nitta, M. Ohtaki et al., "Estimation of dose absorbed fraction for 131I-beta rays in rat thyroid," Journal of Radiation Research, vol. 39, pp. 223-230, 1998.

[138] J. Hermanská, K. Vosmiková, L. Jirsa, M. Kárný, and M. Sámal, "Biophysical inputs into the software 'MIRDose," Sbornik Lekarsky, vol. 99, no. 4, pp. 521-527, 1998.

[139] K. S. Kolbert, K. S. Pentlow, J. R. Pearson et al., "Prediction of absorbed dose to normal organs in thyroid cancer patients treated with $131 \mathrm{I}$ by use of 124I PET and 3-dimensional internal dosimetry software," Journal of Nuclear Medicine, vol. 48, no. 1, pp. 143-149, 2007.

[140] G. H. Kramer, M. J. Chamberlain, and S. Yiu, "A study of thyroid radioiodine monitoring by Monte Carlo simulations: implications for equipment design," Physics in Medicine and Biology, vol. 42, no. 11, pp. 2175-2182, 1997.

[141] G. H. Kramer and P. Crowley, "The assessment of the effect of thyroid size and shape on the activity estimate using Monte Carlo simulation," Health Physics, vol. 78, no. 6, pp. 727-738, 2000. 
[142] Y. Merle, F. Mentre, A. Mallet, and A. Aurengo, "Computerassisted individual estimation of radioiodine thyroid uptake in Grave's disease," Computer Methods and Programs in Biomedicine, vol. 40, no. 1, pp. 33-41, 1993.

[143] J. L. Noteboom, W. A. Hummel, J. T. M. Jansen, D. W. van Bekkum, and J. J. Broerse, "Simulation of measurements of uptake of 123I-iodide in the thyroid of fetal chimpanzees," Radiation Research, vol. 147, no. 6, pp. 686-690, 1997.

[144] A. C. Traino, F. Di Martino, M. Grosso et al., "A predictive mathematical model for the calculation of the final mass of Graves' disease thyroids treated with 131I," Physics in Medicine and Biology, vol. 50, pp. 2181-2191, 2005.

[145] S. Bhati and H. K. Patni, "Monte-Carlo simulation of uncertainty in the estimation of 125 I in the thyroid," Radiation Protection Dosimetry, vol. 136, no. 1, pp. 23-29, 2009.

[146] G. Diaz Londono and A. M. Lallena, "Specific absorbed fractions in thyroid diagnostics and treatment: Monte Carlo calculation with PENELOPE," Radiation Protection Dosimetry, vol. 150, pp. 41-49, 2012.

[147] J. Hammes, U. Pietrzyk, M. Schmidt, H. Schicha, and W. Eschner, "GATE based Monte Carlo simulation of planar scintigraphy to estimate the nodular dose in radioiodine therapy for autonomous thyroid adenoma," Zeitschrift für Medizinische Physik, vol. 21, pp. 290-300, 2012.

[148] A. Khrutchinsky, V. Drozdovitch, S. Kutsen et al., "Mathematical modeling of a survey-meter used to measure radioactivity in human thyroids: Monte Carlo calculations of the device response and uncertainties," Applied Radiation and Isotopes, vol. 70, pp. 743-751, 2012.

[149] A. A. Mowlavi, M. R. Fornasier, and M. de Denaro, "Thyroid volume's influence on energy deposition from 131I calculated by Monte Carlo (MC) simulation," Radiology and Oncology, vol. 45, no. 2, pp. 143-146, 2011.

[150] E. Saeedzadeh, S. Sarkar, A. Abbaspour Tehrani-Fard, M. R. Ay, H. R. Khosravi, and G. Loudos, "3D calculation of absorbed dose for 131I-targeted radiotherapy: a Monte Carlo study," Radiation Protection Dosimetry, vol. 150, pp. 298-305, 2012.

[151] L. Martínez, P. Webb, I. Polikarpov, and M. S. Skaf, "Molecular dynamics simulations of ligand dissociation from thyroid hormone receptors: evidence of the likeliest escape pathway and its implications for the design of novel ligands," Journal of Medicinal Chemistry, vol. 49, no. 1, pp. 23-26, 2006.

[152] A. Vedani, M. Zumstein, M. A. Lill, and B. Ernst, "Simulating $\alpha / \beta$ selectivity at the human thyroid hormone receptor: consensus scoring using multidimensional QSAR," ChemMedChem, vol. 2, no. 1, pp. 78-87, 2007.

[153] "NOMOTHETICOS: Nonlinear Modelling of Thyroid Hormones' Effect on Thyrotropin Incretion in Confirmed Open-loop Situation," http://clinicaltrials.gov/ct2/show/ record/NCT01145040.

[154] C. M. Dayan and V. Panicker, "Novel insights into thyroid hormones from the study of common genetic variation," Nature Reviews Endocrinology, vol. 5, no. 4, pp. 211-218, 2009.

[155] L. Boccone, S. Mariotti, V. Dessì, D. Pruna, A. Meloni, and G. Loudianos, "Allan-Herndon-Dudley syndrome (AHDS) caused by a novel SLC16A2 gene mutation showing severe neurologic features and unexpectedly low TRH-stimulated serum TSH," European Journal of Medical Genetics, vol. 53, no. 6, pp. 392-395, 2010.
[156] E. Crushell and W. Reardon, "Elevated TSH levels in a mentally retarded boy," European Journal of Pediatrics, vol. 169, no. 5, pp. 573-575, 2010.

[157] O. Fuchs, N. Pearr, J. Pohlensz, and H. Schmidt, "Elevated serum triiodothyronine and intellectual and motor disability with paroxysmal dyskinesia caused by a monocarboxylate transporter 8 gene mutation," Developmental Medicine and Child Neurology, vol. 51, no. 3, pp. 240-244, 2009.

[158] C. E. Schwartz and R. E. Stevenson, "The MCT8 thyroid hormone transporter and Allan-Herndon-Dudley syndrome," Best Practice and Research, vol. 21, no. 2, pp. 307-321, 2007.

[159] W. M. van der Deure, R. P. Peeters, and T. J. Visser, "Molecular aspects of thyroid hormone transporters, including MCT8, MCT10, and OATPs, and the effects of genetic variation in these transporters," Journal of Molecular Endocrinology, vol. 44, no. 1, pp. 1-11, 2010.

[160] A. M. Dumitrescu, X. H. Liao, T. B. Best, K. Brockmann, and S. Refetoff, "A novel syndrome combining thyroid and neurological abnormalities is associated with mutations in a monocarboxylate transporter gene," American Journal of Human Genetics, vol. 74, no. 1, pp. 168-175, 2004.

[161] C. M. C. Maranduba, E. C. H. Friesema, F. Kok et al., "Decreased cellular uptake and metabolism in AllanHerndon-Dudley syndrome (AHDS) due to a novel mutation in the MCT8 thyroid hormone transporter," Journal of Medical Genetics, vol. 43, no. 5, pp. 457-460, 2006.

[162] F. J. de Jong, R. P. Peeters, T. den Heijer et al., "The association of polymorphisms in the type 1 and 2 deiodinase genes with circulating thyroid hormone parameters and atrophy of the medial temporal lobe," The Journal of Clinical Endocrinology \& Metabolism, vol. 92, no. 2, pp. 636-640, 2007.

[163] H. C. Hoftijzer, K. A. Heemstra, T. J. Visser et al., "The type 2 deiodinase ORFa-Gly3Asp polymorphism (rs12885300) influences the set point of the hypothalamus-pituitarythyroid axis in patients treated for differentiated thyroid carcinoma," The Journal of Clinical Endocrinology \& Metabolism, vol. 96, pp. E1527-E1533, 2011.

[164] V. Panicker, C. Cluett, B. Shields et al., "A common variation in deiodinase 1 gene DIO1 is associated with the relative levels of free thyroxine and triiodothyronine," The Journal of Clinical Endocrinology \& Metabolism, vol. 93, no. 8, pp. 30753081, 2008.

[165] R. P. Peeters, A. W. van den Beld, H. Attalki et al., "A new polymorphism in the type II deiodinase gene is associated with circulating thyroid hormone parameters," American Journal of Physiology, vol. 289, no. 1, pp. E75-E81, 2005.

[166] R. P. Peeters, H. van Toor, W. Klootwijk et al., "Polymorphisms in thyroid hormone pathway genes are associated with plasma TSH and iodothyronine levels in healthy subjects," The Journal of Clinical Endocrinology \& Metabolism, vol. 88, no. 6, pp. 2880-2888, 2003.

[167] W. M. van der Deure, P. S. Hansen, R. P. Peeters et al., "The effect of genetic variation in the type 1 deiodinase gene on the interindividual variation in serum thyroid hormone levels: an investigation in healthy Danish twins," Clinical Endocrinology, vol. 70, no. 6, pp. 954-960, 2009.

[168] A. T. Alberobello, V. Congedo, H. Liu et al., "An intronic SNP in the thyroid hormone receptor beta gene is associated with pituitary cell-specific over-expression of a mutant thyroid hormone receptor beta2 (R338W) in the index case of pituitary-selective resistance to thyroid hormone," Journal of Translational Medicine, vol. 9, article 144, 2011.

[169] H. G. Sørensen, W. M. van der Deure, P. S. Hansen et al., "Identification and consequences of polymorphisms in 
the thyroid hormone receptor alpha and beta genes," Thyroid, vol. 18, no. 10, pp. 1087-1094, 2008.

[170] S. Lee, B. M. Young, W. Wan, I. H. Chan, and M. L. Privalsky, "A mechanism for pituitary-resistance to thyroid hormone (PRTH) syndrome: a loss in cooperative coactivator contacts by thyroid hormone receptor (TR) $\beta$ 2," Molecular Endocrinology, vol. 25, no. 7, pp. 1111-1125, 2011.

[171] H. Tian, M. A. Mahajan, T. W. Chun, I. Habeos, and H. H. Samuels, "The N-terminal A/B domain of the thyroid hormone receptor- $\beta 2$ isoform influences ligand-dependent recruitment of coactivators to the ligand-binding domain," Molecular Endocrinology, vol. 20, no. 9, pp. 2036-2051, 2006.

[172] A. Malaguti, C. Della Casa, S. Castorina et al., "Molecular mechanisms for pituitary thyrotroph cell growth," Journal of Endocrinological Investigation, vol. 27, no. 6, pp. 151-167, 2004.

[173] K. Pals, H. Vankelecom, and C. Denef, "Triiodothyronine expands the lactotroph and maintains the lactosomatotroph population, whereas thyrotrophin-releasing hormone augments thyrotroph abundance in aggregate cell cultures of postnatal rat pituitary gland," Journal of Neuroendocrinology, vol. 18, no. 3, pp. 203-216, 2006.

[174] E. Szarek, K. Farrand, I. C. Mcmillen, I. R. Young, D. Houghton, and J. Schwartz, "Hypothalamic input is required for development of normal numbers of thyrotrophs and gonadotrophs, but not other anterior pituitary cells in late gestation sheep," The Journal of Physiology, vol. 586, no. 4, pp. 1185-1194, 2008.

[175] L. Alberti, M. C. Proverbio, S. Costagliola et al., "Germline mutations of TSH receptor gene as cause of nonautoimmune subclinical hypothyroidism," The Journal of Clinical Endocrinology \& Metabolism, vol. 87, no. 6, pp. 2549-2555, 2002.

[176] D. Calebiro, G. Gelmini, D. Cordella et al., "Frequent TSH receptor genetic alterations with variable signaling impairment in a large series of children with nonautoimmune isolated hyperthyrotropinemia," The Journal of Clinical Endocrinology \& Metabolism, vol. 97, pp. 156-160, 2012.

[177] M. Tonacchera, A. Perri, G. De Marco et al., "Low prevalence of thyrotropin receptor mutations in a large series of subjects with sporadic and familial nonautoimmune subclinical hypothyroidism," The Journal of Clinical Endocrinology \& Metabolism, vol. 89, no. 11, pp. 5787-5793, 2004.

[178] L. Persani, D. Calebiro, D. Cordella et al., "Genetics and phenomics of hypothyroidism due to TSH resistance," Molecular and Cellular Endocrinology Journal, vol. 322, pp. 72-82, 2010.

[179] R. J. Clifton-Bligh, J. W. Gregory, M. Ludgate et al., "Two novel mutations in the thyrotropin (TSH) receptor gene in a child with resistance to TSH," The Journal of Clinical Endocrinology \& Metabolism, vol. 82, no. 4, pp. 1094-1100, 1997.

[180] N. de Roux, M. Misrahi, R. Brauner et al., "Four families with loss of function mutations of the thyrotropin receptor," The Journal of Clinical Endocrinology \& Metabolism, vol. 81, no. 12, pp. 4229-4235, 1996.

[181] L. Duprez, J. Parma, J. Van Sande et al., "TSH receptor mutations and thyroid disease," Trends in Endocrinology and Metabolism, vol. 9, no. 4, pp. 133-140, 1998.

[182] T. Sunthornthepvarakul, M. E. Gottschalk, Y. Hayashi, and S. Refetoff, "Brief report: resistance to thyrotropin caused by mutations in the thyrotropin-receptor gene," The New England Journal of Medicine, vol. 332, no. 3, pp. 155-160, 1995.
[183] G. Vassart and S. Costagliola, "G protein-coupled receptors: mutations and endocrine diseases," Nature Reviews Endocrinology, vol. 7, no. 6, pp. 362-372, 2011.

[184] G. Radetti, M. Maselli, F. Buzi et al., "The natural history of the normal/mild elevated TSH serum levels in children and adolescents with Hashimoto's thyroiditis and isolated hyperthyrotropinaemia: a 3-year follow-up," Clinical Endocrinology, vol. 76, pp. 394-398, 2012.

[185] M. J. Abramowicz, L. Duprez, J. Parma, G. Vassart, and C. Heinrichs, "Familial congenital hypothyroidism due to inactivating mutation of the thyrotropin receptor causing profound hypoplasia of the thyroid gland," The Journal of Clinical Investigation, vol. 99, no. 12, pp. 3018-3024, 1997.

[186] H. Biebermann, T. Schöneberg, H. Krude, G. Schultz, T. Gudermann, and A. Grüters, "Mutations of the human thyrotropin receptor gene causing thyroid hypoplasia and persistent congenital hypothyroidism," The Journal of Clinical Endocrinology \& Metabolism, vol. 82, no. 10, pp. 3471-3480, 1997.

[187] N. Gagné, J. Parma, C. Deal, G. Vassart, and G. Van Vliet, "Apparent congenital athyreosis contrasting with normal plasma thyroglobulin levels and associated with inactivating mutations in the thyrotropin receptor gene: are athyreosis and ectopic thyroid distinct entities?" The Journal of Clinical Endocrinology \& Metabolism, vol. 83, no. 5, pp. 1771-1775, 1998.

[188] E. Martino and A. Pinchera, "Central hypothyroidism," in Werner and Ingbar's the Thyroid, L. E. Braverman and R. D. Utiger, Eds., pp. 754-768, Lippincott Williams \& Wilkins, Philadelphia, Pa, USA, 9th edition, 2005.

[189] P. Beck-Peccoz, S. Amr, M. Menezes-Ferreira, G. Faglia, and B. D. Weintraub, "Decreased receptor binding of biologically inactive thyrotropin in central hypothyroidism. Effect of treatment with thyrotropin-releasing hormone," The New England Journal of Medicine, vol. 312, no. 17, pp. 1085-1090, 1985.

[190] R. Collu, "Genetic aspects of central hypothyroidism," Journal of Endocrinological Investigation, vol. 23, no. 2, pp. 125134, 2000.

[191] P. Beck-Peccoz, F. Brucker-Davis, L. Persani, R. C. Smallridge, and B. D. Weintraub, "Thyrotropin-secreting pituitary tumors," Endocrine Reviews, vol. 17, no. 6, pp. 610-638, 1996.

[192] S. Refetoff, "Resistance to thyroid hormone," in Werner and Ingbar's the Thyroid, L. E. Braverman and R. P. Uller, Eds., pp. 1109-1129, Lippincott Williams \& Wilkins, Philadelphia, Pa, USA, 2005.

[193] Q. L. Li, P. Feng, T. Satoh et al., "Regulation of the human TRH (hTRH) gene by human thyroid hormone receptor $\beta 1$ (hTR $\beta 1$ ) mutants," Endocrine Research, vol. 23, no. 4, pp. 297-309, 1997.

[194] G. Rothenbuchner, U. Loos, W. R. Kiessling, J. Birk, and E. F. Pfeiffer, "The influence of total starvation on the pituitarythyroid-axis in obese individuals," Acta Endocrinologica, Supplement, vol. 173, p. 144, 1973.

[195] G. I. Portnay, J. T. O’Brien, J. Bush et al., “The effect of starvation on the concentration and binding of thyroxine and triiodothyronine in serum and on the response to TRH," The Journal of Clinical Endocrinology \& Metabolism, vol. 39, no. 1, pp. 191-194, 1974.

[196] I. J. Chopra, "Nonthyroidal illness syndrome or euthyroid sick syndrome?" Endocrine Practice, vol. 2, pp. 45-52, 1996.

[197] L. J. De Groot, "Dangerous dogmas in medicine: the nonthyroidal illness syndrome," The Journal of Clinical 
Endocrinology \& Metabolism, vol. 84, no. 1, pp. 151-164, 1999.

[198] G. Iervasi, A. Pingitore, P. Landi et al., "Low-T3 syndrome: a strong prognostic predictor of death in patients with heart disease," Circulation, vol. 107, no. 5, pp. 708-713, 2003.

[199] E. Scoscia, S. Baglioni, A. Eslami, G. Iervasi, S. Monti, and T. Todisco, "Low triiodothyronine (T3) state: a predictor of outcome in respiratory failure? Results of a clinical pilot study," European Journal of Endocrinology, vol. 151, no. 5, pp. 557-560, 2004.

[200] A. G. Angelousi, D. E. Karageorgopoulos, A. M. Kapaskelis, and M. E. Falagas, "Association between thyroid function tests at baseline and the outcome of patients with sepsis or septic shock: a systematic review," European Journal of Endocrinology, vol. 164, no. 2, pp. 147-155, 2011.

[201] R. H. Costa-e-Sousa and A. N. Hollenberg, "Minireview: the neural regulation of the hypothalamic-pituitary-thyroid axis," Endocrinology, vol. 153, pp. 4128-4135, 2012.

[202] E. Schifferdecker, S. Hering, B. O. Bohm et al., "Thyroid hormone binding inhibition in critically ill patients-who is the inhibitor?" Experimental and Clinical Endocrinology, vol. 95, no. 2, pp. 267-270, 1990.

[203] E. Schifferdecker, S. Hering, H. Forster et al., "Freie Fettsäuren im Serum bei krisenhaften Erkrankungen: Spielen sie eine Rolle bei der Proteinbindung von Schilddrüsenhormonen? [Free fatty acids in the serum in critical diseases: do they play a role in the protein binding of thyroid hormones?]," Klin Wochenschr, vol. 66, pp. 308-313, 1988.

[204] A. Burger, P. Nicod, P. Suter, M. B. Vallotton, P. Vagenakis, and L. Braverman, "Reduced active thyroid hormone levels in acute illness," The Lancet, vol. 1, no. 7961, pp. 653-655, 1976.

[205] K. Carlin and S. Carlin, "Possible etiology for euthyroid sick syndrome," Medical Hypotheses, vol. 40, no. 1, pp. 38-43, 1993.

[206] C. S. Pittman, T. Shimizu, A. Burger, and B. Chambers Jr., "The nondeiodinative pathways of thyroxine metabolism: 3,5,3',5'-tetraiodothyroacetic acid turnover in normal and fasting human subjects," The Journal of Clinical Endocrinology \& Metabolism, vol. 50, no. 4, pp. 712-716, 1980.

[207] T. S. Scanlan, "Minireview: 3-iodothyronamine (T1AM): a new player on the thyroid endocrine team?" Endocrinology, vol. 150, no. 3, pp. 1108-1111, 2009.

[208] K. P. Doyle, K. L. Suchland, T. M. P. Ciesielski et al., "Novel thyroxine derivatives, thyronamine and 3-iodothyronamine, induce transient hypothermia and marked neuroprotection against stroke injury," Stroke, vol. 38, no. 9, pp. 2569-2576, 2007.

[209] W. J. L. Wood, T. Geraci, A. Nilsen, A. E. DeBarber, and T. S. Scanlan, "Iodothyronamines are oxidatively deaminated to iodothyroacetic acids in vivo," ChemBioChem, vol. 10, no. 2, pp. 361-365, 2009.

[210] A. Boelen, W. M. Wiersinga, and E. Fliers, "Fasting-induced changes in the hypothalamus-pituitary-thyroid axis," Thyroid, vol. 18, no. 2, pp. 123-129, 2008.

[211] K. A. Kohel, D. S. MacKenzie, D. C. Rostal, J. S. Grumbles, and V. A. Lance, "Seasonality in plasma thyroxine in the desert tortoise, Gopherus agassizii," General and Comparative Endocrinology, vol. 121, no. 2, pp. 214-222, 2001.

[212] S. C. Nicol, N. A. Andersen, and T. E. Tomasi, "Seasonal variations in thyroid hormone levels in free-living echidnas (Tachyglossus aculeatus)," General and Comparative Endocrinology, vol. 117, no. 1, pp. 1-7, 2000.
[213] T. E. Tomasi, E. C. Hellgren, and T. J. Tucker, "Thyroid hormone concentrations in black bears (Ursus americanus): hibernation and pregnancy effects," General and Comparative Endocrinology, vol. 109, no. 2, pp. 192-199, 1998.

[214] L. Mebis, A. Eerdekens, F. Guiza et al., "Contribution of nutritional deficit to the pathogenesis of the nonthyroidal illness syndrome in critical illness: a rabbit model study," Endocrinology, vol. 153, pp. 973-984, 2012.

[215] J. D. Klemperer, I. Klein, M. Gomez et al., "Thyroid hormone treatment after coronary-artery bypass surgery," The New England Journal of Medicine, vol. 333, no. 23, pp. 1522-1527, 1995.

[216] J. D. Klemperer, I. L. Klein, K. Ojamaa et al., "Triiodothyronine therapy lowers the incidence of atrial fibrillation after cardiac operations," Annals of Thoracic Surgery, vol. 61, no. 5, pp. 1323-1329, 1996.

[217] A. M. Ranasinghe, D. W. Quinn, D. Pagano et al., "Glucose-insulin-potassium and tri-iodothyronine individually improve hemodynamic performance and are associated with reduced troponin I release after on-pump coronary artery bypass grafting," Circulation, vol. 114, no. 1, pp. I245I250, 2006.

[218] K. L. Wyne, "The role of thyroid hormone therapy in acutely ill cardiac patients," Critical Care, vol. 9, no. 4, pp. 333-334, 2005.

[219] M. Güden, B. Akpinar, E. Sağbaş, I. Sanisoğlu, E. Cakali, and O. Bayindir, "Effects of intravenous triiodothyronine during coronary artery bypass surgery," Asian Cardiovascular and Thoracic Annals, vol. 10, no. 3, pp. 219-222, 2002.

[220] A. P. A. Magalhäes, M. Gus, L. B. Silva, and B. D. Schaan, "Oral triiodothyronine for the prevention of thyroid hormone reduction in adult valvular cardiac surgery," Brazilian Journal of Medical and Biological Research, vol. 39, no. 7, pp. 969-978, 2006.

[221] A. Ronald and J. Dunning, "Best evidence topic-cardiac general: does perioperative thyroxine have a role during adult cardiac surgery?" Interactive Cardiovascular and Thoracic Surgery, vol. 5, no. 2, pp. 166-178, 2006.

[222] C. G. Acker, A. R. Singh, R. P. Flick, J. Bernardini, A. Greenberg, and J. P. Johnson, "A trial of thyroxine in acute renal failure," Kidney International, vol. 57, no. 1, pp. 293298, 2000.

[223] G. A. Brent and J. M. Hershman, "Thyroxine therapy in patients with severe nonthyroidal illnesses and low serum thyroxine concentration," The Journal of Clinical Endocrinology \& Metabolism, vol. 63, no. 1, pp. 1-8, 1986.

[224] R. H. Caplan, "Comment on dangerous dogmas in medicine- the nonthyroidal illness syndrome," The Journal of Clinical Endocrinology \& Metabolism, vol. 84, no. 6, pp. 2262-2263, 1999.

[225] R. D. Utiger, "Altered thyroid function in nonthyroidal illness and surgery-to treat or not to treat?" The New England Journal of Medicine, vol. 333, no. 23, pp. 1562-1563, 1995.

[226] L. Mebis and G. van den Berghe, "The hypothalamuspituitary-thyroid axis in critical illness," Netherlands Journal of Medicine, vol. 67, no. 10, pp. 332-340, 2009.

[227] P. R. Larsen and M. J. Berry, "Nutritional and hormonal regulation of thyroid hormone deiodinases," Annual Review of Nutrition, vol. 15, pp. 323-352, 1995.

[228] A. L. Maia, I. M. Goemann, E. L. S. Meyer, and S. M. Wajner, "Deiodinases: the balance of thyroid hormone: type 1 iodothyronine deiodinase in human physiology and disease," Journal of Endocrinology, vol. 209, no. 3, pp. 283297, 2011. 
[229] M. Murakami, Y. Kamiya, T. Morimura et al., "Thyrotropin receptors in brown adipose tissue: thyrotropin stimulates type II iodothyronine deiodinase and uncoupling protein1 in brown adipocytes," Endocrinology, vol. 142, no. 3, pp. 1195-1201, 2001.

[230] N. Nakao, H. Ono, T. Yamamura et al., "Thyrotrophin in the pars tuberalis triggers photoperiodic response," Nature, vol. 452, no. 7185, pp. 317-322, 2008.

[231] A. Boelen, J. Kwakkel, W. M. Wiersinga, and E. Fliers, "Chronic local inflammation in mice results in decreased $\mathrm{TRH}$ and type 3 deiodinase mRNA expression in the hypothalamic paraventricular nucleus independently of diminished food intake," Journal of Endocrinology, vol. 191, no. 3, pp. 707-714, 2006.

[232] K. M. Pantalone and C. Nasr, "Approach to a low tsh level: patience is a virtue," Cleveland Clinic Journal of Medicine, vol. 77, no. 11, pp. 803-811, 2010.

[233] J. Figge, M. Leinung, A. D. Goodman et al., "The clinical evaluation of patients with subclinical hyperthyroidism and free triiodothyronine (free T3) toxicosis," American Journal of Medicine, vol. 96, no. 3, pp. 229-234, 1994.

[234] J. Takamatsu, M. Sugawara, K. Kuma et al., "Ratio of serum triiodothyronine to thyroxine and the prognosis of triiodothyronine-predominant Graves' disease," Annals of Internal Medicine, vol. 100, no. 3, pp. 372-375, 1984.

[235] B. W. Kim, G. H. Daniels, B. J. Harrison et al., "Overexpression of type 2 iodothyronine deiodinase in follicular carcinoma as a cause of low circulating free thyroxine levels," The Journal of Clinical Endocrinology \& Metabolism, vol. 88, no. 2, pp. 594-598, 2003.

[236] A. Miyauchi, Y. Takamura, Y. Ito et al., "3,5,3'-Triiodothyronine thyrotoxicosis due to increased conversion of administered levothyroxine in patients with massive metastatic follicular thyroid carcinoma," The Journal of Clinical Endocrinology \& Metabolism, vol. 93, no. 6, pp. 22392242, 2008.

[237] A. A. Shahin, S. Abdoh, and M. Abdelrazik, "Prolactin and thyroid hormones in patients with systemic sclerosis: correlations with disease manifestations and activity," Zeitschrift fur Rheumatologie, vol. 61, no. 6, pp. 703-709, 2002.

[238] M. Murakami, O. Araki, Y. Hosoi et al., "Expression and regulation of type II iodothyronine deiodinase in human thyroid gland," Endocrinology, vol. 142, no. 7, pp. 2961-2967, 2001.

[239] S. Suzuki, S. Shigematsu, H. Inaba, M. Takei, T. Takeda, and M. Komatsu, "Pituitary resistance to thyroid hormones: pathophysiology and therapeutic options," Endocrine, vol. 40, pp. 366-371, 2011.

[240] E. Bochukova, N. Schoenmakers, M. Agostini et al., "A mutation in the thyroid hormone receptor alpha gene," The New England Journal of Medicine, vol. 366, pp. 243-249, 2012.

[241] M. M. Kaplan, S. L. Swartz, and P. R. Larsen, "Partial peripheral resistance to thyroid hormone," American Journal of Medicine, vol. 70, no. 5, pp. 1115-1121, 1981.

[242] E. Tjørve, K. M. C. Tjørve, J. O. Olsen, R. Senum, and H. Oftebro, "On commonness and rarity of thyroid hormone resistance: a discussion based on mechanisms of reduced sensitivity in peripheral tissues," Medical Hypotheses, vol. 69, no. 4, pp. 913-921, 2007.

[243] E. G. Movius, M. M. Phyillaier, and J. Robbins, "Phloretin inhibits cellular uptake and nuclear receptor binding of triiodothyronine in human Hep G2 hepatocarcinoma cells," Endocrinology, vol. 124, no. 4, pp. 1988-1997, 1989.
[244] P. C. Lisbôa, F. H. Curty, R. M. Moreira, and C. C. PazosMoura, "Effects of estradiol benzoate on 5 '-iodothyronine deiodinase activities in female rat anterior pituitary gland, liver and thyroid gland," Brazilian Journal of Medical and Biological Research, vol. 30, no. 12, pp. 1479-1484, 1997.

[245] S. Benvenga, R. M. Ruggeri, A. Russo, D. Lapa, A. Campenni, and F. Trimarchi, "Usefulness of L-carnitine, a naturally occurring peripheral antagonist of thyroid hormone action, in iatrogenic hyperthyroidism: a randomized, double-blind, placebo-controlled clinical trial," The Journal of Clinical Endocrinology \& Metabolism, vol. 86, no. 8, pp. 3579-3594, 2001.

[246] S. Benvenga, M. Lakshmanan, and F. Trimarchi, "Carnitine is a naturally occurring inhibitor of thyroid hormone nuclear uptake," Thyroid, vol. 10, no. 12, pp. 1043-1050, 2000.

[247] G. M. Santos, C. J. A. Pantoja, E. S. A. Costa et al., "Thyroid hormone receptor binding to DNA and T3-dependent transcriptional activation are inhibited by uremic toxins," Nuclear Receptor, vol. 3, article 1, 2005.

[248] L. J. DeGroot and P. A. Rue, "Roentgenographic contrast agents inhibit triiodothyronine binding to nuclear receptors in vitro," The Journal of Clinical Endocrinology \& Metabolism, vol. 49, no. 4, pp. 538-542, 1979.

[249] V. R. Vorperian, T. C. Havighurst, S. Miller, and C. T. January, "Adverse effects of low dose amiodarone: a meta-analysis," Journal of the American College of Cardiology, vol. 30, no. 3, pp. 791-798, 1997.

[250] C. G. Hahn, A. C. Pawlyk, P. C. Whybrow, L. Gyulai, and S. M. Tejani-Butt, "Lithium administration affects gene expression of thyroid hormone receptors in rat brain," Life Sciences, vol. 64, no. 20, pp. 1793-1802, 1999.

[251] P. Englebienne, M. Verhas, C. V. Herst, and K. De Meirleir, "Type I interferons induce proteins susceptible to act as thyroid receptor (TR) corepressors and to signal the TR for destruction by the proteasome: possible etiology for unexplained chronic fatigue," Medical Hypotheses, vol. 60, no. 2, pp. 175-180, 2003.

[252] L. J. DeGroot, A. H. Coleoni, P. A. Rue, H. Seo, E. Martino, and S. Refetoff, "Reduced nuclear triiodothyronine receptors in starvation induced hypothyroidism," Biochemical and Biophysical Research Communications, vol. 79, no. 1, pp. 173178, 1977.

[253] T. Tagami, H. Nakamura, S. Sasaki, Y. Miyoshi, and K. Nakao, "Starvation-induced decrease in the maximal binding capacity for triiodothyronine of the thyroid hormone receptor is due to a decrease in the receptor protein," Metabolism, vol. 45, no. 8, pp. 970-973, 1996.

[254] Z. G. Sheng, Y. Tang, Y. X. Liu et al., "Low concentrations of bisphenol a suppress thyroid hormone receptor transcription through a nongenomic mechanism," Toxicology and Applied Pharmacology Journal, vol. 259, pp. 133-142, 2012.

[255] P. J. Davis, H. Y. Lin, S. A. Mousa et al., "Overlapping nongenomic and genomic actions of thyroid hormone and steroids," Steroids, vol. 76, no. 9, pp. 829-833, 2011.

[256] P. J. Davis, F. B. Davis, S. A. Mousa, M. K. Luidens, and H. Y. Lin, "Membrane receptor for thyroid hormone: physiologic and pharmacologic implications," Annual Review of Pharmacology and Toxicology, vol. 51, pp. 99-115, 2011.

[257] S. Y. Cheng, J. L. Leonard, and P. J. Davis, "Molecular aspects of thyroid hormone actions," Endocrine Reviews, vol. 31, no. 2, pp. 139-170, 2010.

[258] F. Axelband, J. Dias, F. M. Ferrão, and M. Einicker-Lamas, "Nongenomic signaling pathways triggered by thyroid 
hormones and their metabolite 3-iodothyronamine on the cardiovascular system," Journal of Cellular Physiology, vol. 226, no. 1, pp. 21-28, 2011.

[259] E. Yehuda-Shnaidman, B. Kalderon, N. Azazmeh, and J. BarTana, "Gating of the mitochondrial permeability transition pore by thyroid hormone," FASEB Journal, vol. 24, no. 1, pp. 93-104, 2010.

[260] H. J. Cao, H. Y. Lin, M. K. Luidens, F. B. Davis, and P. J. Davis, "Cytoplasm-to-nucleus shuttling of thyroid hormone receptor- $\beta 1$ (TR $\beta 1)$ is directed from a plasma membrane integrin receptor by thyroid hormone," Endocrine Research, vol. 34, no. 1-2, pp. 31-42, 2009.

[261] P. J. Davis, M. Zhou, F. B. Davis, L. Lansing, S. A. Mousa, and H. Y. Lin, "Mini-review: cell surface receptor for thyroid hormone and nongenomic regulation of ion fluxes in excitable cells," Physiology and Behavior, vol. 99, no. 2, pp. 237-239, 2010.

[262] P. J. Davis, J. L. Leonard, and F. B. Davis, "Mechanisms of nongenomic actions of thyroid hormone," Frontiers in Neuroendocrinology, vol. 29, no. 2, pp. 211-218, 2008.

[263] M. Bhargava, J. Lei, C. N. Mariash, and D. H. Ingbar, "Thyroid hormone rapidly stimulates alveolar Na,K-ATPase by activation of phosphatidylinositol 3-kinase," Current Opinion in Endocrinology, Diabetes and Obesity, vol. 14, no. 5, pp. 416-420, 2007.

[264] P. J. Davis and F. B. Davis, "Nongenomic actions of thyroid hormone," Thyroid, vol. 6, no. 5, pp. 497-504, 1996.

[265] L. N. Vandenberg, T. Colborn, T. B. Hayes et al., "Hormones and endocrine-disrupting chemicals: low-dose effects and nonmonotonic dose responses," Endocrine Reviews, vol. 33, pp. 378-455, 2012.

[266] S. S. Andra and K. C. Makris, "Thyroid disrupting chemicals in plastic additives and thyroid health," Journal of Environmental Science and Health C, vol. 30, pp. 107-151, 2012.

[267] M. Boas, U. Feldt-Rasmussen, and K. M. Main, "Thyroid effects of endocrine disrupting chemicals," Molecular and Cellular Endocrinology Journal, vol. 355, pp. 240-248, 2012.

[268] J. D. Meeker and K. K. Ferguson, "Relationship between urinary phthalate and bisphenol A concentrations and serum thyroid measures in U.S. adults and adolescents from the National Health and Nutrition Examination Survey (NHANES) 2007-2008," Environmental Health Perspectives, vol. 119, pp. 1396-1402, 2011.

[269] M. M. Leijs, G. W. ten Tusscher, K. Olie et al., "Thyroid hormone metabolism and environmental chemical exposure," Environmental Health, vol. 11, supplement 1, p. S10, 2012.

[270] K. Ji, S. Kim, Y. Kho et al., "Serum concentrations of major perfluorinated compounds among the general population in Korea: dietary sources and potential impact on thyroid hormones," Environment International, vol. 45, pp. 78-85, 2012.

[271] T. Iwasaki, W. Miyazaki, A. Takeshita, Y. Kuroda, and N. Koibuchi, "Polychlorinated biphenyls suppress thyroid hormone-induced transactivation," Biochemical and Biophysical Research Communications, vol. 299, no. 3, pp. 384-388, 2002.

[272] W. Miyazaki, T. Iwasaki, A. Takeshita, Y. Kuroda, and N. Koibuchi, "Polychlorinated biphenyls suppress thyroid hormone receptor-mediated transcription through a novel mechanism," The Journal of Biological Chemistry, vol. 279, no. 18, pp. 18195-18202, 2004.

[273] U. Rickenbacher, J. D. McKinney, S. J. Oatley, and C. C. F. Blake, "Structurally specific binding of halogenated biphenyls to thyroxine transport protein," Journal of Medicinal Chemistry, vol. 29, no. 5, pp. 641-648, 1986.

[274] R. T. Zoeller, "Environmental chemicals impacting the thyroid: targets and consequences," Thyroid, vol. 17, no. 9, pp. 811-817, 2007.

[275] C. Liu, C. Wang, M. Yan, C. Quan, J. Zhou, and K. Yang, "PCB153 disrupts thyroid hormone homeostasis by affecting its biosynthesis, biotransformation, feedback regulation, and metabolism," Hormone and Metabolic Research, vol. 44, pp. 662-669, 2012.

[276] A. H. Buckman, A. T. Fisk, J. L. Parrott, K. R. Solomon, and S. B. Brown, "PCBs can diminish the influence of temperature on thyroid indices in rainbow trout (Oncorhynchus mykiss)," Aquatic Toxicology, vol. 84, no. 3, pp. 366-378, 2007.

[277] N. Higashihara, K. Shiraishi, K. Miyata, Y. Oshima, Y. Minobe, and K. Yamasaki, "Subacute oral toxicity study of bisphenol $\mathrm{F}$ based on the draft protocol for the 'Enhanced OECD Test Guideline no. 407,'” Archives of Toxicology, vol. 81, no. 12, pp. 825-832, 2007.

[278] K. J. Gauger, S. Giera, D. S. Sharlin, R. Bansal, E. Iannacone, and R. T. Zoeller, "Polychlorinated biphenyls 105 and 118 form thyroid hormone receptor agonists after cytochrome P4501A1 activation in rat pituitary GH3 cells," Environmental Health Perspectives, vol. 115, no. 11, pp. 1623-1630, 2007.

[279] S. Giera, R. Bansal, T. M. Ortiz-Toro, D. G. Taub, and R. T. Zoeller, "Individual polychlorinated biphenyl (PCB) congeners produce tissue- and gene-specific effects on thyroid hormone signaling during development," Endocrinology, vol. 152, no. 7, pp. 2909-2919, 2011.

[280] O. Koulouri, M. A. Auldin, R. Agarwal et al., "Diagnosis and treatment of hypothyroidism in TSH deficiency compared to primary thyroid disease: pituitary patients are at risk of under-replacement with levothyroxine," Clinical Endocrinology, vol. 74, no. 6, pp. 744-749, 2011.

[281] J. Takamatsu, K. Kuma, and T. Mozai, "Serum triiodothyronine to thyroxine ratio: a newly recognized predictor of the outcome of hyperthyroidism due to Graves' disease," The Journal of Clinical Endocrinology \& Metabolism, vol. 62, no. 5, pp. 980-983, 1986.

[282] N. Amino, Y. Yabu, T. Miki et al., "Serum ratio of triiodothyronine to thyroxine, and thyroxine-binding globulin and calcitonin concentrations in Grave's disease and destructioninduced thyrotoxicosis," The Journal of Clinical Endocrinology \& Metabolism, vol. 53, no. 1, pp. 113-116, 1981.

[283] K. Horn, D. Koeppen, C. R. Pickardt, and P. C. Scriba, "Thyroidal autoregulation in nontoxic goiter patients: normalization of the T3/T4 ratio in serum by treatment with potassium iodide," Klinische Wochenschrift, vol. 53, no. 2, pp. 94-95, 1975.

[284] P. Laurberg, "Mechanisms governing the relative proportions of thyroxine and 3,5,3'-triiodothyronine in thyroid secretion," Metabolism, vol. 33, no. 4, pp. 379-392, 1984.

[285] M. M. Berger, M. J. Reymond, A. Shenkin et al., "Influence of selenium supplements on the post-traumatic alterations of the thyroid axis: a placebo-controlled trial," Intensive Care Medicine, vol. 27, no. 1, pp. 91-100, 2001.

[286] D. A. Fisher, "Physiological variations in thyroid hormones: physiological and pathophysiological considerations," Clinical Chemistry, vol. 42, no. 1, pp. 135-139, 1996.

[287] B. J. Dong, "How medications affect thyroid function," Western Journal of Medicine, vol. 172, no. 2, pp. 102-106, 2000.

[288] A. Mortoglou and H. Candiloros, "The serum triiodothyronine to thyroxine (T3/T4) ratio in various thyroid disorders 
and after Levothyroxine replacement therapy," Hormones, vol. 3, pp. 120-126, 2004.

[289] G. Sesmilo, O. Simó, L. Choque, R. Casamitjana, M. PuigDomingo, and I. Halperin, "Serum free triiodothyronine (T3) to free thyroxine (T4) ratio in treated central hypothyroidism compared with primary hypothyroidism and euthyroidism," Endocrinologia y Nutricion, vol. 58, no. 1, pp. 9-15, 2011.

[290] D. Rosołowska-Huszcz, L. Kozłowska, and A. Rydzewski, "Influence of low protein diet on nonthyroidal illness syndrome in chronic renal failure," Endocrine, vol. 27, no. 3, pp. 283-288, 2005.

[291] S. Liu, J. Ren, Y. Zhao et al., "Nonthyroidal illness syndrome: is it far away from Crohn's disease?" Journal of Clinical Gastroenterology. In press.

[292] M. Grußendorf, Metabolismus der Schilddrüsenhormone, Georg Thieme, Stuttgart, Germany, 1st edition, 1988.

[293] J. E. Dumont and G. Vassart, "Thyroid regulation," in Endocrinology, DeGroot, Ed., WB Saunders, 1995.

[294] F. S. Greenspan, "The thyroid gland," in Basic \& Clinical Endocrinology, F. S. Greenspan, G. J. Strewler, and C. T. Stamford, Eds., pp. 192-262, Appleton \& Lange, 5th edition, 1997.

[295] T. J. Visser, M. M. Kaplan, J. L. Leonard, and P. R. Larsen, "Evidence for two pathways of iodothyronine 5'deiodination in rat pituitary that differ in kinetics, propylthiouracil sensitivity, and response to hypothyroidism," The Journal of Clinical Investigation, vol. 71, no. 4, pp. 992-1002, 1983.

[296] M. den Brinker, K. F. M. Joosten, T. J. Visser et al., "Euthyroid sick syndrome in meningococcal sepsis: the impact of peripheral thyroid hormone metabolism and binding proteins," The Journal of Clinical Endocrinology \& Metabolism, vol. 90, no. 10, pp. 5613-5620, 2005.

[297] T. Kano, T. Kojima, T. Takahashi, and Y. Muto, "Serum thyroid hormone levels in patients with fulminant hepatitis: usefulness of rT3 and the rT3/T3 ratio as prognostic indices," Gastroenterologia Japonica, vol. 22, no. 3, pp. 344-353, 1987.

[298] K. Banovac, L. Bzik, M. Sekso, and M. Petek, "Decreased ratio of serum T3:rT3 in patients with hyperthyroidism," Endokrinologie, vol. 71, no. 2, pp. 159-163, 1978.

[299] S. Ruhla, A. M. Arafat, M. O. Weickert et al., "T3/rT3-ratio is associated with insulin resistance independent of TSH," Hormone and Metabolic Research, vol. 43, no. 2, pp. 130-134, 2011.

[300] C. M. Lessels and T. P. Boag, "Unrepeatable repeatabilities-a common mistake," The Auk, vol. 104, pp. 116-121, 1987.

[301] A. Jeyabalan, A. Urban, A. Ackermann et al., "Die berechnete Sekretionsleistung der Schilddrüse unterstützt die Differentialdiagnose zwischen latenter Hyperthyreose und NonThyroidal-Illness-Syndrom mit thyreotroper Adaptation," in Kongress Der Deutschen Gesellschaft Für Innere Medizin, vol. 117, p. PS97, Wiesbaden, Germany, 2011.

[302] J. Pohlenz, R. E. Weiss, P. E. Macchia et al., "Five new families with resistance to thyroid hormone not caused by mutations in the thyroid hormone receptor beta gene Resistance to thyroid hormone caused by two mutant thyroid hormone receptors beta, R243Q and R243W, with marked impairment of function that cannot be explained by altered in vitro 3,5 , 3 '-triiodothyroinine binding affinity," The Journal of Clinical Endocrinology \& Metabolism, vol. 84, pp. 3919-3928, 1999.

[303] V. Panicker, S. G. Wilson, T. D. Spector et al., "Heritability of serum TSH, free T4 and free T3 concentrations: a study of a large UK twin cohort," Clinical Endocrinology, vol. 68, no. 4, pp. 652-659, 2008.

[304] N. D. Christofides and J. E. M. Midgley, "Inaccuracies in free thyroid hormone measurement by ultrafiltration and tandem mass spectrometry," Clinical Chemistry, vol. 55, no. 12, pp. 2228-2230, 2009.

[305] J. Jonklaas, N. Kahric-Janicic, O. P. Soldin, and S. J. Soldin, "Correlations of free thyroid hormones measured by tandem mass spectrometry and immunoassay with thyroidstimulating hormone across 4 patient populations," Clinical Chemistry, vol. 55, no. 7, pp. 1380-1388, 2009.

[306] R. H. Lee, C. A. Spencer, J. H. Mestman et al., "Free T4 immunoassays are flawed during pregnancy," American Journal of Obstetrics and Gynecology, vol. 200, no. 3, pp. 260.e1-260.e6, 2009.

[307] J. E. M. Midgley and N. D. Christofides, "Point—legitimate and illegitimate tests of free-analyte assay function," Clinical Chemistry, vol. 55, no. 3, pp. 439-441, 2009.

[308] J. E. Midgley and N. D. Christofides, "Free thyroxine assays: no going back!," American Journal of Obstetrics and Gynecology, vol. 202, no. 2, p. e6, 2010.

[309] G. Shivaraj, B. D. Prakash, V. Sonal, K. Shruthi, H. Vinayak, and M. Avinash, "Thyroid function tests: a review," European Review for Medical and Pharmacological Sciences, vol. 13, pp. 341-349, 2009.

[310] C. A. Spencer, "Clinical utility and cost-effectiveness of sensitive thyrotropin assays in ambulatory and hospitalized patients," Mayo Clinic Proceedings, vol. 63, no. 12, pp. 12141222, 1988.

[311] C. A. Spencer, J. S. LoPresti, A. Patel et al., "Applications of a new chemiluminometric thyrotropin assay to subnormal measurement," The Journal of Clinical Endocrinology \& Metabolism, vol. 70, no. 2, pp. 453-460, 1990.

[312] R. B. Wilcox and J. C. Nelson, "Counterpoint: legitimate and illegitimate tests of free-analyte assay function: we need to identify the factors that influence free-analyte assay results," Clinical Chemistry, vol. 55, no. 3, pp. 442-444, 2009.

[313] T. P. Loh, S. L. Kao, D. J. Halsall et al., "Macro-thyrotropin: a case report and review of literature," The Journal of Clinical Endocrinology \& Metabolism, vol. 97, pp. 1823-1828, 2012.

[314] M. Rix, P. Laurberg, C. Porzig, and S. R. Kristensen, "Elevated thyroid-stimulating hormone level in a euthyroid neonate caused by macro thyrotropin-IgG complex," Acta Paediatrica, vol. 100, pp. e135-e137, 2011.

[315] H. Sakai, G. Fukuda, N. Suzuki, C. Watanabe, and M. Odawara, "Falsely elevated thyroid-stimulating hormone (TSH) level due to macro-TSH," Endocrine Journal, vol. 56, no. 3, pp. 435-440, 2009.

[316] R. N. Cohen and F. E. Wondisford, "Chemistry and biosynthesis of thyrotropin," in Werner and Ingbar's the Thyroid, L. E. Braverman and R. P. Uller, Eds., pp. 159-175, Lippincott Williams \& Wilkins, Philadelphia, Pa, USA, 2005.

[317] M. Grossmann, B. D. Weintraub, and M. W. Szkudlinski, "Novel insights into the molecular mechanisms of human thyrotropin action: structural, physiological, and therapeutic implications for the glycoprotein hormone family," Endocrine Reviews, vol. 18, no. 4, pp. 476-501, 1997.

[318] M. Grossmann, M. W. Szkudlinski, R. Wong, J. A. Dias, T. H. Ji, and B. D. Weintraub, "Substitution of the seat-belt region of the thyroid-stimulating hormone (TSH) $\beta$-subunit with the corresponding regions of choriogonadotropin or follitropin confers luteotropic but not follitropic activity to chimeric TSH," The Journal of Biological Chemistry, vol. 272, no. 24, pp. 15532-15540, 1997. 
[319] M. W. Szkudlinski, M. Grossmann, H. Leitolf, and B. D. Weintraub, "Human thyroid-stimulating hormone: structure-function analysis," Methods, vol. 21, no. 1, pp. 67$81,2000$.

[320] K. Nakabayashi, H. Matsumi, A. Bhalla et al., "Thyrostimulin, a heterodimer of two new human glycoprotein hormone subunits, activates the thyroid-stimulating hormone receptor," The Journal of Clinical Investigation, vol. 109, no. 11, pp. 1445-1452, 2002.

[321] G. Vassart and S. Costagliola, "The thyrotropin receptor," in Werner and Ingbar's the Thyroid, L. E. Braverman and R. P. Uller, Eds., pp. 176-183, Lippincott Williams \& Wilkins, Philadelphia, Pa, USA, 2005.

[322] L. R. Joshi and B. D. Weintraub, "Naturally occurring forms of thyrotropin with low bioactivity and altered carbohydrate content act as competitive antagonists to more bioactive forms," Endocrinology, vol. 113, no. 6, pp. 2145-2154, 1983.

[323] J. Sanders, R. N. Miguel, J. Furmaniak, and B. R. Smith, "TSH receptor monoclonal antibodies with agonist, antagonist, and inverse agonist activities," Methods in Enzymology, vol. 485, pp. 393-420, 2010.

[324] M. C. Gershengorn and S. Neumann, "Update in TSH receptor agonists and antagonists," The Journal of Clinical Endocrinology \& Metabolism, vol. 97, no. 12, pp. 4287-4292, 2012.

[325] S. Neumann, W. Huang, S. Titus et al., "Small-molecule agonists for the thyrotropin receptor stimulate thyroid function in human thyrocytes and mice," Proceedings of the National Academy of Sciences of the United States of America, vol. 106, no. 30, pp. 12471-12476, 2009.

[326] T. Heinzeller, "Entwicklungsgeschichte, Ontogenese und Histologie," in Schilddrüsenerkrankungen, G. R. Stuttgart, Ed., pp. 3-15, Wissenschaftliche Verlagsgesellschaft, 2004.

[327] R. O'Rahilly, “The timing and sequence of events in the development of the human endocrine system during the embryonic period proper," Anatomy and Embryology, vol. 166, no. 3, pp. 439-451, 1983.

[328] D. Glinoer, "The regulation of thyroid function in pregnancy: pathways of endocrine adaptation from physiology to pathology," Endocrine Reviews, vol. 18, no. 3, pp. 404-433, 1997.

[329] J. W. Dietrich, "Thyreotoxische Krise [thyroid storm]," Med Klin Intensivmed Notfmed, vol. 107, pp. 448-453, 2012.

[330] N. U. Chiniwala, P. D. Woolf, C. P. Bruno, S. Kaur, H. Spector, and K. Yacono, "Thyroid storm caused by a partial hydatidiform mole," Thyroid, vol. 18, no. 4, pp. 479-481, 2008.

[331] L. Walkington, J. Webster, B. W. Hancock, J. Everard, and R. E. Coleman, "Hyperthyroidism and human chorionic gonadotrophin production in gestational trophoblastic disease," British Journal of Cancer, vol. 104, no. 11, pp. 16651669, 2011.

[332] M. A. Arrabal-Polo, A. Jimenez-Pacheco, M. Arrabal-Martin et al., "Hyperthyroidism as a clinical manifestation of a embryonal carcinoma of the testis," Acta Clinica Belgica, vol. 67, pp. 214-216, 2012.

[333] S. A. Giralt, F. Dexeus, R. Amato, A. Sella, and C. Logothetis, "Hyperthyroidism in men with germ cell tumors and high levels of beta-human chorionic gonadotropin," Cancer, vol. 69, no. 5, pp. 1286-1290, 1992.

[334] K. Kato, M. H. Mostafa, K. Mann, A. E. Schindler, and R. Hoermann, "The human chorionic gonadotropin molecule from patients with trophoblastic diseases has a high thyrotropic activity but is less active in the ovary," Gynecological Endocrinology, vol. 18, no. 5, pp. 269-277, 2004.
[335] R. Hoermann, S. Poertl, I. Liss, S. M. Amir, and K. Mann, "Variation in the thyrotropic activity of human chorionic gonadotropin in Chinese hamster ovary cells arises from differential expression of the human thyrotropin receptor and microheterogeneity of the hormone," The Journal of Clinical Endocrinology \& Metabolism, vol. 80, no. 5, pp. 16051610, 1995.

[336] P. Rodien, C. Brémont, M. L. R. Sanson et al., "Familial gestational hyperthyroidism caused by a mutant thyrotropin receptor hypersensitive to human chorionic gonadotropin," The New England Journal of Medicine, vol. 339, no. 25, pp. 1823-1826, 1998.

[337] S. L. Okada, J. L. Ellsworth, D. M. Durnam et al., "A glycoprotein hormone expressed in corticotrophs exhibits unique binding properties on thyroid-stimulating hormone receptor," Molecular Endocrinology, vol. 20, no. 2, pp. 414425, 2006.

[338] C. J. J. van Zeijl, O. V. Surovtseva, W. M. Wiersinga, E. Fliers, and A. Boelen, "Acute inflammation increases pituitary and hypothalamic glycoprotein hormone subunit B5 mRNA expression in association with decreased thyrotrophin receptor mRNA expression in mice," Journal of Neuroendocrinology, vol. 23, no. 4, pp. 310-319, 2011.

[339] K. Ikekubo, M. Hino, Y. Saiki et al., "Immeasurably low and non-TRH-stimulatable TSH associated with normal I-123 uptake in two goitrous euthyroid patients: possible existence of other thyroid-hormone regulated thyroid stimulators other than TSH," Endocrine Journal, vol. 52, no. 1, pp. 61-68, 2005.

[340] C. Li, Y. Hirooka, S. Habu, J. Takagi, M. Gotoh, and T. Nogimori, "Distribution of thyrostimulin in the rat: an immunohistochemical study," Endocrine Regulations, vol. 38, no. 4, pp. 131-142, 2004.

[341] C. Suzuki, H. Nagasaki, Y. Okajima et al., "Inflammatory cytokines regulate glycoprotein subunit $\beta 5$ of thyrostimulin through nuclear factor- $\kappa \mathrm{B}$," Endocrinology, vol. 150, no. 5, pp. 2237-2243, 2009.

[342] N. Takasu and M. Matsushita, "Changes of TSH-stimulation blocking antibody (TSBAb) and thyroid stimulating antibody (TSAb) over 10 years in 34 TSBAb-positive patients with hypothyroidism and in 98 TSAb-positive Graves' patients with hyperthyroidism: reevaluation of TSBAb and TSAb in TSH-receptor-antibody (TRAb)-positive patients," Journal of Thyroid Research, vol. 2012, Article ID 182176, 11 pages, 2012.

[343] J. M. H. Kremer, J. Wilting, and L. H. M. Janssen, "Drug binding to human alpha-1-acid glycoprotein in health and disease," Pharmacological Reviews, vol. 40, no. 1, pp. 1-47, 1988.

[344] S. Urien, F. Bree, B. Testa, and J. P. Tillement, "pHdependency of basic ligand binding to $\alpha 1$-acid glycoprotein (orosomucoid)," Biochemical Journal, vol. 280, part 1, pp. 277-280, 1991.

[345] T. Zimmermann-Belsing, A. K. Rasmussen, U. FeldtRasmussen, and T. C. Bog-Hansen, "The influence of alpha1acid glycoprotein (orosomucoid) and its glycoforms on the function of human thyrocytes and $\mathrm{CHO}$ cells transfected with the human TSH receptor," Molecular and Cellular Endocrinology, vol. 188, no. 1-2, pp. 241-251, 2002.

[346] T. Akamizu, F. Matsuda, J. Okuda et al., "Molecular analysis of stimulatory anti-thyrotropin receptor antibodies (TSAbs) involved in Graves' disease. Isolation and reconstruction of antibody genes, and production of monoclonal TSAbs," Journal of Immunology, vol. 157, no. 7, pp. 3148-3152, 1996. 
[347] T. Akamizu, K. Moriyama, M. Miura, M. Saijo, F. Matsuda, and K. Nakao, "Characterization of recombinant monoclonal antithyrotropin receptor antibodies (TSHRAbs) derived from lymphocytes of patients with Graves' disease: epitope and binding study of two stimulatory TSHRAbs," Endocrinology, vol. 140, no. 4, pp. 1594-1601, 1999.

[348] N. G. Morgenthaler, M. R. Kim, J. Tremble et al., "Human immunoglobulin $\mathrm{G}$ autoantibodies to the thyrotropin receptor from Epstein-Barr virus-transformed B lymphocytes: characterization by immunoprecipitation with recombinant antigen and biological activity," The Journal of Clinical Endocrinology \& Metabolism, vol. 81, no. 9, pp. 3155-3161, 1996.

[349] K. Moriyama, J. Okuda, M. Saijo et al., "Recombinant monoclonal thyrotropin-stimulation blocking antibody (TSBAb) established from peripheral lymphocytes of a hypothyroid patient with primary myxedema," Journal of Endocrinological Investigation, vol. 26, no. 11, pp. 1076-1080, 2003.

[350] J. Okuda, T. Akamizu, H. Sugawa, F. Matsuda, L. Hua, and T. Mori, "Preparation and characterization of monoclonal antithyrotropin receptor antibodies obtained from peripheral lymphocytes of hypothyroid patients with primary myxedema," The Journal of Clinical Endocrinology \& Metabolism, vol. 79, no. 6, pp. 1600-1604, 1994.

[351] T. Yoshida, Y. Ichikawa, K. Ito, and M. Homma, "Monoclonal antibodies to the thyrotropin receptor bind to a $56-\mathrm{kDa}$ subunit of the thyrotropin receptor and show heterogeneous bioactivities," The Journal of Biological Chemistry, vol. 263, no. 31, pp. 16341-16347, 1988.

[352] L. D. Kohn, K. Suzuki, W. H. Hoffman et al., "Characterization of monoclonal thyroid-stimulating and thyrotropin binding-inhibiting autoantibodies from a Hashimoto's patient whose children had intrauterine and neonatal thyroid disease," The Journal of Clinical Endocrinology \& Metabolism, vol. 82, no. 12, pp. 3998-4009, 1997.

[353] W. A. Valente, P. Vitti, Z. Yavin et al., "Monoclonal antibodies to the thyrotropin receptor: stimulating and blocking antibodies derived from the lymphocytes of patients with Graves disease," Proceedings of the National Academy of Sciences of the United States of America, vol. 79, no. 21 I, pp. 6680-6684, 1982.

[354] W. A. Valente, Z. Yavin, E. Yavin et al., "Monoclonal antibodies to the thyrotropin receptor. The identification of blocking and stimulating antibodies," Journal of Endocrinological Investigation, vol. 5, no. 5, pp. 293-301, 1982.

[355] J. Sanders, J. Jeffreys, H. Depraetere et al., "Thyroidstimulating monoclonal antibodies," Thyroid, vol. 12, no. 12, pp. 1043-1050, 2002.

[356] T. Ando, R. Latif, A. Pritsker, T. Moran, Y. Nagayama, and T. F. Davies, "A monoclonal thyroid-stimulating antibody," The Journal of Clinical Investigation, vol. 110, no. 11, pp. 16671674, 2002.

[357] J. Sanders, M. Evans, L. D. K. E. Premawardhana et al., "Human monoclonal thyroid stimulating autoantibody," The Lancet, vol. 362, no. 9378, pp. 126-128, 2003.

[358] M. Evans, J. Sanders, T. Tagami et al., "Monoclonal autoantibodies to the TSH receptor, one with stimulating activity and one with blocking activity, obtained from the same blood sample," Clinical Endocrinology, vol. 73, no. 3, pp. 404-412, 2010.

[359] J. Sanders, F. Allen, J. Jeffreys et al., "Characteristics of a monoclonal antibody to the thyrotropin receptor that acts as a powerful thyroid-stimulating autoantibody antagonist," Thyroid, vol. 15, no. 7, pp. 672-682, 2005.
[360] B. R. Smith, J. Sanders, and J. Furmaniak, "TSH receptor antibodies," Thyroid, vol. 17, no. 10, pp. 923-938, 2007.

[361] J. Sanders, M. Evans, C. Betterle et al., "A human monoclonal autoantibody to the thyrotropin receptor with thyroidstimulating blocking activity," Thyroid, vol. 18, no. 7, pp. 735-746, 2008.

[362] S. Costagliola, M. Bonomi, N. G. Morgenthaler et al., "Delineation of the discontinuous-conformational epitope of a monoclonal antibody displaying full in vitro and in vivo thyrotropin activity," Molecular Endocrinology, vol. 18, no. 12, pp. 3020-3034, 2004.

[363] J. A. Gilbert, A. G. Gianoukakis, S. Salehi et al., "Monoclonal pathogenic antibodies to the thyroid-stimulating hormone receptor in Graves' disease with potent thyroid-stimulating activity but differential blocking activity activate multiple signaling pathways," Journal of Immunology, vol. 176, no. 8, pp. 5084-5092, 2006.

[364] C. Liu, D. Hermsen, J. Domberg et al., "Comparison of M22based ELISA and human-TSH-receptor-based luminescence assay for the measurement of thyrotropin receptor antibodies in patients with thyroid diseases," Hormone and Metabolic Research, vol. 40, no. 7, pp. 479-483, 2008.

[365] M. Grossmann, H. Leitolf, B. D. Weintraub, and M. W. Szkudlinski, "A rational design strategy for protein hormone superagonists," Nature Biotechnology, vol. 16, no. 9, pp. 871875, 1998.

[366] M. W. Szkudlinski, N. G. Teh, M. Grossmann, J. E. Tropea, and B. D. Weintraub, "Engineering human glycoprotein hormone superactive analogues," Nature Biotechnology, vol. 14, no. 10, pp. 1257-1263, 1996.

[367] N. Azzam, R. Bar-Shalom, and F. Fares, "Conversion of TSH heterodimer to a single polypeptide chain increases bioactivity and longevity," Endocrinology, vol. 153, pp. 954960, 2012.

[368] C. M. Dayan, P. Saravanan, and G. Bayly, "Whose normal thyroid function is better-yours or mine?" The Lancet, vol. 360, no. 9330, pp. 353-354, 2002.

[369] P. Laurberg, S. Andersen, A. Carlé, J. Karmisholt, N. Knudsen, and I. B. Pedersen, "The TSH upper reference limit: where are we at?" Nature Reviews Endocrinology, vol. 7, no. 4, pp. 232-239, 2011.

[370] G. Effraimidis, T. G. A. Strieder, J. G. P. Tijssen, and W. M. Wiersinga, "Natural history of the transition from euthyroidism to overt autoimmune hypo- or hyperthyroidism: a prospective study," European Journal of Endocrinology, vol. 164, no. 1, pp. 107-113, 2011.

[371] W. Gartner and M. Weissel, "Do iodine-containing contrast media induce clinically relevant changes in thyroid function parameters of euthyroid patients within the first week?" Thyroid, vol. 14, no. 7, pp. 521-524, 2004.

[372] B. G. A. Stuckey, G. N. Kent, L. C. Ward, S. J. Brown, and J. P. Walsh, "Postpartum thyroid dysfunction and the longterm risk of hypothyroidism: results from a 12-year followup study of women with and without postpartum thyroid dysfunction," Clinical Endocrinology, vol. 73, no. 3, pp. 389395, 2010.

[373] M. P. J. Vanderpump, W. M. G. Tunbridge, J. M. French et al., "The incidence of thyroid disorders in the community: a twenty-year follow-up of the Whickham Survey," Clinical Endocrinology, vol. 43, no. 1, pp. 55-68, 1995.

[374] J. P. Walsh, A. P. Bremner, P. Feddema, P. J. Leedman, S. J. Brown, and P. O'Leary, "Thyrotropin and thyroid antibodies as predictors of hypothyroidism: a 13-year, longitudinal study of a community-based cohort using 
current immunoassay techniques," The Journal of Clinical Endocrinology \& Metabolism, vol. 95, no. 3, pp. 1095-1104, 2010.

[375] T. E. Hamilton, S. Davis, L. Onstad, and K. J. Kopecky, “Thyrotropin levels in a population with no clinical, autoantibody, or ultrasonographic evidence of thyroid disease: implications for the diagnosis of subclinical hypothyroidism," The Journal of Clinical Endocrinology \& Metabolism, vol. 93, no. 4, pp. 1224-1230, 2008.

[376] C. A. Spencer, J. G. Hollowell, M. Kazarosyan, and L. E. Braverman, "National Health and Nutrition Examination Survey III Thyroid-Stimulating Hormone (TSH)thyroperoxidase antibody relationships demonstrate that TSH upper reference limits may be skewed by occult thyroid dysfunction," The Journal of Clinical Endocrinology \& Metabolism, vol. 92, no. 11, pp. 4236-4240, 2007.

[377] P. Vejbjerg, N. Knudsen, H. Perrild et al., "The association between hypoechogenicity or irregular echo pattern at thyroid ultrasonography and thyroid function in the general population," European Journal of Endocrinology, vol. 155, no. 4, pp. 547-552, 2006.

[378] S. Andersen, K. M. Pedersen, N. H. Bruun, and P. Laurberg, "Narrow individual variations in serum T4 and T3 in normal subjects: a clue to the understanding of subclinical thyroid disease," The Journal of Clinical Endocrinology \& Metabolism, vol. 87, no. 3, pp. 1068-1072, 2002.

[379] R. Hoermann and J. E. Midgley, "TSH measurement and its implications on personalised clinical decision making," Journal of Thyroid Research, vol. 2012, Article ID 438037, 9 pages, 2012.

[380] R. A. Dickey, L. Wartofsky, and S. Feld, “Optimal thyrotropin level: Normal ranges and reference intervals are not equivalent," Thyroid, vol. 15, no. 9, pp. 1035-1039, 2005.

[381] L. Wartofsky and R. A. Dickey, "The evidence for a narrower thyrotropin reference range is compelling," The Journal of Clinical Endocrinology \& Metabolism, vol. 90, no. 9, pp. 54835488, 2005.

[382] L. Wartofsky, D. Van Nostrand, and K. D. Burman, "Overt and 'subclinical' hypothyroidism in women," Obstetrical and Gynecological Survey, vol. 61, no. 8, pp. 535-542, 2006.

[383] M. I. Surks, G. Goswami, and G. H. Daniels, "The thyrotropin reference range should remain unchanged," The Journal of Clinical Endocrinology \& Metabolism, vol. 90, no. 9, pp. 5489-5496, 2005.

[384] M. Amidi, D. F. Leon, W. J. DeGroot, F. W. Kroetz, and J. J. Leonard, "Effect of the thyroid state on myocardial contractility and ventricular ejection rate in man," Circulation, vol. 38, no. 2, pp. 229-239, 1968.

[385] S. Selvaraj, I. Klein, S. Danzi, N. Akhter, R. O. Bonow, and S. J. Shah, "Association of serum triiodothyronine with Btype natriuretic peptide and severe left ventricular diastolic dysfunction in heart failure with preserved ejection fraction," American Journal of Cardiology, vol. 110, pp. 234-239, 2012.

[386] J. Belehradek and J. S. Huxley, "Changes in oxygen consumption during metamorphosis induced by thyroid administration in the axolotl," The Journal of Physiology, vol. 64, pp. 267-278, 1927.

[387] W. Dock and J. K. Lewis, "The effect of thyroid feeding on the oxygen consumption of the heart and of other tissues," The Journal of Physiology, vol. 74, pp. 401-406, 1932.

[388] E. Ortega Martinez De Victoria, N. Pannacciulli, C. Bogardus, and J. Krakoff, "Plasma concentrations of free triiodothyronine predict weight change in euthyroid persons,"
American Journal of Clinical Nutrition, vol. 85, no. 2, pp. 440445, 2007.

[389] R. E. Rawson, P. W. Concannon, P. J. Roberts, and B. C. Tennant, "Seasonal differences in resting oxygen consumption, respiratory quotient, and free thyroxine in woodchucks," American Journal of Physiology, vol. 274, no. 4, pp. R963R969, 1998.

[390] L. D. Carlson, "Nonshivering thermogenesis and its endocrine control," Federation Proceedings, vol. 19, supplement 5, pp. 25-30, 1960.

[391] I. S. Edelman, "Thyroid thermogenesis," The New England Journal of Medicine, vol. 290, no. 23, pp. 1303-1308, 1974.

[392] R. E. Smith, "Thermogenesis and thyroid action," Nature, vol. 204, no. 4965, pp. 1311-1312, 1964.

[393] R. Burini, S. Santidrian, M. Moreyra, P. Brown, H. N. Munro, and V. R. Young, "Interaction of thyroid status and diet on muscle protein breakdown in the rat, as measured by $\mathrm{N}(\tau)$ methylhistidine excretion," Metabolism, vol. 30, no. 7, pp. 679-687, 1981.

[394] K. D. Burman, L. Wartofsky, R. E. Dinterman, P. Kesler, and R. W. Wannemacher Jr., "The effect of T3 and reverse T3 administration on muscle protein catabolism during fasting as measured by 3-methylhistidine excretion," Metabolism, vol. 28, no. 8, pp. 805-813, 1979.

[395] H. Von Kazuyoshi, "Über das aus hühnerharn isolierte methylhistidin," Journal of Biochemistry, vol. 54, no. 3, pp. 253-258, 1963.

[396] H. N. Munro and V. R. Young, "Urinary excretion of $\mathrm{N}$ (tau) methylhistidine (3 methylhistidine): a tool to study metabolic responses in relation to nutrient and hormonal status in health and disease of man," American Journal of Clinical Nutrition, vol. 31, no. 9, pp. 1608-1614, 1978.

[397] M. Rodier, J. L. Richard, J. Bringer, G. Cavalie, H. Bellet, and J. Mirouze, "Thyroid status and muscle protein breakdown as assessed by urinary 3-methylhistidine excretion: study in thyrotoxic patients before and after treatment," Metabolism, vol. 33, no. 1, pp. 97-100, 1984.

[398] F. Wang, Y. Tan, C. Wang et al., "Thyroid-stimulating hormone levels within the reference range are associated with serum lipid profiles independent of thyroid hormones," The Journal of Clinical Endocrinology \& Metabolism, vol. 97, pp. 2724-2731, 2012.

[399] J. P. Peters and E. B. Man, "The interrelations of serum lipids in patients with thyroid disease," The Journal of Clinical Investigation, vol. 22, pp. 715-720, 1943.

[400] G. Atis, A. Dalkilinc, Y. Altuntas et al., "Hyperthyroidism: a risk factor for female sexual dysfunction," Journal of Sexual Medicine, vol. 8, no. 8, pp. 2327-2333, 2011.

[401] M. Pugeat, N. Nader, K. Hogeveen, G. Raverot, H. Déchaud, and C. Grenot, "Sex hormone-binding globulin gene expression in the liver: drugs and the metabolic syndrome," Molecular and Cellular Endocrinology, vol. 316, no. 1, pp. 53$59,2010$.

[402] D. M. Selva and G. L. Hammond, "Thyroid hormones act indirectly to increase sex hormone-binding globulin production by liver via hepatocyte nuclear factor- $4 \alpha$," Journal of Molecular Endocrinology, vol. 43, no. 1, pp. 19-27, 2009.

[403] P. de Nayer, M. P. Lambot, M. C. Desmons, B. Rennotte, P. Malvaux, and C. Beckers, "Sex hormone-binding protein in hyperthyroxinemic patients: a discriminator for thyroid status in thyroid hormone resistance and familial dysalbuminemic hyperthyroxinemia," The Journal of Clinical Endocrinology \& Metabolism, vol. 62, no. 6, pp. 1309-1312, 1986. 
[404] D. H. Sarne, S. Refetoff, R. L. Rosenfield, and J. P. Farriaux, "Sex hormone-binding globulin in the diagnosis of peripheral tissue resistance to thyroid hormone: the value of changes after short term triiodothyronine administration," The Journal of Clinical Endocrinology \& Metabolism, vol. 66, no. 4 , pp. $740-746,1988$.

[405] A. W. Meikle, "The Interrelationships between thyroid dysfunction and hypogonadism in men and boys," Thyroid, vol. 14, supplement 1, pp. S17-S25, 2004.

[406] E. B. Skowronska-Jozwiak, K. Krawczyk-Rusiecka, K. C. Lewandowski, Z. Adamczewski, and A. Lewi Ski, "Successful treatment of thyrotoxicosis is accompanied by a decrease in serum sclerostin levels," Thyroid Research, vol. 5, article 14, 2012.

[407] J. Mittag, T. Behrends, K. Nordstrom, J. Anselmo, B. Vennstrom, and L. Schomburg, "Serum copper as a novel biomarker for resistance to thyroid hormone," Biochemical Journal, vol. 443, pp. 103-109, 2012.

[408] J. D. Meeker, M. G. Rossano, B. Protas et al., "Multiple metals predict prolactin and thyrotropin (TSH) levels in men," Environmental Research, vol. 109, no. 7, pp. 869-873, 2009.

[409] L. Feher and H. F. Hevizy, "On the correlation of ceruloplasmin and the neuro-endocrine system. I. Correlation between the ceruloplasmin level and thyroid function," Magyar Belorvosi Archivum, vol. 15, pp. 210-213, 1962.

[410] J. Rechenberger, "Serumkupfer und Schilddrüsentatigkeit [serum copper and thyroid activity]," Dtsch Z Verdau Stoffwechselkr, vol. 17, pp. 139-145, 1957.

[411] K. F. Koenig, E. Potlukova, B. Mueller, M. Christ-Crain, and M. Trendelenburg, "MBL serum levels in patients with sepsis correlate with thyroid function but not with outcome," Clinical Immunology, vol. 144, pp. 80-82, 2012.

[412] E. Potlukova, J. Jiskra, T. Freiberger et al., "The production of mannan-binding lectin is dependent upon thyroid hormones regardless of the genotype: a cohort study of 95 patients with autoimmune thyroid disorders," Clinical Immunology, vol. 136, no. 1, pp. 123-129, 2010.

[413] B. Biondi and L. Wartofsky, "Combination treatment with T4 and T3: toward personalized replacement therapy in hypothyroidism?" The Journal of Clinical Endocrinology \& Metabolism, vol. 97, pp. 2256-2271, 2012.

[414] D. Gullo, A. Latina, F. Frasca, R. Moli, G. Pellegriti, and R. Vigneri, "Levothyroxine monotherapy cannot guarantee euthyroidism in all athyreotic patients," PLoS One, vol. 6, no. 8, Article ID e22552, 2011.

[415] M. M. Kaplan, D. H. Sarne, and A. B. Schneider, "In search of the impossible dream? Thyroid hormone replacement therapy that treats all symptoms in all hypothyroid patients," The Journal of Clinical Endocrinology \& Metabolism, vol. 88, no. 10 , pp. 4540-4542, 2003.

[416] A. M. Sawka, H. C. Gerstein, M. J. Marriott, G. M. MacQueen, and R. T. Joffe, "Does a combination regimen of thyroxine (T4) and 3,5,3'-triiodothyronine improve depressive symptoms better than $\mathrm{T} 4$ alone in patients with hypothyroidism? Results of a double-blind, randomized, controlled trial," The Journal of Clinical Endocrinology \& Metabolism, vol. 88, no. 10, pp. 4551-4555, 2003.

[417] J. P. Walsh, L. Shiels, E. M. Lim et al., "Combined thyroxine/liothyronine treatment does not improve well-being, quality of life, or cognitive function compared to thyroxine alone: a randomized controlled trial in patients with primary hypothyroidism," The Journal of Clinical Endocrinology \& Metabolism, vol. 88, no. 10, pp. 4543-4550, 2003.
[418] B. C. Appelhof, E. Fliers, E. M. Wekking et al., "Combined therapy with levothyroxine and liothyronine in two ratios, compared with levothyroxine monotherapy in primary hypothyroidism: a double-blind, randomized, controlled clinical trial," The Journal of Clinical Endocrinology \& Metabolism, vol. 90, no. 5, pp. 2666-2674, 2005.

[419] S. Grozinsky-Glasberg, A. Fraser, E. Nahshoni, A. Weizman, and L. Leibovici, "Thyroxine-triiodothyronine combination therapy versus thyroxine monotherapy for clinical hypothyroidism: meta-analysis of randomized controlled trials," The Journal of Clinical Endocrinology \& Metabolism, vol. 91, no. 7, pp. 2592-2599, 2006.

[420] B. Nygaard, E. W. Jensen, J. Kvetny, A. Jarløv, and J. Faber, "Effect of combination therapy with thyroxine (T4) and $3,5,3^{\prime}$-triiodothyronine versus T4 monotherapy in patients with hypothyroidism, a double-blind, randomised cross-over study," European Journal of Endocrinology, vol. 161, no. 6, pp. 895-902, 2009.

[421] V. V. Fadeyev, T. B. Morgunova, J. P. Sytch, and G. A. Melnichenko, "TSH and thyroid hormones concentrations in patients with hypothyroidism receiving replacement therapy with L-thyroxine alone or in combination with Ltriiodothyronine," Hormones, vol. 4, no. 2, pp. 101-107, 2005.

[422] M. Chao, X. Jiawei, H. Xia et al., "Thyroxine alone or thyroxine plus triiodothyronine replacement therapy for hypothyroidism," Nuclear Medicine Communications, vol. 30, no. 8, pp. 586-593, 2009.

[423] V. Panicker, P. Saravanan, B. Vaidya et al., "Common variation in the DIO2 gene predicts baseline psychological well-being and response to combination thyroxine plus triiodothyronine therapy in hypothyroid patients," The Journal of Clinical Endocrinology \& Metabolism, vol. 94, no. 5, pp. 1623-1629, 2009.

[424] B. C. Appelhof, R. P. Peeters, W. M. Wiersinga et al., "Polymorphisms in type 2 deiodinase are not associated with well-being, neurocognitive functioning, and preference for combined thyroxine/3,5,3'- triiodothyronine therapy," The Journal of Clinical Endocrinology \& Metabolism, vol. 90, no. 11, pp. 6296-6299, 2005. 


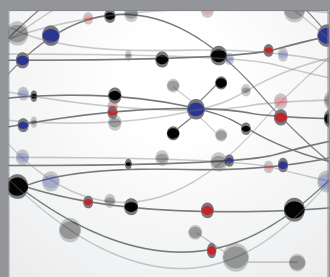

The Scientific World Journal
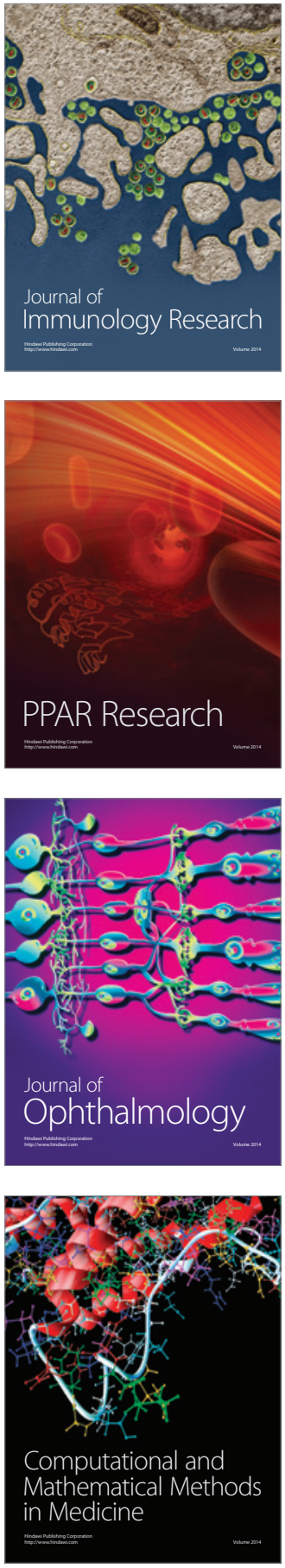

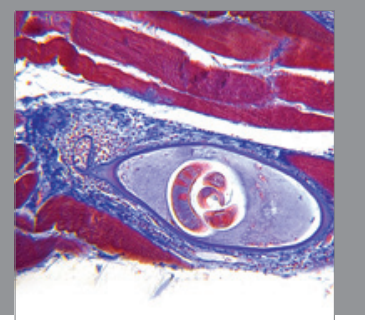

Gastroenterology

Research and Practice
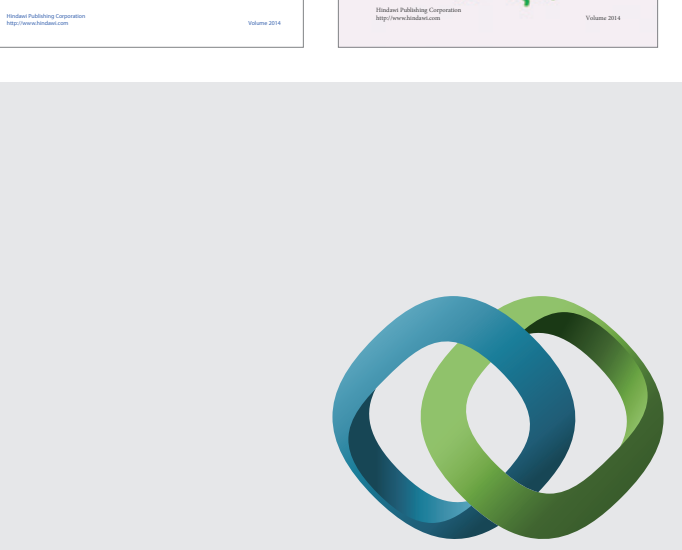

\section{Hindawi}

Submit your manuscripts at

http://www.hindawi.com
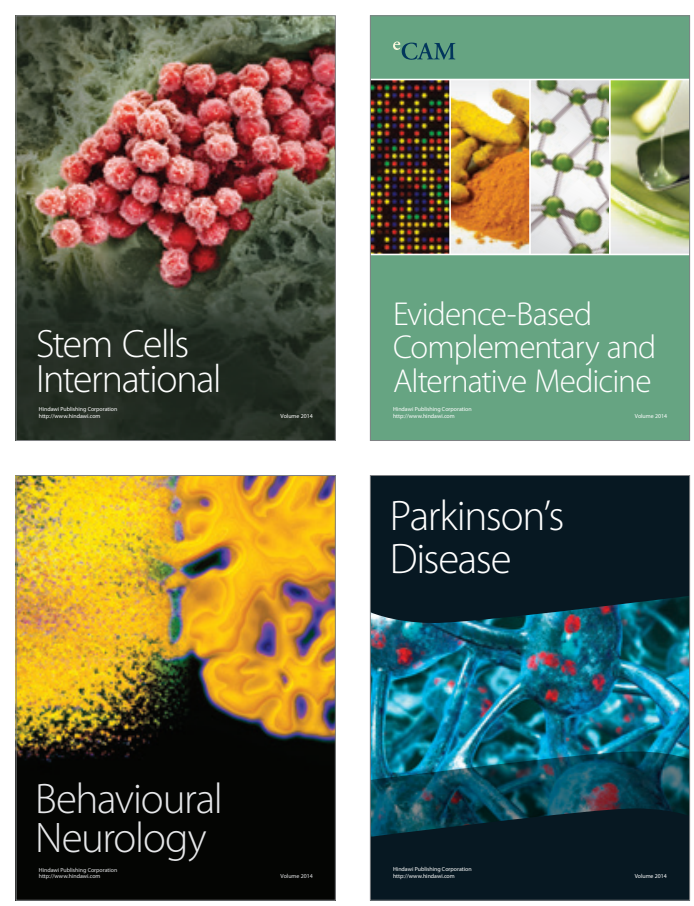

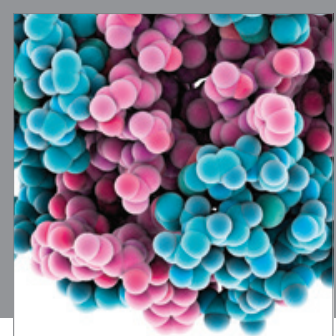

Journal of
Diabetes Research

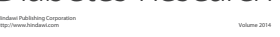

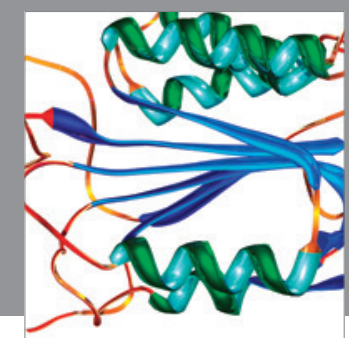

Disease Markers
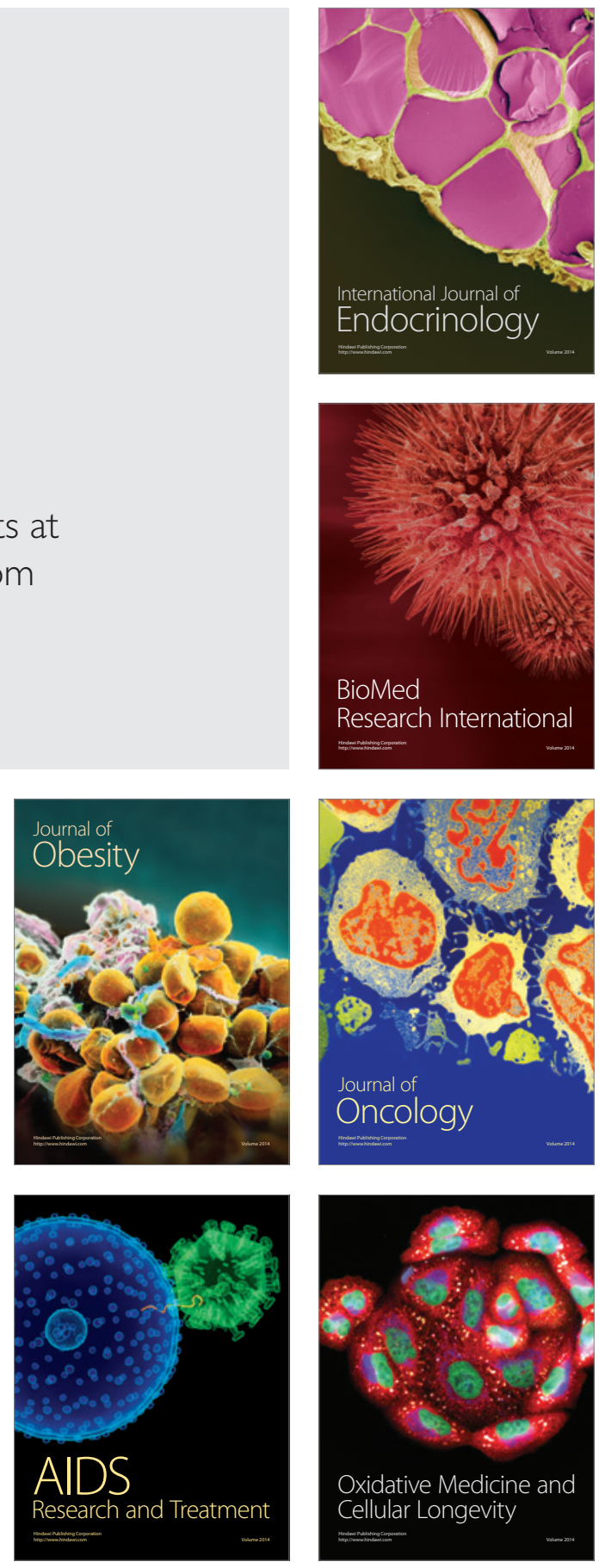